\title{
Effector CD8 T-cell entry into subcutaneous and intraperitoneal B16 melanoma tumors
}

\author{
Amber Nicole Woods \\ Stanardsville, Virginia
}

B.Sc., College of William and Mary, 2011

MS, University of Virginia, 2014

\begin{abstract}
A Dissertation presented to the Graduate Faculty of the University of Virginia in Candidacy for the Degree of Doctor of Philosophy
\end{abstract}

Department of Microbiology, Immunology, and Cancer Biology

University of Virginia

December, 2017 


\section{Abstract}

Although $\mathrm{CD} 8^{+} \mathrm{T}$ cells are critical for controlling tumors, how they are recruited and home to primary and metastatic lesions is incompletely understood. We characterized the homing receptor $(\mathrm{HR})$ ligands on tumor vasculature to determine what drives HR ligand expression and the requirements for $\mathrm{T}$ cell entry. The anatomic location of B16-OVA tumors affected the expression of Eselectin, Mucosal Addressin Cell Adhesion Molecule 1 (MAdCAM-1), and Vascular Cell Adhesion Molecule 1 (VCAM-1), whereas the HR ligands C-X-C motif chemokine ligand 9 (CXCL9) and Intracellular Adhesion Molecule 1 (ICAM1) were expressed on the vasculature regardless of location. Expression of these molecules differed based on anatomic location in other implantable tumors as well, indicating that differences in expression were not tumor intrinsic. CXCL9 and VCAM-1 expression was significantly reduced in B16F1 tumors that did not express the strong antigen Ovalbumin and when B16-OVA tumors were grown in Rag $1^{-/-}$mice indicating that expression was driven by adaptive immune cells. Repletion of Rag ${ }^{-/}$mice with CD8 T-cells from WT and IFN $\gamma^{-/-}$animals revealed that IFN $\gamma$-secreting CD8 T-cells were sufficient to drive VCAM-1 and CXCL9 expression on B16-OVA tumor vasculature. VCAM-1 and CXCL9/10 enabled CD8 ${ }^{+}$T-cell effectors expressing $\alpha 4 \beta 1$ integrin and CXCR3 to enter both subcutaneous and peritoneal tumors, whereas E-Selectin enabled E-Selectin Ligand $^{+}$effectors to enter subcutaneous tumors. However, MAdCAM-1 did not mediate $\alpha 4 \beta 7^{+}$effector entry into peritoneal tumors. These data establish the relative importance of certain HRs expressed on activated effectors and certain 
HR ligands expressed on tumor vasculature in the effective immune control of tumors.

We also addressed whether the melanoma therapy, anti-CTLA-4, impacted HR ligand expression on tumor-associated vasculature and CD8 T-cell accumulation in tumors. Treating tumors with the checkpoint blockade inhibitor anti-CTLA4 led to a significant increase in both the number of CD8 T-cells in the tumor and the expression of the HR ligands VCAM-1 and ICAM- 1 on the tumor vasculature. Addition of peptide vaccine in Incomplete Freund's Adjuvant (IFA) to the checkpoint blockade treatment sequestered CD8 T-cells at the vaccination site and did not result in increased CD8 T-cell accumulation or HR ligand expression on the tumor vasculature. These data suggest that current first-line therapies have the potential to improve CD8 T-cell trafficking to tumors, but combinatorial therapies need to be evaluated and therapies may be improved by boosting ligand expression on the vasculature prior to treatment. 


\section{Table of Contents}

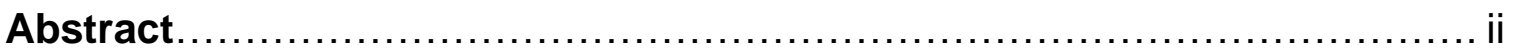

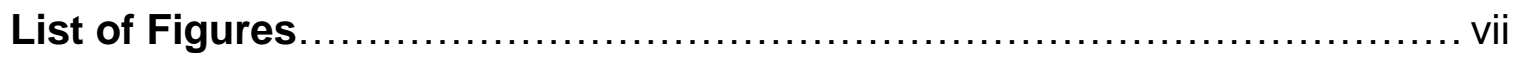

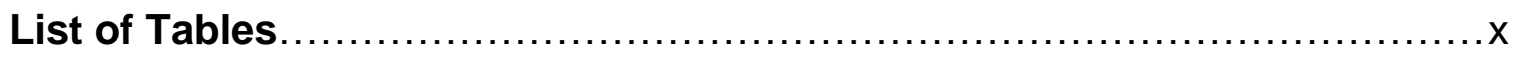

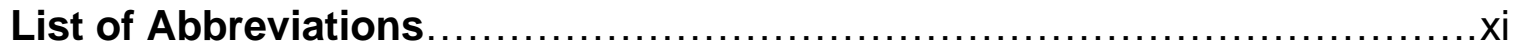

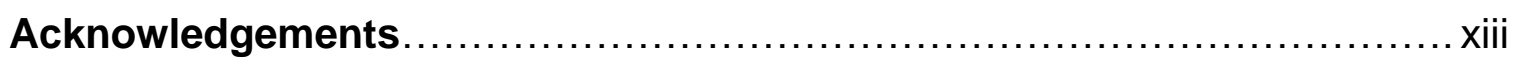

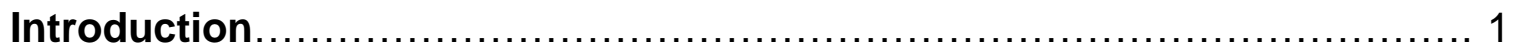

I. Prognostic significance of immune cell representation in tumors.........2

II. CD8 T-cell representation in tumors as a predictive marker of

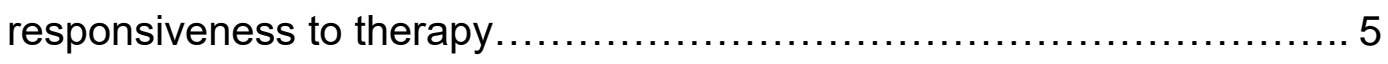

III. Determinants of CD8 T-cell representation in tumors \& other tissues...9

A. Trafficking of effector T-cells into tissues..................... 11

B. Trafficking of effector T-cells into tumors..................... 17

C. Positive feedback loops in vascular ligand expression..........21

D. Mechanical properties of vasculature.......................22

VI. Altering the tumor vasculature to support enhanced entry of T-cells...23

A. Rationale for modifying tumor associated vasculature..........23

B. Strategies for modifying tumor associated vasculature.........25

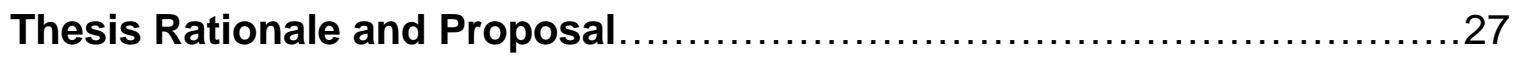

\section{Materials and Methods}

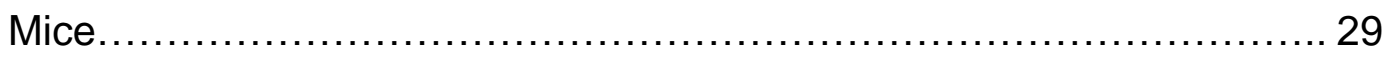

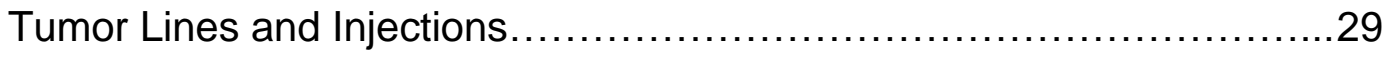

Immunofluorescence Microscopy............................... 29 
Effector Cell Generation and Transfer................................... 30

Homing Receptor/Ligand Blocking ...................................... 31

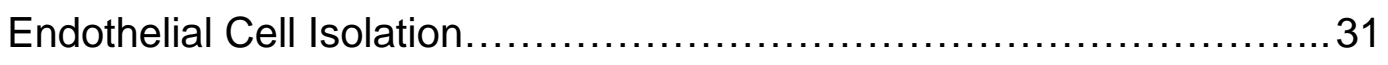

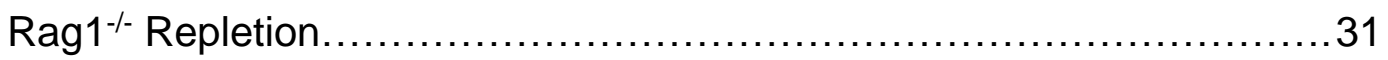

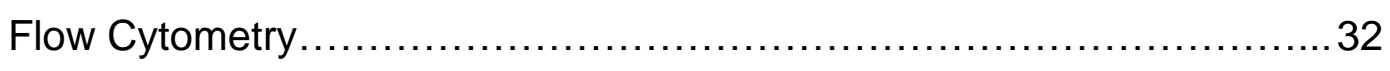

Anti-CTLA-4 and gp100/IFA Vaccination Studies........................ 32

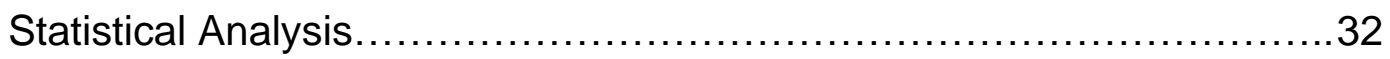

\section{Differential expression of homing receptor ligands on tumor associated} vasculature that control CD8 effector T cell entry

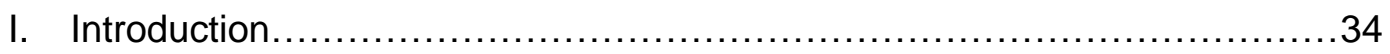

II. Results

A. Expression of some but not all vascular HR ligands depends on tumor anatomical location.

B. HR ligand expression on tumor vasculature is higher than normal tissue vasculature. 40

C. The level of HR ligand expression on tumor vasculature depends on adaptive immunity ....................................................... 40

D. CXCL9 and VCAM-1 expression on tumor vasculature is driven by IFN $\gamma$ but not TNF $\alpha$.

E. VCAM-1, HA, and ICAM-1 mediate $\alpha 4 \beta 1^{+}$effector CD8 T-cell entry into SC and IP tumors. 43

F. MAdCAM-1 does not mediate $\alpha 4 \beta 7^{+}$effector CD8 T-cell entry into IP tumors 45

G. E-Selectin is required for ESL ${ }^{+}$CD8 T-cell entry into SC tumors......47 47 
III. Discussion

Appendix: Effect of anti-CTLA4 + gp100 Vaccination on CD8 T-cell accumulation in tumors and $\mathrm{HR}$ ligand expression on tumor vasculature

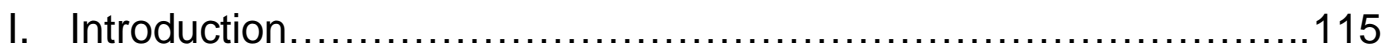

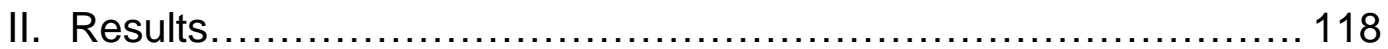

A. Expression of vascular ligands at the vaccination site is unchanged by CD8 T-cell accumulation...................... 118

B. Anti-CTLA-4 increases vascular HR ligand expression on tumor-

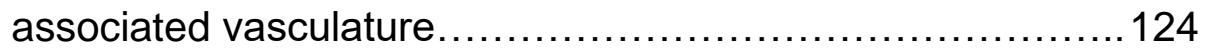

III. Discussion........................................................ 130

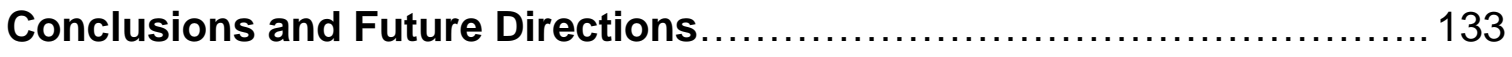

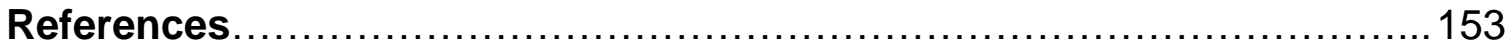




\section{List of Figures}

Figure 1: E-selectin and MAdCAM-1 are differentially expressed on SC and IP B16-OVA tumor-associated vasculature

Figure 2: E-selectin and MAdCAM-1 are differentially expressed on SC and IP MC38 and LLC-OVA tumor-associated vasculature. 51

Figure 3: P-selectin is similarly expressed on SC and IP B16-OVA tumor vasculature

Figure 4: ICAM-1 and HA are similarly expressed on SC and IP B16-OVA tumor vasculature 55

Figure 5: SC and IP B16-OVA tumor-associated vasculature express CXCL9 at different levels.

Figure 6: Intensity of VCAM-1 expression is different on SC and IP B16-OVA tumor-associated vasculature

Figure 7: VCAM-1, E-Selectin, and MAdCAM-1 expression on lung and brain tumor vasculature.

Figure 8: E-Selectin, VCAM-1, and CXCL9 expression is higher on SC B16-OVA tumor vasculature compared to skin-associated vasculature. 63

Figure 9: MAdCAM-1 and VCAM-1 are expressed on colon and IP B16-OVA vasculature

Figure 10: VCAM-1 expression is higher on SC tumor-associated vasculature of B16-OVA grown in B6 compared to Rag $1^{-/-}$mice and B16-F1 67

Figure 11: E-selectin, VCAM-1 and CXCL9 expression on tumor associated vasculature of B16-OVA grown in B6 and Rag $1^{-/-}$mice and B16-F1 
Figure 12: B16-OVA tumors have more CD8 T-cell infiltrate than B16-F1.

Figure 13: Expected and actual co-expression of ligands on B16-OVA tumorassociated vasculature

Figure 14: CXCL9 and VCAM-1 expression are dependent on IFN $\gamma \ldots \ldots \ldots \ldots . \ldots 75$

Figure 15: CD8 T-cells secreting IFN $\gamma$ but not TNF $\alpha$ are sufficient to drive CXCL9 and VCAM-1 expression on tumor-associated vasculature. 77

Figure 16: SC, IV, and IP immunization drive distinct homing receptor profiles on effector CD8 T-cells................................................... 79

Figure 17: $\alpha 4 \beta 1$ is required for CD8 T-cell entry into B16-OVA tumors.......... 81

Figure 18: VCAM-1 on tumor-associated vasculature is required for CD8 T-cell

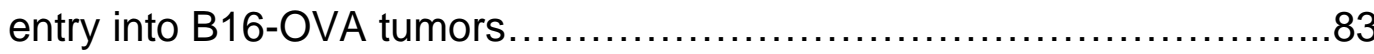

Figure 19: LFA-1 is required for CD8 T-cell entry into B16-OVA tumors.......... 85

Figure 20: CD44 is required for CD8 T-cell entry into B16-OVA tumors...........87

Figure 21: CXCR3 is required for CD8 T-cell entry into SC and IP B16-OVA

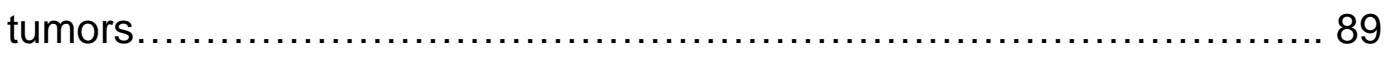

Figure 22: WT effectors effectively controlled tumor outgrowth for several weeks,

but $\mathrm{CXCR3}^{-/}$effectors had no discernable effect.........................91

Figure 23: MAdCAM-1 is not required for CD8 T-cell entry into IP B16-OVA

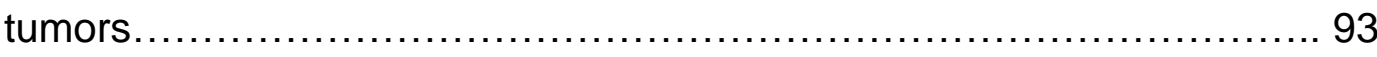

Figure 24: $\alpha 4 \beta 1, \alpha 4 \beta 7$, and VCAM-1 are sufficient for IP primed effector entry

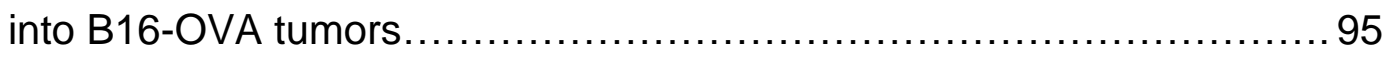

Figure 25: MAdCAM-1 is not expressed on the luminal surface of IP tumorassociated vasculature 
Figure 26: VCAM-1 is expressed on the luminal surface of IP tumor-associated vasculature

Figure 27: SC effectors infiltrated SC tumors to a substantially greater extent than did IP effectors.

Figure 28: E-selectin is required for $\mathrm{ESL}^{+}$effector CD8 T-cell entry into SC tumors. 103

Figure 29: Schema of Major Findings......................................... 105

Figure 30: VCAM-1 and ICAM-1 expression at gp100/IFA vaccination site......120 Figure 31: Antigen-specific and non-specific CD8 T-cell accumulation at gp100/IFA vaccination site. 122

Figure 32: VCAM-1 and ICAM-1 expression on tumor vasculature following anti-

CTLA4 treatment. 126

Figure 33: Antigen-specific and non-specific CD8 T-cell accumulation in anti-

CTLA4 treated tumors 128

Figure 34: Positive Feedback Loop..... 135

Figure 35: Factors Limiting CD8 T-cell Trafficking. 137 


\section{List of Tables}

Table 1: HR ligand induction site and route of vaccination...................... 15

Table 2: HR ligand expression on normal tissue vasculature and tumors........ 16 


\section{List of Abbreviations}

$\mathrm{B} 6-\mathrm{C} 57 \mathrm{BI} / 6$

BMDC - Bone marrow dendritic cell

CCR - C-C motif chemokine receptor

CTLA-4 - Cytotoxic T lymphocyte antigen 4

CXCL - C-X-C motif chemokine ligand

CXCR - C-X-C motif chemokine receptor

DC - Dendritic cell

ESL - E-selectin ligand

$\mathrm{FH}$ - Tyrosinase-specific CD8 T cells

GM-CSF - Granulocyte macrophage colony stimulating factor

HA - Hyaluronic acid

HEV - High endothelial venule

HR - Homing receptor

ICAM - Intracellular adhesion molecule

IFA - Incomplete Freund's adjuvant

IFN $\gamma-$ Interferon- $\gamma$

IL - Interleukin

IP - Intraperitoneal

IV - Intravenous

LFA-1 - Leukocyte function-associated antigen

LPS - Lipopolysaccharide

LN - Lymph node 
LLC - Lewis lung carcinoma

LT $\alpha$ - Lymphotoxin alpha

MACS - Magnetic activated cell sorting

MAdCAM-1 - Mucosal addressin cell adhesion molecule

NK - Natural killer

OT-1 - Ova-specific CD8 T-cells

OVA - Ovalbumin

PD-1 - Programmed death-1

PD-L1 - Programmed death ligand-1

PNAd - Peripheral node addressin

PSL - P-selectin ligand

RAG - Recombinase activating gene

SC - Subcutaneous

TCR - T-cell receptor

Th - T helper

TLR - Toll-like receptor

TM - Thermolysin medium

TNF $\alpha$ - Tumor necrosis factor- $\alpha$

TNFR - Tumor necrosis factor receptor

Treg - Regulatory T-cell

VCAM - Vascular cell adhesion molecule

VEGF - Vascular endothelial growth factor

WT - Wild type 


\section{Acknowledgements}

I would first like to thank Dr. Vic Engelhard, my thesis advisor, for his support and guidance throughout my thesis work. He has taught me how to design conclusive experiments, critically evaluate literature, and effectively communicate my science. I would also like to thank the members of my committee: Ulrike Lorenz, Tim Bullock, Amy Bouton, and Kimberly Kelly for their ideas and constructive criticism over the years. Thank you to past and present members of the lab for advice, help, support, and entertainment during my time in lab. In particular, thank you to Nithya Srivinisan whose work was the springboard for my project, Kara Cummings who keeps the lab up and running and makes sure we follow all the rules, Sherin Rouhani and Nicole McKenna for their friendship, hours of entertainment in the mouse room, and intellectual support. Thank you to the members of the tumor group, David Peske, Ashley Wilson, Marit Melssen, and Anthony Rodriguez for insightful discussions and experimental assistance. Thank you to the many rotation students who I had the pleasure of working with during my graduate studies. Thank you to the Ravichandran lab for letting me spend countless hours on their microscope. Thank you to Peggy Morris and the Carter Center support staff for assisting with travel, training grants, and everything else they do to keep the Center going.

Finally, l'd like to thank my friends and family for their love and support during my thesis work. Thank you to my parents for the innumerable meals cooked. Thank you to my in-laws and grandparents for watching my babies so I could go into lab. Thank you to my wonderful husband Jayson for tremendous 
love support and to Austin and Abigail for being so cute and lovable. And last, but certainly not least, I thank God for the opportunity to attend graduate school and for supporting me throughout the process. 


\section{Introduction}

CD8 T-cells provide a critical brake on the initial development of tumors. In established tumors, the presence of CD8 T-cells is correlated with a positive patient prognosis. Importantly, immunosuppressive mechanisms limit the effectiveness of CD8 T-cells and they are rarely curative without manipulation. Cancer immunotherapies aim to make anti-tumor immunity dominant through antibody blockade of immunosuppressive signaling pathways, vaccination, or adoptive transfer of activated or engineered T-cells. These approaches have yielded striking responses in small subsets of patients with solid tumors, most notably those with melanoma. Importantly, the subset of patients who respond to vaccination or immunosuppression blockade therapies are those with CD8 Tcells present in the tumor prior to initiating therapy. Current adoptive cell therapy approaches can be dramatically effective, but they require infusion of extremely large numbers of T-cells, while the number that actually infiltrate the tumor is very small. Thus, poor representation of CD8 T-cells in tumors is a fundamental hurdle to successful immunotherapy, over and above the well-established barrier of immunosuppression. The factors that determine whether immune cells are present in tumors, with a focus on the representation of cytotoxic CD8 T-cells will be discussed in this introduction. Emphasis on the critically important role of tumor-associated vasculature as a gateway that enables the active infiltration of both effector and naïve CD8 T-cells that exert anti-tumor activity will pave the way for understanding the research within. Additionally, strategies to enhance the 
gateway function and extend the effectiveness of immunotherapies to a broader set of cancer patients will be discussed.

\section{Prognostic significance of immune cell representation in tumors}

In the late $19^{\text {th }}$ century, William Coley observed that spontaneous remission of tumors sometimes occurred in patients who contracted acute bacterial infections and suggested a role for the immune system in cancer regression. He subsequently developed a mixture of bacterial toxins that he believed activated the immune system, and reported they were effective and even curative for some patients (1). Still, his method was controversial, and fell out of favor with the advent of chemo- and radiotherapy (2). It was not until the late $20^{\text {th }}$ century that the importance of the immune system in tumor control was firmly established. Seminal studies examining the development of tumors in immunodeficient mice (3-6) established that cytotoxic CD8 T-cells and NK cells controlled the incidence and severity of spontaneously occurring and chemically induced tumors. However, immune selective pressure also edited these tumors, enabling the expansion of tumor clones that had stopped expressing target antigens and making them less susceptible to immunological control. In addition, other immune elements, including regulatory T-cells (Treg) and several myeloid populations, were shown to suppress immunity, contributing to tumor outgrowth, angiogenesis, and metastasis (7-11). Nevertheless, early correlative studies of patients with many tumor types, including melanoma (12) and neurological 
tumors $(13,14)$, demonstrated that the presence of intratumoral lymphocytes was associated with a positive prognosis and longer survival.

Different immune cell subsets have now been correlated with prevention of tumor establishment and outgrowth (15) as well as a positive or negative prognosis in late stage tumors (16). In fact, the same cell types are often beneficial at both stages of tumor development. Cells that are present in the tumor mass, and most often linked to a positive prognosis, include cytotoxic lymphocytes (CD8 T-cells and NK cells) and CD4 T-cells with a Th1 (interferon- $\gamma$, [IFN $\gamma]$ producing) phenotype. Cells in the tumor mass that represent myeloid lineages, including neutrophils, macrophages, and myeloid derived suppressor cells, are most commonly associated with a negative prognosis. Other tumorinfiltrating cell types have not been consistently linked to a single prognostic outcome. In different studies, Th2 and Th17 cells, Treg, and NKT-cells have been linked to both positive and negative prognoses (16). The reasons for these variable associations are unclear. For Treg this could reflect the imprecision with which phenotypic markers (e.g. FoxP3) clearly identify true regulatory cells with suppressive function, as opposed to activated effector cells in humans $(17,18)$. It has been proposed that Th17 cells might have different phenotypes or functions depending on the tumor type and therefore exert either pro- or anti-tumorigenic activity $(19,20)$.

Recognizing that multiple subsets of immune cells are often present in tumors at the same time, their relative representations and function may be as 
important as their simple presence, as these create a balance between positive and negative influences. The ratio of CD8 T-cells to Treg or total CD4 T-cells has been shown to be prognostically important in ovarian, colorectal, and pancreatic cancer (21-24). Furthermore, although high levels of CD8 T-cells in tumors have been linked to positive clinical outcomes more commonly than for any other cell type and in a number of different tumors, their functional status in the tumor is also relevant. For example, CD8 T-cells were only associated with longer survival of renal cell carcinoma patients if they were actively proliferating (25). CD8 Tcells that expressed CD45RO, a marker of antigen experience, were associated with both enhanced expression of cytotoxicity genes and positive prognosis in colorectal cancer patients $(26,27)$. Gene signatures associated with cytotoxicity and IFN $\gamma$ signaling as markers of effector CD8 T-cells have similarly been associated with a positive prognosis in many other tumor types (28).

Interestingly, the precise localization of CD8 T-cells within the tumor also alters their prognostic significance. The density and location of CD8 T-cells in colorectal carcinomas, encompassed as an analysis termed the 'Immunoscore', was shown to exceed traditional histopathological staging in prognostic power $(26,29)$. CD8 T-cell presence in both the center of the tumor and the invasive margins was associated with a better outcome than presence in only one location (27). The presence of CD8 T-cells was associated with improved survival if the CD8 T-cells were localized to intraepithelial, but not stromal regions of ovarian carcinoma tumors (24). In metastatic melanoma, three distinct 'immunotypes' 
have been defined based on the presence and intratumoral distribution of immune cells (30). Immunotype A tumors were poorly or negligibly infiltrated by immune cells, and these patients had the poorest prognosis. Immunotype B tumors contained CD8 T-cells that remained perivascular. This phenotype was associated with an intermediate prognosis. Finally, Immunotype C tumors contained CD8 T-cells well away from blood vessels throughout the tumor and were associated with the best overall prognosis. Therefore, even among patients with the same histological tumor type, there is a remarkable heterogeneity in overall CD8 T-cell representation and intratumoral distribution. Most importantly, this heterogeneity indicates that fundamental processes controlling T-cell infiltration into and migration within tumors vary.

\section{CD8 T-cell representation in tumors as a predictive marker of responsiveness to therapy}

The emergence of clinically evident cancers reveals that despite the presence and activity of CD8 T-cells, tumors can escape their control (15). Numerous strategies to harness and/or enhance the anti-tumor properties of CD8 T-cells have been developed, and in recent years, have led to encouraging successes. Melanoma has historically been the most studied tumor for immunotherapies, in part because it is also the most responsive to a wide spectrum of such therapies. However, efficacy of certain treatments has also been shown in renal cell carcinoma, lung cancer, and bladder cancer. Nevertheless, only a fraction of patients with any of these cancers respond to 
these therapies. Efforts to identify the basis for responsiveness have suggested that a major determinant is the presence of effector CD8 T-cells in tumors prior to initiating therapy.

High dose IL-2 has consistently been shown to elicit clinical responses, including complete responses, in a small fraction of patients $(31,32)$. Gene expression profiling of pre-treatment tumor biopsies has revealed that a preexisting immune related gene signature, indicating elevated representation of CD4 and CD8 T-cells and elevated expression of T-cell derived cytokines and Tcell attracting chemokines, is associated with clinical responses to IL-2 (33-35). A similar association has also been observed with clinical responses to other immunotherapies, including therapeutic cancer vaccines $(36,37)$, and treatment with the checkpoint blockade antibodies anti-CTLA-4 (38), and anti-PD-1/antiPD-L1 $(39,40)$. The pre-treatment presence of effector T-cells is also associated with enhanced responsiveness to some chemotherapy and radiotherapy treatments in colorectal cancer (41-44), breast cancer (45-47) head and neck cancer (48), and non-small cell lung cancer (49).

Given that the immunotherapies and traditional therapies outlined augment immunity and/or inhibit tumor growth through diverse and distinct mechanisms of action, the reason(s) that a pre-existing infiltrate of CD8 T-cells in the tumor is associated with clinical responses are not entirely clear. The connection is most easily explained for anti-PD-1/PD-L1 therapy and IL-2 therapies. IL-2 may act to expand the intratumoral effector T-cell population or 
rescue it from an anergic phenotype (50,51). PD-1 expression on effector T-cells, and engagement with its ligand PD-L1, inhibits their secretion of effector cytokines, blunts their cytotoxic function, and promotes cell death, thereby protecting peripheral tissues from excessive immune-mediated damage (52). In tumors, the ligands PD-L1 and PD-L2 can be expressed on tumor and stromal cells and likewise restrict immune attack and drive T-cell apoptosis $(53,54)$. In keeping with this, patients whose tumors or stroma express PD-L1 are more likely to respond to anti-PD-1 $(40,55)$. The pre-existing accumulation of effector CD8 T-cells in the tumor therefore represents the immediate target of anti-PD-1 therapy.

Anti-CTLA-4 is proposed to act primarily in the lymph node (LN) to enhance T-cell priming rather than locally in the tumor (56). This is supported by the emergence of a broader TCR repertoire among tumor infiltrating lymphocytes upon treatment, likely reflecting expansion of lower-affinity T-cells due to a lowered threshold of activation with CTLA-4 blockade $(57,58)$. In mouse models, anti-CTLA-4 can also deplete Treg $(59,60)$. Although this mechanism has not been demonstrated in humans, responsiveness to anti-CTLA-4 has been associated with the pre-existing level of intratumoral FoxP3 $3^{+}$cells (61). IL-2, in addition to local effects in the tumor, could also support a more robust proliferative response in the $\mathrm{LN}$. Therapeutic vaccination likewise aims to enhance the response to specific tumor antigens that occurs in tumor-draining LN. Finally, chemotherapies or radiotherapies may promote the immunogenic 
death of tumor cells acting as a natural vaccination to promote T-cell priming against antigens from the killed cells (62-65). Radiotherapy is also associated with abscopal effects, whereby local irradiation leads to regression of distant metastases. This phenomenon is poorly understood, but requires effector CD8 Tcells, indicating it is immune-mediated (66-68).

Thus, for a variety of therapies, the presence and distribution of effector CD8 T-cells in the tumor microenvironment prior to therapy predicts a positive response. This is true even for interventions that do not seem to be directly targeting the CD8 T-cells already in the tumor. In all of these instances, we suggest that the prognostic significance of pre-existing CD8 T-cells in the tumor reflects a microenvironment, and a tumor-associated vasculature, that is permissive to CD8 T-cell accumulation. As a consequence, new CD8 effectors generated in local secondary lymphoid tissue by any of these treatments may more readily enter the tumor and control it.

The adoptive transfer of ex vivo expanded lymphocytes has also shown clinical efficacy in a substantial percentage of treated patients with melanoma (69). The pre-existing presence of CD8 T-cells in the tumor is naturally a prerequisite for treatment, as that is the source of the cells that are harvested, expanded, and reinfused. New adoptive transfer therapies using T-cells derived from the blood rather than the tumor, which are genetically engineered to recognize tumor antigens, have recently been shown to have some anti-tumor activity in solid tumors (70). It would be expected that the presence of 
endogenous T-cells in the responding patients' tumors is required, but this remains to be investigated.

\section{Determinants of CD8 T-cell representation in tumors and other tissues}

The overall representation of T-cells in tissues, including tumors, is determined by the balance of several fundamental processes: cells entering tissues from the blood vasculature, cells leaving through draining lymphatics, and cells proliferating and dying in-situ. To accumulate in a tumor at a peripheral site, however, typically effector T-cells are first activated in the draining LN by specific antigen. Tumors that are poorly infiltrated by effector T-cells may be poorly immunogenic due to a paucity of antigens. Consistent with this, we have observed that murine B16 melanoma tumors transfected to express ovalbumin as a strong neo-antigen are infiltrated by larger numbers of effector CD8 T-cells than the parental B16 line, which is poorly antigenic (71). Similar results have been reported for other implantable murine tumors (72). Responses to antiCTLA-4 or anti-PD-1/PD-L1, which are associated with a pre-existing CD8 T-cell infiltrate, have also been associated with mutational burden $(73,74)$, providing a link between T-cell representation and tumor antigenicity.

Poor representation of T-cells in tumors might also result from interference with dendritic cell (DC) maturation or trafficking. For example, type I IFN signaling is required to generate DCs capable of inducing antigen-specific antitumor CD8 T-cell responses in B16 tumor-bearing mice (75). Type I IFN is induced by tumor DNA that acts through the STING cytosolic DNA sensing 
pathway in DC $(76,77)$. Thus, defects in STING or type I IFN signaling might restrict DC activation and subsequent T-cell priming. Murine melanoma cells that failed to express chemokines that recruited cross-presenting DCs generated a poor T-cell response to an otherwise immunogenic tumor (78). High STAT-3 signaling, another common pathway activated in melanoma and other tumors, can also inhibit DC maturation, as measured by expression of $\mathrm{MHC}$ molecules and CD86 on the surface of CD11c ${ }^{+}$cells, thus limiting CD8 T-cell activation (79). In pancreatic tumors, the Kras driver mutation has been shown to prevent accumulation of T-cells by inducing the expression of GM-CSF, which promotes the infiltration of immunosuppressive myeloid derived suppressor cells (80-82).

In addition to the importance of these factors, there is also ample evidence to suggest that the tumor vasculature limits the representation of CD8 T-cells in tumors. Subcutaneous (SC) and intravenous (IV) routes of vaccination with bone marrow-derived DCs presenting tumor antigen both induce robust CD8 T-cell responses, but these differentially infiltrate and control tumors growing in SC sites or lungs (83). This will be discussed further in a later section. The importance of vaccination route in enabling effective control of tumors growing in different anatomical locations has been confirmed with other vaccine modalities as well (84-86). This was shown to be related to the ability of vaccine induced Tcells to enter tumors. Many other studies have also shown that even when circulating antigen-specific T-cells are present in blood, their accumulation in the tumor can be minimal $(83,87-90)$. In this regard, limited infiltration of T-cells into 
tumors prevented rejection after Treg depletion in a B16 melanoma model (91). Similarly, an exceedingly small number of adoptively transferred tumor-specific effector T-cells get into tumors, in both human and mouse studies (92-99). Finally, adoptively transferred T-cells also controlled SC tumors but not gastric tumors in one murine study (100), suggesting that adoptively transferred T-cells can also differentially enter tumors based on their anatomical location. Detailed understanding of the homing characteristics of effector T-cells and tumor vasculature may explain why, even with robust effector T-cells in circulation, entry into tumors is limited.

\section{A. Trafficking of effector T-cells into tissues}

Trafficking of leukocytes, including T-cells, from blood into lymphoid and peripheral tissues involves sequential interactions between homing receptors on leukocytes and corresponding ligands on vascular endothelial cells (101). An initial transient adhesion, in which leukocytes engage and roll slowly on the vascular surface, is followed by chemokine mediated activation of the highaffinity conformation of integrins, leading to firm adhesion and transmigration into the underlying tissue $(102,103)$. Effector differentiation in the LN up-regulates expression of new homing receptors that enable CD8 T-cell entry into peripheral tissues where the corresponding vascular ligands are expressed (104).

The specific HR upregulated on effector CD8 T-cells depend on the location of the priming LN and, in turn, on the properties of DCs and LN stromal cells that vary depending on the local environment (105-112). For example, T- 
cells activated in gut-associated LN, or by DCs from gut-associated lymphoid tissues, upregulate the integrin $\alpha 4 \beta 7$ and the chemokine CCR9 $(111,113)$. Conversely, T-cells activated in skin-associated LN, or by the corresponding DCs, express E-Selectin Ligand (ESL), P-Selectin Ligand (PSL), and the chemokine CCR10 $(106,108,110,112)$ (Table 1).

Similar results are observed when T-cells are activated in different $L N$ beds by exogenously administered DCs. Intraperitoneal (IP) immunization with bone marrow derived DC activates T-cells in the mesenteric and mediastinal $\mathrm{LN}$ that upregulate $\alpha 4 \beta 7$ integrin $(114,115)$. SC immunization activates T-cells in skin-draining LN, most of which upregulate ESL and PSL, while some express $\alpha 4 \beta 1$ integrin (114). IV immunization activates T-cells in the mediastinal $L N$ and spleen that express $\alpha 4 \beta 1$ integrin without co-expression of either ESL or $\alpha 4 \beta 7$ integrin (114-116). Finally, some HR are upregulated on murine CD8 T-cells regardless of the site of activation. CXCR3, the receptor for CXCL9, 10, and 11 is upregulated on a substantial fraction of effector CD8 T-cells. A subset of these cells also express PSL, indicating that PSL expression is not restricted to cells primed in skin-draining LNs. This PSL+ subset also co-expresses several other chemokine receptors (CCR3, 4, 5, and 6) (114). Collectively, these results define 3 major populations of effector CD8 T-cells based on expression of molecules that initiate slow rolling and confer tissue specificity. By contrast, broad based expression of chemokine receptors enables sensing of the presence of a variety 
of different inflammation induced chemokines for the purposes of further immobilization and tissue entry.

Expression of the corresponding vascular ligands also varies depending on the anatomical location and inflammatory state of the underlying tissues (Table 2). In some cases, this provides a basis for tissue selective T-cell trafficking. E- and P-selectin on skin vasculature facilitate slow-rolling interactions with ESL ${ }^{+}$and $\mathrm{PSL}^{+}$effector T-cells (117-121). E-selectin is homeostatically expressed at low levels only on skin vasculature (122-124). E-selectin expression is enhanced by numerous inflammatory stimuli, including IL-1, tumor necrosis factor- $\alpha$ (TNF $\alpha)$, IFN $\gamma$, lipopolysaccharide (LPS), thrombin, and radiation (125-130). TNF $\alpha$, IL-1, LPS, thrombin, histamine, and radiation also upregulate P-selectin within minutes as it is released from pre-formed stores in WeibelPalade bodies on endothelial cells and alpha granules of platelets $(129,131)$. Inflammation induces transient expression of E- and P-selectin in a broad range of tissues (132). Chemokines have also been implicated in selective T-cell trafficking to the skin. CCL27 and CCL17 are both homeostatically displayed on cutaneous venules and are upregulated by inflammatory stimuli $(124,133)$. CCL17 binds CCR4 on skin homing CD4 T-cells to mediate integrin activation and induce extravasation $(134,135)$, while CCL27 binds to CCR10 and promotes movement into the epidermis $(112,133,136)$.

MAdCAM-1, a major ligand for $\alpha 4 \beta 7$ integrin, and CCL25, the ligand for CCR9, are selectively expressed on the vasculature of gut-associated tissues 
(e.g. intestinal lamina propria) $(107,137)$. CCL25 is constitutively expressed at high levels on gut-associated vasculature and is not enhanced by inflammatory stimuli (138), while MAdCAM-1 is expressed constitutively at low levels and enhanced by TNF $\alpha$ and IL-1 (139). Low affinity $\alpha 4 \beta 7 / M A d C A M-1$ interactions have been shown to initiate slow rolling of leukocytes (140). Subsequent engagement of CCR9 with CCL25 induces the high affinity forms of $\alpha 4 \beta 7$ integrin or LFA-1 which can mediate firm adhesion to gut vasculature (140-144).

Other vascular ligands are expressed more ubiquitously among different tissues, and therefore promote T-cell trafficking into a broader range of inflammatory sites. The integrin ligand VCAM-1 is constitutively expressed at low levels on vasculature of many tissues and is induced to much higher levels by TNF $\alpha$, IFNy, IL-1, and LPS, thrombin, and radiation (114,145-150). $\alpha 4 \beta 1 /$ VCAM1 interactions contribute to T-cell trafficking into brain, lung, and interestingly, also the skin and gut $(137,151-153)$. In addition, $\alpha 4 \beta 1 /$ VCAM- 1 interactions can support both slow rolling and firm adhesion of effector T-cells without chemokinemediated activation, but possibly in cooperation with LFA-1 (154). Expression of certain chemokines is also induced during inflammation in multiple different tissues. CXCL9, 10 and 11, all ligands for CXCR3, are induced by IFN $\gamma$ $(155,156)$. CCL3, 4 and 5, all ligands for CCR5, are broadly induced by viruses and bacterial endotoxin $(157,158)$ and promote T-cell infiltration into inflamed tissues (159-161). 
Table 1: HR ligand induction site and route of vaccination

\begin{tabular}{|c|c|c|}
\hline $\begin{array}{l}\text { Homing } \\
\text { Receptor }\end{array}$ & Site/Route of Induction & DC Vaccination Route \\
\hline E-Selectin Ligand & Skin-associated LN & SC \\
\hline CCR10 & Skin-associated LN & SC \\
\hline$\alpha 4 \beta 7$ & $\begin{array}{l}\text { Mediastinal and Gut-associated } \\
\text { LN, Peyer's Patches }\end{array}$ & IP \\
\hline CCR9 & Gut-associated LN & IP \\
\hline$\alpha 4 \beta 1$ & $\begin{array}{l}\text { Skin-associated LN, Gut- } \\
\text { associated LN, and Spleen }\end{array}$ & SC, IV, IP \\
\hline P-Selectin Ligand & $\begin{array}{l}\text { Skin-associated LN, Gut- } \\
\text { associated LN, and Spleen }\end{array}$ & SC, IV, IP \\
\hline CXCR3 & $\begin{array}{l}\text { Skin-associated LN, Gut- } \\
\text { associated LN, and Spleen }\end{array}$ & SC, IV, IP \\
\hline
\end{tabular}


Table 2: HR ligand expression on normal tissue vasculature and tumors

\begin{tabular}{|c|c|c|c|c|}
\hline $\begin{array}{l}\text { Homing } \\
\text { Receptor } \\
\text { Ligand }\end{array}$ & $\begin{array}{l}\text { Corresponding } \\
\text { Receptor }\end{array}$ & $\begin{array}{l}\text { Expression } \\
\text { on Normal } \\
\text { Vasculature }\end{array}$ & $\begin{array}{l}\text { Induced } \\
\text { By: }\end{array}$ & $\begin{array}{l}\text { Reported on } \\
\text { Tumor } \\
\text { Vasculature }\end{array}$ \\
\hline E-Selectin & $\begin{array}{l}\text { E-Selectin } \\
\text { Ligand }\end{array}$ & Skin & $\begin{array}{l}\text { II-1, } \\
\text { TNFa, } \\
\text { IFNy, } \\
\text { LPS, } \\
\text { thrombin, } \\
\text { radiation }\end{array}$ & $\begin{array}{l}\text { Merkel cell } \\
\text { carcinoma of } \\
\text { skin }\end{array}$ \\
\hline MAdCAM-1 & $\alpha 4 \beta 7$ & $\begin{array}{l}\text { Gut- } \\
\text { associated } \\
\text { tissues } \\
\text { (intestinal } \\
\text { lamina } \\
\text { propria) }\end{array}$ & II-1, TNF $\alpha$ & $\begin{array}{l}\text { Gastric } \\
\text { adenocarcinoma }\end{array}$ \\
\hline VCAM-1 & $\alpha 4 \beta 1$ & $\begin{array}{l}\text { Multiple } \\
\text { tissues } \\
\text { (brain, lung, } \\
\text { skin, gut) }\end{array}$ & $\begin{array}{l}\text { II-1, } \\
\text { TNFa, } \\
\text { IFNy, } \\
\text { LPS, } \\
\text { thrombin, } \\
\text { radiation }\end{array}$ & $\begin{array}{l}\text { Melanoma, } \\
\text { colorectal } \\
\text { cancer, } \\
\text { colorectal } \\
\text { hepatic } \\
\text { metastasis, } \\
\text { pancreatic islet } \\
\text { cell carcinoma, } \\
\text { glioblastoma }\end{array}$ \\
\hline P-Selectin & $\begin{array}{l}\text { P-Selectin } \\
\text { Ligand }\end{array}$ & Skin & $\begin{array}{l}\text { II-1, } \\
\text { TNFa, } \\
\text { LPS, } \\
\text { thrombin, } \\
\text { histamine, } \\
\text { radiation }\end{array}$ & \\
\hline CXCL9,10,11 & CXCR3 & $\begin{array}{l}\text { Multiple } \\
\text { tissues }\end{array}$ & IFNy & $\begin{array}{l}\text { Melanoma, } \\
\text { colorectal cancer }\end{array}$ \\
\hline
\end{tabular}




\section{B. Trafficking of effector T-cells into tumors}

Although tumors are sites at which significant T-cell death and inflammation may be occurring, the expression of many HR ligands on tumor vasculature is low. E-selectin is often not expressed on the vasculature of squamous cell carcinomas of the skin or metastatic melanomas, despite being present on adjacent tissue vasculature $(162,163)$. MAdCAM-1 is expressed at low levels on gastric adenocarcinoma vasculature relative to normal mucosal tissue (164). VCAM-1 and ICAM-1 expression are also low on vasculature of melanoma, colorectal cancer, colorectal hepatic metastasis, and glioblastoma (163,165-167). Chemokines commonly associated with T-cell trafficking, including the CCR5 ligands CCL3, CCL4, and CCL5, or the CXCR3 ligands CXCL9, CXCL10, and CXCL11 are low in poorly infiltrated melanomas and colorectal carcinomas (168-170). Vascular endothelial growth factor (VEGF), Endothelin B receptor, and CD73 are three factors that have been implicated in limiting ligand expression on vasculature, in part, through blocking inflammationinduced ligand upregulation $(166,171,172)$.

In some cases, expression of vascular ligands has also been shown to vary with the location of tumor growth or the tumor type. E-selectin was more often expressed at higher levels in Merkel cell carcinomas in the skin compared to melanoma $(163,173)$. In an assessment of several different implantable tumors growing SC, only a subset of tumors, including B16 melanoma, expressed vascular E-selectin (174). We have found that the vasculature of B16 melanoma 
and Lewis Lung carcinoma (LLC) tumors grown SC expresses E-selectin and relatively high levels of VCAM-1, while that of tumors grown IP expresses low levels of VCAM-1 and is negative for E-selectin. Conversely, MAdCAM-1 is expressed on a significantly higher fraction of the vasculature in IP B16 tumors compared to SC tumor vasculature. This indicates that HR ligand expression on tumor vasculature resembles, and is presumably derived from, that of adjacent normal tissue. There is a paucity of information concerning expression of Eselectin, VCAM-1, and MAdCAM-1 among human tumor types and locations. Whether chemokines such as CCL27 and CCL25, which are normally expressed in skin and gut, are differentially expressed in tumors growing in different anatomic locations remains unknown.

Several studies have evaluated which HR ligands enable infiltration of effector CD8 T-cells into tumors, either directly or as a correlation. VCAM-1 expression correlates with T-cell representation in pancreatic islet cell carcinoma and melanoma $(91,96,175)$ while ICAM-1 expression correlates with T-cell entry into melanoma, pancreatic islet carcinoma, and glioblastoma $(91,96,165,171,175,176)$. CD8 T-cell infiltration into SC B16 melanomas was also significantly reduced in ICAM-1\% mice even following an inflammatory systemic hyperthermia therapy (176). We have shown that antibody blockade of $\alpha 4 \beta 1 /$ VCAM-1 and LFA-1/ICAM-1 interactions significantly reduces the number of adoptively transferred $\alpha 4 \beta 1^{+}$effector CD8 T-cells that enter SC or IP B16 tumors. These molecular pairs are not redundant, suggesting that $\alpha 4 \beta 1 / \mathrm{VCAM}-1$ 
acts to initiate slow rolling while LFA-1/ICAM-1 mediates arrest. Infiltration of adoptively transferred CXCR3--- effector CD8 T-cells into SC or IP B16 tumors is almost entirely eliminated, implying that this is the major chemokine axis enabling entry. CXCR3 has also been associated with CD8 T-cell entry in other tumor models $(169,177,178)$, and with increased survival in melanoma patients (178). This also identifies an important role for the CXCR3 ligands CXCL9, 10, and 11. The direct role of VCAM-1, ICAM-1, and ligands for CXCR3 or other chemokine receptors in mediating T-cell entry into additional murine and human tumors still needs to be thoroughly examined.

E-selectin has also been implicated in CD8 T-cell entry into tumors. Low expression in melanomas was associated with an absence of ESL + CD8 T-cells (162). Higher vascular E-selectin expression among Merkel cell carcinomas in different patients was associated with larger numbers of CD8 T-cells, although it is unclear if the infiltrating T-cells were $\mathrm{ESL}^{+}$(173). Fucosyltransferase IV and VII knockout CD8 T-cells cannot generate the carbohydrate structure to form functional ESL (179-182) and their entry into SC B16-OVA tumors is reduced compared to wild-type cells (183). However, whether wild-type CD8 T-cell entry was dependent on either ESL or PSL (which is also fucosyltransferase dependent) or both was not determined. We have shown that adoptively transferred $\mathrm{ESL}^{+}$effector CD8 T-cells enter SC B16 tumors with E-selectin ${ }^{+}$ vasculature more efficiently than IP tumors with E-selectin ${ }^{\text {neg }}$ vasculature. Entry of $\mathrm{ESL}^{+}$effector CD8 T-cells into SC tumors growing in E-selectin ${ }^{-/-}$mice was 
also reduced compared to entry into SC tumors in wild-type mice, while blockade of P-selectin/PSL interactions with a recombinant $\mathrm{P}$-selectin fusion protein had no effect. Thus, ESL/E-selectin interactions enable effector CD8 T-cell entry into skin-associated tumors where E-selectin is expressed on the vasculature.

Given the low level of MAdCAM-1 expression on SC tumor vasculature, it is not surprising that blocking antibodies to its receptor, $\alpha 4 \beta 7$, had no impact on T-cell entry into SC melanomas (176). In human colorectal carcinoma patients, high MAdCAM-1 gene expression in tumor lysates correlates with the presence of CD8 T-cells (184), but direct evidence that it mediates CD8 T-cell entry is lacking. The role of MAdCAM-1 in enabling T-cell infiltration into tumors deserves further scrutiny, especially in cancers of mucosal tissues or tumors that metastasize to mucosal sites.

Although selectin, integrin, and chemokine expression on tumor vasculature is generally low, it can still respond to inflammatory signals analogous to normal vasculature. For example, treating human squamous cell carcinomas with the TLR7 agonist, Imiquimod, or with TNF $\alpha$ induced expression of E-selectin on the vasculature and significantly increased the number of ESL+ CD8+ T-cells in the tumor (162). Likewise, inflammation induced by systemic hyperthermia significantly increased the number of CD8 T-cells rolling on tumor vasculature, and this could be blocked by a cocktail of E- and P-selectin blocking antibodies (176). Additionally, treatment of pancreatic islet carcinomas with $\mathrm{CpG}$ upregulated VCAM-1 and ICAM-1 on tumor vasculature and significantly 
increased T-cell infiltration, likely due to enhanced homing ligand expression (96). These data highlight that upregulation of HR ligand expression on tumor associated vasculature is an important maneuver to be developed in conjunction with other therapies that depend on immune infiltrates for their effectiveness.

\section{Positive feedback loops in vascular ligand expression}

It is interesting that TNF $\alpha$ and IFNy increase HR ligand expression and are released by effector CD8 T-cells. This raises the possibility that early stage effector CD8 T-cell entry into tumors could initiate a positive feedback loop in which their secretion of cytokines further upregulates HR ligand expression, enhancing the entry of additional effector CD8 T-cells. Indeed, exogenous antigen-specific T-cells that enter EL-4 thymoma increase accumulation of host T-cells as well (185). This increased accumulation was dependent on IFN $\gamma$ released by the transferred cells, and associated with increased expression of several chemokines that are chemotactic for effector T-cells (186). We have found that B16-OVA tumors grown in Rag $1^{-/}$mice, which lack B and T-cells, express significantly lower levels of VCAM-1 and MAdCAM-1. The adaptive immune effector activities that upregulate HR ligand expression in these tumors remain to be elucidated. Importantly, the efficacy of PD-1 blockade in enhancing tumor control has been associated with induction of this positive feedback loop: enhanced IFN $\gamma$ secretion by intratumoral CD8 T-cells in anti-PD-1 treated mice increased expression of chemokines, including CXCL10, and resulted in greater T-cell entry and tumor control (187). 


\section{Mechanical properties of vasculature}

In normal angiogenesis, VEGF-activated endothelial cells detach from their neighbors and sprout in the direction of pro-angiogenic factors, including VEGF itself (188). Proliferation results in the formation of tubes that recruit pericytes to provide stability. In a final resolution stage, the endothelial cells remodel and prune to form a functional vasculature. The enhanced availability of pro-angiogenic factors in tumors results in vessels that are disorganized, tortuous, leaky, and lack pericyte coverage. This abnormal architecture results in hypoxia in the tumor microenvironment and high intratumoral pressure. Loss of the gene encoding Regulator of G-protein Signaling 5 resulted in normalization of this tumor vasculature and, intriguingly, also enhanced T-cell representation within tumors (189). This study concluded that this was due to a reduction in intratumoral pressure, which enabled more robust T-cell entry (189). This makes sense if fluid flow were a direct determinant of migration, but T-cells crawl on extracellular matrix to move within tissue. Instead, the decreased space between endothelial cells in normalized vasculature may create a more continuous vascular surface to support T-cell rolling as a prelude to entry. The effect of normalizing the tumor vasculature on vascular ligand expression was also not addressed. MAdCAM-1 expression, for example, has been shown to be dependent on proximity of endothelial cells to one another (190), a property that could be altered by normalizing vasculature. While high dose anti-angiogenic therapy destroys vasculature and inhibits entry, low dose anti-angiogenic therapy 
may promote entry and enhance immunological tumor control alone or in combination with other strategies $(191,192)$.

\section{Altering the tumor vasculature to support enhanced entry of T-cells}

\section{A. Rationale for modifying tumor associated vasculature}

As described, characteristics of the tumor vasculature determine whether or not tumors are permissive to the entry of both effector and naïve CD8 T-cells. Because the presence of CD8 T-cells in tumors is such a strong prognostic factor and predictor of responsiveness to immunotherapies, strategies that can alter the tumor vasculature to support the enhanced entry of T-cells hold the potential to extend the effectiveness of these immunotherapies to a much broader crosssection of patients for whom they would otherwise be ineffective.

If a tumor contains only small numbers of CD8 T-cells, however, can altering just the properties of the vasculature actually have a meaningful effect? This is likely to depend on the precise nature of the tumor. For example, if the tumor has antigens that can be recognized by CD8 T-cells, but remains poorly infiltrated due to defects at the level of innate cell activation, or driver mutations that promote limited lymphocytic infiltration, then exogenous manipulations to initiate inflammation in the tumor or directly upregulate ligands for homing receptors would likely have a positive effect. Indeed in pancreatic cancer patients and murine models, vaccination and chemotherapy initiated accumulation of Tcells in the previously T-cell poor tumor $(193,194)$. As effector T-cells reach the tumor in response to these interventions, they would secrete pro-inflammatory 
cytokines, and initiate the positive feedback loop to support recruitment of additional effector CD8 T-cells into the tumor by maintaining an inflamed tumor vasculature. A similar effect would be expected in response to interventions designed to induce HEV-like blood vessels and promote naïve T-cell entry. Indeed, several studies have shown that maneuvers to induce intratumoral naïve T-cell priming, such as targeting of $L T \alpha$ to the tumor, or intratumoral vaccination with CCL21-secreting peptide-pulsed DCs are effective, even in the absence of LN (195-197). Once naïve T-cells become activated, they would also be expected to contribute to the positive feedback loop, supporting the continual influx of T-cells through inflamed blood vessels.

There are still theoretical advantages to targeting the tumor to primarily enhance either naïve or effector T-cell entry. For example, the induction of HEVlike blood vessels appears to require LT $\alpha$-TNFR signaling regardless of the site of tumor growth. Therefore, inducing vessels expressing PNAd and CCL21 at different anatomic locations may be easier than attempting to induce the different molecules involved in effector cell trafficking that may have a known tissueselective preference for one site or another, such as E-selectin and MAdCAM-1. Additionally, the HR ligands VCAM-1 and CXCL9 which are expressed regardless of the site of tumor growth are potential molecules to induce. Altering the vasculature to support entry of effector T-cells may work synergistically with current vaccination or adoptive transfer therapies by enhancing the very small fraction of transferred cells that enter the tumor. 


\section{B. Strategies for modifying tumor associated vasculature}

The simplest method for altering tumor associated vasculature to support enhanced entry of CD8 T-cells would be through systemic administration of inflammatory stimuli, such as TNF $\alpha, \mathrm{LT} \alpha$, LIGHT, and IFN $\gamma$, or agonistic antibodies targeting their receptors to induce upregulation of ligands for naïve and effector T-cell homing receptors. Unfortunately, this strategy is limited by the toxicity of these agents when given systemically. Therefore, an alternative strategy would be the concentrated delivery of inflammatory cytokines or other stimuli directly to the tumor site. While these strategies are still early in development, methods such as tumor-endothelium targeted microbubbles (198) or engineered adeno-associated viruses that localize to specific tumor targets (199) are potential options.

Direct modulation of the tumor vasculature is not the only possibility, however. One interesting intervention involves a temporary induction of mild hyperthermia, which is associated with the expression of IL-6 to enhance ICAM-1 expression on tumor vasculature (176). Inhibiting VEGF (192) or the Endothelin B Receptor that indirectly decrease expression of homing receptor ligands is another potential strategy (171). Tissue engineering approaches to implant scaffolds to support development of TLS at the tumor site may also be feasible (200). Furthermore, the matching of vaccination routes or in-vitro treatments of

adoptively transferred cells should be optimized to induce T-cell populations that 
express appropriate HR to bind to the ligands expressed on tumor vasculature, which may vary with location of growth.

Interventions to enhance T-cell trafficking are not proposed to entirely supplant, but rather work in concert with current therapeutic strategies. For example, they may be combined with local radiotherapy or chemotherapy to enhance tumor antigenicity, or applied in combination with vaccination or adoptive transfer to increase the efficiency of CD8 T-cell entry into tumors. Rational combinations of immunotherapies are already showing increased efficacy in murine models and human patients (201). Modifying the tumor vasculature and microenvironment to support the entry of naïve and activated Tcells has the potential to further broaden the cohort of patients that will respond to current immunotherapies.

This introduction was adapted from Peske, JD, Woods, $A B$, Engelhard, VH. Advances in Cancer Research (2015). Control of CD8 T-cell Infiltration into Tumors by Vasculature and Microenvironment. 


\section{Thesis Rationale and Proposal}

Immunologic tumor control and clinical response to adoptive T-cell therapy are ultimately dependent on the number of CD8 T-cells that can infiltrate a tumor. As described, interactions between homing receptors on the CD8 T-cell and corresponding ligands on the tumor vasculature are essential for CD8 T-cell entry into peripheral tissues, including tumors. While the HR/ligand interactions for entry into many peripheral tissues have been described, currently, we lack a comprehensive understanding of which HR expressed on T-cells are required for infiltration into tumors as well as how the level of corresponding ligand expression on tumors at various sites affects their ability to infiltrate. Therefore, we felt several important and related questions needed to be considered. First, what HR ligands are expressed on tumor vasculature? Does ligand expression vary based on anatomical site and/or tumor type? Are ligands expressed at sufficient levels to enable T-cell entry? Is tumor vascular ligand expression characteristic of the local peripheral tissue, or the tumor itself, and is it regulated positively or negatively by elements of the innate and adaptive immune systems? In many cases, the answers to these questions were only starting to be addressed.

This project fully characterized the HR ligands expressed on the vasculature of tumors and how it differed based on site of tumor growth. Then subsequently showed that the adaptive immune system is critical for enhancing expression of HR ligands on tumor-associated vasculature. Finally, this work 
determined which HR/HR ligand interactions are sufficient for entry of CD8 Tcells into both subcutaneous and intraperitoneal melanomas. Current adoptive cell transfer therapies and vaccination strategies do not take into account expression of homing molecules induced on the cellular surface. Therefore, understanding cellular trafficking based on HR expression represents a real opportunity for improving adoptive cell transfer and vaccination immunotherapies. In its final stages, this work addressed the impact of commonly used antiCTLA-4 checkpoint blockade on the representation of CD8 T-cells in the tumor microenvironment and on expression of HR ligands on tumor associatedvasculature. Because checkpoint blockade is rarely given as a monotherapy, Tcell accumulation and HR ligand expression were analyzed in tumors treated with anti-CTLA4 alone and then at the vaccination site and in the tumor of mice treated with both anti-CTLA4 and the peptide vaccine gp100 in Incomplete Freund's Adjuvant (IFA). This work details the impact of vaccination on the effectiveness of anti-CTLA4 in inducing ligand expression on tumor-associated vasculature and CD8 T-cell accumulation in the tumor. 


\section{Materials and Methods}

Mice. C57BI/6 (B6) mice were from Charles River/NCl. Rag1 ${ }^{-/-}$(B6.129S7Rag1 $\left.{ }^{\mathrm{tm} 1} \mathrm{Mom} / \mathrm{J}\right), \mathrm{IFN} \gamma^{-1}$, and E-Selectin ${ }^{-/}$(B6.129S4-Sele $\left.{ }^{\wedge \mathrm{tm} 1} \mathrm{Dmil} / \mathrm{J}\right)$ were from Jackson Laboratories. OT-1 Rag $1^{-/}, \mathrm{TNF}^{-/-}$and Thy 1.1 congenic were from Taconic. CXCR3 ${ }^{--}$mice were a gift from Eugene Butcher. AAD (202) and FH TCR (203) transgenic mice were from our own facility. Animals were housed and bred in pathogen-free facilities and used between 6 and 22 weeks of age. The University of Virginia Animal Care and Use Committee approved all procedures. Experiments were carried out in accordance with the recommendations in the Guide for the Care and Use of Laboratory Animals of the National Institutes of Health.

Tumor lines and injections. B16-F1 melanoma, B16-OVA (cytoplasmic ovalbumin expressing) (204), B16-AAD (expression of the chimeric major histocompatibility molecule HLA-A2) (205), MC38 cell line (gift of Steven

Rosenberg, National Institutes of Health) was transfected to express cytoplasmic ovalbumin, or LLC-OVA (gift of E. Podack, University of Miami) were injected IV, IP, intracranial, or SC in the scruff of the neck. Experiments were performed 1121 days post injection.

Immunofluorescence Microscopy. All tissues were flash frozen and cut into $0.7 \mu \mathrm{m}$ sections for staining. Frozen sections were fixed in a 1:1 acetone:ethanol solution, blocked sequentially with anti-Fc (2.4G2) (BioXCell), Avidin/Biotin Blocking Kit (Vector), $\mathrm{H}_{2} \mathrm{O}_{2}$ and $\mathrm{NaN}_{3}$, then stained with the following antibodies: 
CD31-FITC (E Bioscience) or CD31-AF647 (Biolegend), MAdCAM-1-Biotin (E Bioscience), VCAM-1-Biotin (E Bioscience), and ICAM-1-Biotin (E Bioscience). For biotinylated antibodies, Streptavidin DyLight 550 (ThermoFisher) was used as secondary. Amplification was completed using the Perkin Elmer TSA Biotin Kit. Slides were mounted in SlowFade Gold (Invitrogen) and images collected on an Axiolmager with Apotome (Zeiss). ImageJ software $(\mathrm{NIH})$ was used to quantify the percent of $\mathrm{CD} 31^{+}$pixels that were also VCAM-1+, MAdCAM-1+, $\mathrm{HA}$, or ICAM $-1^{+}$. Briefly, a threshold was set on the $\mathrm{CD} 31^{+}$single color image and on the HR ligand ${ }^{+}$single color images. The thresholded area was then selected and the area fraction of the CD31 that was positive for HR ligand was calculated.

Effector Cell Generation and Transfer. Bone marrow was harvested from the femur and tibia of B6 mice and cultured in the presence of IL-4 and GM-CSF for 7 days. Bone Marrow Dendritic Cells (BMDCs) were then activated overnight on CD40L-expressing $3 \mathrm{~T} 3$ cells. After 18hrs of activation, BMDCs were collected and pulsed with SIINFEKL peptide in the presence of $\beta_{2}$ microglobin. Bulk $\mathrm{H}$ $2 \mathrm{~K}^{\mathrm{b}}+$ ovalbumin-specific OT-I Thy $1.1+\mathrm{T}$-cells were adoptively transferred into B6 mice, and immunized with SIINFEKL peptide-pulsed activated BMDC injected by $\mathrm{SC}$, IV, or IP routes. Alternatively, CD8 T-cells from $\mathrm{FH}$ or $\mathrm{FHxCXCR} 3^{-1-}$ transgenic mice were adoptively transferred into AAD mice, and immunized with YMDGTMSQV peptide-pulsed activated BMDC. FTY720 (Novartis) was administered IP daily for $4-5$ days until harvest to retain effector CD8 T-cells in the activating LN. On day 5-6, the appropriate LN and/or spleen was harvested 
based on site of immunization. Tissue was homogenized, red blood cell lysed using RBC lysis buffer (Sigma) for 3 min at $37^{\circ} \mathrm{C}$, and CD8 T-cells were enriched using anit-CD8 magnetic beads and an AutoMACS (Miltenyi). Cells were then counted and at least $300,000-500,000$ were transferred into tumor-bearing animals IV.

Homing Receptor/Ligand Blocking. Effectors were generated as described, then blocked with either $100 \mu \mathrm{g}$ anti-Rat IgG (Jackson Immunoresearch), anti- $\alpha 4$ clone PS/2 (ATCC), anti-CD44 clone IM7, anti- $\alpha 4 \beta 7$ clone DATK32 or antiCD11a clone M17/4 (all from BioXcell) for $30 \mathrm{~min}$ at $4^{\circ} \mathrm{C}$ immediately prior to IV transfer into tumor-bearing animals. Ligands were blocked by IP injection of $100 \mu \mathrm{g}$ anti-VCAM-1 clone M/K-2.7 or anti-MAdCAM-1 clone MECA-367 (both from BioXcell) 6hrs prior to effector transfer IV.

Endothelial Cell Isolation. Tissue was harvested and placed into DMEM (Cellgro) medium containing $0.42 \mathrm{U} / \mathrm{mL}$ Liberase TM (Roche), 60U/mL DNase I (Sigma), 2\%FCS, essential and non-essential amino acids, sodium pyruvate, and HEPES for $15-45$ minutes at $37^{\circ} \mathrm{C}$. Tissue was homogenized and incubated with anti-CD31 magnetic beads (Miltenyi) in AwesomeMACS (PBS with 0.5\% BSA, 2mM EDTA, 2mM L-glutamine, $10 \mathrm{mM}$ sodium pyruvate, essential and nonessential amino acids, and dextrose). Separations were done using the Possel AutoMACS protocol (Miltenyi).

Rag $1^{-/-}$repletion. LN and spleen were harvested from WT B6, TNF $\alpha^{-/-}$or IFN $\gamma^{-/-}$ mice. Tissue was homogenized, RBC lysed, and CD8s were enriched using CD8 
microbeads and the AutoMACS (Miltenyi). Five million enriched CD8 T-cells were adoptively transferred into Rag $1^{-/}$mice. Three days post-adoptive transfer, 400,000 B16-OVA cells were injected SC. Tumors were harvested and processed as described 14 days after tumor injection.

Flow Cytometry. Cells were Fc blocked (2.4G2, BioXCell) and stained with fluorescent antibodies in KASS MACS (PBS with 0.5\% BSA, 2mM L-glutamine, 10mM sodium pyruvate, essential and non-essential amino acids, dextrose, and $1 \mathrm{mM} \mathrm{CaCl})$. CD31 enriched endothelial cells were resuspended in Dapi and run live. Lymphocytes were fixed in 2\% PFA. Antibodies to CD31, CD45, CD8, Thy1.1 (all from eBioscience), CXCL9 (Biolegend), E-Selectin, P-Selectin (both Becton Dickinson), E-Selectin Fusion Protein and P-Selectin Fusion Protein (both $R \& D)$ were used. Fixation and permeabilization for CXCL9 analysis was done using the BD Cytofix/Cytoperm Kit. All cells were resuspended in AwesomeMACS and run on BD FACS Canto II or Becton Dickson Cytoflex flow cytometers. FlowJo software was used for analysis.

Anti-CTLA-4 and gp100/IFA Vaccination Studies. Animal experiments performed in this study were conducted after the approval of the Institiutional Animal Care and Use Committee at the University of Texas MD Anderson Cancer Center. In brief, 50,000 B16-BL6 cells were injected SC into the right flank. Three days later, $1 / 10$ of the spleen from Thy $1.1^{+}$pmel-1 mouse was injected IV into tumor bearing animals. On days 3, 6, and 9 animals were either left untreated, vaccinated with $100 \mu \mathrm{g} g \mathrm{hp} 100\left(\mathrm{H}-2 \mathrm{D}^{\mathrm{b}}\right.$ —restricted heteroclitic 
mouse gp10025-33 peptide, KVPRNQDWL) in saline or saline plus Incomplete Freund's Adjuvant (IFA) (1:1, vol/vol) SC, and/or treated with $100 \mu \mathrm{g}$ anti-CTLA-4 IP. In some animals, IFN $\gamma$ was blocked with IP injection of $200 \mu \mathrm{g}$ anti-IFN $\gamma$ on days $3,5,7,9$, and 11 . Tumors and vaccination sites were harvested on day 15 and frozen in OCT. Blocks of tissue from the vaccination site and the tumor were sent to the Engelhard lab from the lab of Dr. Willem Overwijk at MD Anderson. Tissue blocks were sectioned at the UVA Research Histology Core. Frozen sections were then handled as described in Immunofluorescence Microscopy. Statistical Analysis. All analyses were performed using unpaired student's Ttest. 


\section{Differential expression of homing receptor ligands on}

\section{tumor associated vasculature that control CD8 effector}

\section{T cell entry}

\section{Introduction}

The importance of CD8 T-cells in immunologic control of solid tumors has been well-established $(24,26,30,206)$. Cytokines, checkpoint blockade inhibitors, and vaccines have all been used to increase the representation and/or activity of intratumoral CD8 T-cells, and the effectiveness of these immunotherapies has been correlated with the presence of CD8 T-cells in tumors prior to treatment (36-39). However, many human tumors of several histological types show poor CD8 T-cell infiltration $(24,26,30,206,207)$. This limits the effectiveness of many new generation immunotherapeutics. A better understanding of the molecular mechanisms underlying CD8 T-cell infiltration into tumors holds the promise of improving clinical outcomes.

CD8 T-cell entry into peripheral tissues involves a series of sequential interactions between homing receptors (HR) on the surface of activated CD8 Tcells and their corresponding ligands on vascular endothelial cells $(208,101,103)$. Initial engagement of circulating lymphocytes with the vessel wall leads to slow rolling mediated by $\mathrm{E}$ - and/or P-selectins interacting with their corresponding ligands, or by $\alpha 4 \beta 1$ or $\alpha 4 \beta 7$ integrins interacting with VCAM-1 or MAdCAM-1, respectively $(117,154,209)$. Subsequent chemokine receptor binding to 
chemokines presented by endothelial cells leads to firm adhesion by inducing a high affinity conformation of these $\alpha 4$ integrins or LFA-1 $(103,140,144)$. Cells then transmigrate into underlying tissue.

Expression of several different HR on activated CD8 T-cells is determined by the secondary lymphoid organ in which priming occurs. E-Selectin Ligand (ESL) is selectively upregulated on CD8 T-cells activated in skin-draining LN $(110,210,114) . \alpha 4 \beta 7$ integrin and the chemokine receptor CCR9 are selectively upregulated on CD8 T-cells activated in gut-draining LN, while CD8 T-cells activated in mediastinal LN and spleen express $\alpha 4 \beta 1$ in lieu of either ESL or $\alpha 4 \beta 7(110,114,111,211)$. Conversely, expression of LFA-1 and several chemokine receptors, including $\mathrm{CXCR} 3$, does not depend on the priming site (114). Expression of distinct HR by activated T-cells determines their ability to enter certain inflamed peripheral tissues, particularly skin and gut.

This tropism of T-cells expressing distinct HR depends upon patterns of expression of the corresponding HR ligands by tissue vasculature. E-Selectin, which enables entry of ESL+ effectors, is selectively expressed on skin vasculature (124). MAdCAM-1 and CCL25, which enable entry of $\alpha 4 \beta 7^{+} \mathrm{CCR} 9^{+}$ T-cells, are selectively expressed on gut vasculature $(142,212)$. On the other hand, VCAM-1, which enables entry of $\alpha 4 \beta 1^{+}$effectors, is expressed on the inflamed vasculature of many tissues, including skin and gut (213). Similarly, CXCL9, 10, and 11, which enable entry of CXCR3 ${ }^{+}$effectors, are upregulated in many inflamed tissues $(214,215)$. ICAM-1, the ligand for LFA-1, is also broadly 
expressed (216). These HR ligands are all expressed at low or negligible levels on resting vasculature and increased by pro-inflammatory stimuli (103). Thus, tissue-specific and inflammation-induced expression of HR ligands determines which tissues are infiltrated by CD8 effectors primed in different secondary lymphoid organs. Importantly however, vaccination routes used to elicit T-cell responses rarely take into account which $\mathrm{HR}$ will be induced, nor which ligands are expressed based on the anatomical location of the target tissue.

In contrast to inflamed peripheral tissues, relatively little is known about the HR ligands expressed on tumor vasculature or the HR/ligand interactions that lead to efficient entry of CD8 T-cells into tumors growing in distinct anatomic locations. LFA-1/ICAM-1 interactions are common mediators of leukocyte engagement with other cells and, not surprisingly, have been shown to play an important role in CD8 T-cell entry into murine melanoma and human glioblastoma $(175,176,217)$. CXCR3 interactions with CXCL9 or CXCL10 have been shown to mediate CD8 T-cell entry into subcutaneous (SC) and intracranial murine melanomas (218-220) and correlated with infiltration into melanomas growing in lungs (221). $\alpha 4 \beta 1 / \mathrm{VCAM}-1$ interactions were required for CD8 T-cell accumulation in intracranial melanoma (222), and in SC melanoma following kinase inhibitor-induced VCAM-1 upregulation (219). Expression of VCAM-1 correlates with increased T-cell representation in pancreatic islet-cell carcinoma, glioblastoma, and melanoma $(91,96,175)$, but a cause and effect relationship was not established. E-selectin/ESL interactions were shown to be important for 
CD8 T-cell entry into B16-F10 melanomas following inflammatory stimuli, and in human squamous cell carcinoma, TLR mediated upregulation of E-selectin was correlated with increased representation of CLA+ CD8 T-cells $(162,176)$. However, the importance of E-selectin/ESL interactions in mediating CD8 T-cell entry into SC B16 melanomas in the absence of inflammatory stimuli has not been addressed. In human colorectal cancers high MAdCAM-1 gene expression was associated with increased CD8 T-cell representation (184), but to date, the role of $\alpha 4 \beta 7$ in CD8 T-cell entry into tumors in anatomically relevant sites has not been evaluated. Thus, while a small number of studies have identified individual HR that can contribute to T-cell infiltration into some tumors, and several suggestive correlations have been identified, a comprehensive analysis of the molecules that mediate entry of CD8 T-cells into any one kind of tumor, and how this varies with anatomical location, has not yet been conducted.

In the present study, we systematically identified the sets of molecules required for CD8 T-cell entry into B16 melanomas grown in SC and intraperitoneal (IP) compartments. We directly compared HR ligand expression on B16 melanoma vasculature to that of adjacent tissue vasculature and determined what cells and cytokines drive expression of HR ligands on tumor vasculature. Finally, we determined which $\mathrm{HR}$ /ligand interactions are required for CD8 T-cell entry into B16 melanomas growing in SC or IP spaces. Understanding the molecular requirements for CD8 T-cell entry into tumors growing in different 
locations and applying this knowledge clinically has the potential to enhance the efficacy of multiple cancer immunotherapies.

\section{Results}

\section{Expression of some but not all vascular HR ligands depends on tumor}

anatomical location. It is well-established that skin-associated vascular endothelial cells express E-selectin while gut-associated vascular endothelial cells express MAdCAM-1. We were interested to know whether tumorassociated vasculature expressed either of these ligands, and whether this differed based on site of tumor growth, or tissue origin of the tumor. Thus, we evaluated $\mathrm{CD} 31^{+}$vascular endothelial cells isolated from SC or IP B16-F1 melanoma tumors expressing ovalbumin (B16-OVA) by flow cytometry, or examined them by immunofluorescent microscopy of frozen sections. The vascular endothelial cells of SC tumors expressed E-selectin, but few expressed MAdCAM-1 even following tyramide signal amplification (Figure 1). In contrast, the vascular endothelial cells of IP tumors expressed MAdCAM-1, while Eselectin expression was very low. We observed a similar pattern of expression for MAdCAM-1 on endothelial cells from IP and SC tumors of ovalbuminexpressing Lewis Lung carcinoma (LLC-OVA) and E-selectin on endothelial cells from SC and IP tumors of ovalbumin-expressing MC38 (Figure 2). These results suggest that the same anatomic micro-environmental influences that drive expression of E-selectin and MAdCAM-1 on normal tissue vasculature also pattern tumor vasculature. 
We next evaluated the expression of HR ligands that are upregulated on the endothelium of many inflamed tissues. While P-selectin is considered by some to be a skin-associated molecule, it is more broadly expressed (223). In keeping with the latter, P-selectin was expressed similarly on SC and IP tumor vasculature (Figure 3). ICAM-1 and Hyaluronic Acid (HA), ligands for LFA-1 and CD44 respectively, were also expressed comparably on the vasculature of both SC and IP tumors (Figure 4). By intracellular staining, CXCL9, a ligand for CXCR3, was expressed in CD31+ endothelial cells from both SC and IP tumors, although the percent of positive cells was significantly higher in the latter (Figure 5). Conversely, by IF staining, VCAM-1, the ligand for $\alpha 4 \beta 1$ integrin, was expressed on a higher percentage of CD31+ pixels from SC tumors, and was detectable without tyramide amplification, while visualizing VCAM-1 on IP tumor vessels required amplification (Figure 6). These results suggest that SC and IP tumors have distinct microenvironment features that lead to differential expression of VCAM-1 and CXCL9, respectively, although both are considered to be induced by similar inflammatory stimuli $(150,224)$.

We also assessed HR ligand expression on the vasculature of tumors growing in lung and brain, common sites of melanoma metastasis. VCAM-1 was expressed on tumor endothelial cells from both sites, but at a lower percentage compared to SC and IP tumors (Figure 7). Interestingly, E-Selectin was expressed on brain but not lung tumor endothelial cells, while MAdCAM-1 was 
not expressed on either. These findings validate VCAM-1 being broadly expressed, while E-selectin and MAdCAM-1 are controlled by anatomical site.

\section{HR ligand expression on tumor vasculature is higher than normal tissue}

vasculature. Tumors are generally considered to be inflamed, but also immunosuppressed. Because HR ligand expression on vascular endothelium is upregulated by inflammatory cytokines, we evaluated how expression of HR ligands on tumor vasculature compared with vasculature from normal tissue. The percentage of $\mathrm{CD} 31^{+}$endothelial cells from SC tumors that were E-selectin ${ }^{+}$, VCAM-1+ ${ }^{+}$, or CXCL9+ was significantly higher than that of endothelial cells isolated from skin (Figure 8). Similarly, the percentage of CD31+ pixels from IP tumor that were VCAM-1+ was significantly higher in IP tumors than CD $31^{+}$pixels from the gut (Figure 9). Surprisingly however, the percentage of CD31+ pixels that were MAdCAM-1+ was significantly lower in tumor than gut. The elevated expression of most of these HR ligands on SC and IP tumor vasculature is consistent with the idea that inflammatory stimuli in the tumor microenvironment are responsible.

\section{The level of HR ligand expression on tumor vasculature depends on} adaptive immunity. To determine whether the inflammatory stimuli driving HR ligand expression on tumor vasculature were dependent on the adaptive immune system, we evaluated B16-OVA tumors grown in normal B6 and Rag $1^{-/}$mice. By IF and flow cytometry, the fraction of CD $31^{+}$cells expressing VCAM-1 was reduced by $70-90 \%$ in tumors from Rag $1^{-/}$mice compared to those from B6 mice 
(Figure $10 \& 11$ ). Similarly, expression of CXCL9 by CD31+ cells was reduced to negligible levels (Figure 11). Interestingly, while there was a trend to lower expression of E-selectin, it was not statistically significant (Figure 11). We also compared HR ligand expression on the vasculature of B16-OVA tumors with that of parental B16-F1 tumors, which lack a strong antigen and are less wellinfiltrated by CD8 T-cell effectors $(71,204,225)$ (Figure 12). In keeping with the above, VCAM-1 and CXCL9 expression on B16-F1 associated vasculature was significantly lower than on B16-OVA tumors, while E-selectin expression was comparable (Figure $10 \& 11$ ). Collectively these results point to a role for adaptive immune effectors, presumably located within the tumor, in upregulating expression of VCAM-1 and CXCL9, but not E-selectin, on SC tumor vasculature. We also analyzed patterns of co-expression of each of these HR ligands by individual CD31+ cells. Using the total percentage of cells expressing each marker as determined from flow cytometry data, we calculated expected levels of co-expression based on random distribution of expression, and compared these to what was actually observed (Figure 13). We found that the fraction of cells expressing only E-selectin was consistent with independent control of expression of this ligand. However, the fraction of cells expressing either VCAM-1 or CXCL9 alone was significantly lower than predicted, while populations expressing these ligands together were significantly higher. These results point to a coordinated control of VCAM-1 and CXCL9, consistent with the action of localized effector cells releasing inflammatory mediators in proximity to individual endothelial cells. 


\section{CXCL9 and VCAM-1 expression on tumor vasculature is driven by IFN $\gamma$ but}

not TNF $\alpha$. CXCL9 expression on inflamed tissue vasculature is upregulated by IFN $\gamma$ (224) while VCAM-1 expression has been reported to be upregulated by either IFN $\gamma$ or TNF $\alpha(150,226)$. To determine the role of these cytokines in driving CXCL9 and VCAM-1 expression on tumor vasculature, SC B16-OVA tumors were grown in WT B6, TNF $\alpha^{-1}$, and IFN $\gamma^{-1-}$ mice. As expected, CXCL9 expression in $\mathrm{CD} 31^{+}$cells from tumors grown in IFN $\gamma^{-1-}$ mice was almost nonexistent, pointing to a non-redundant role for this cytokine (Figure 14). Interestingly, VCAM-1 expression was also negligible in the vasculature of tumors grown in IFN $\gamma^{-/-}$mice, but was comparable in vasculature of tumors grown in WT B6 or TNF $\alpha^{-/-}$mice (Figure 14). Thus, despite reports of TNF $\alpha$ mediated control of VCAM-1 expression, it does not do so in B16 melanoma, and control of both of these HR ligands is mediated only by IFN $\gamma$.

Because the immune infiltrate of B16-OVA tumors is dominated by CD8 Tcells, we asked whether they were the source of IFN $\gamma$ controlling VCAM-1 and CXCL9 expression. Thus, SC B16-OVA tumors were grown in Rag $1^{-/}$mice that had previously been repleted with bulk CD8 T-cells from WT, IFN $\gamma^{-1-}$, or TNF $\alpha^{-1-}$ animals (71). Expression of CXCL9 and VCAM-1 in tumors grown in mice repleted with WT CD8 T-cells was comparable to that observed in tumors grown in WT B6 mice (Figure 15). Expression of these molecules was comparable in tumors grown in mice repleted with $\mathrm{TNF} \alpha^{-1-} \mathrm{CD} 8 \mathrm{~T}$-cells, confirming a lack of control of either VCAM-1 or CXCL9 by this cytokine. However, expression of 
these molecules was substantially lower in tumors grown in mice repleted with IFN $\gamma^{-1-}$ CD8 T-cells (Figure 15). Interestingly, despite the significant differences in ligand expression, infiltration of $\mathrm{WT}$, IFN $\gamma^{-1-}$, or $\mathrm{TNF} \alpha^{-1-} \mathrm{CD} 8 \mathrm{~T}$-cells was similar. These results establish a non-redundant role for IFN $\gamma$ in the upregulation of CXCL9 and VCAM-1 on tumor-associated vasculature, and the sufficiency of CD8 T-cells to be its source.

VCAM-1, HA, and ICAM-1 mediate $\alpha 4 \beta 1^{+}$effector CD8 T-cell entry into SC and IP tumors. We next sought to determine which vascular HR ligands and their corresponding HRs mediate effector CD8 T-cell entry into SC and IP tumors. We generated effectors with different HR expression profiles by IV, SC, or IP immunization with peptide-pulsed DC to activate OT-I T-cells in different secondary lymphoid organs (114). Seven days later, these effectors were isolated and adoptively transferred into Thy 1.1 congenic mice bearing late-stage SC or IP tumors, and those that had infiltrated tumors were quantitated 18 hours later. We first evaluated IV primed effectors because they uniformly express $\alpha 4 \beta 1$, CD44 (Figure 16), CXCR3, and LFA-1 (114). After transfer of 300,000500,000 such effectors, $0.1-2 \%$ had infiltrated both SC and IP B16-OVA tumors 18 hours later. This is consistent with the low level of infiltration observed in other murine and human studies of adoptively transferred T-cells (69). We found no evidence for a consistent difference in the level of infiltration into either SC or IP tumors.

To evaluate the importance of individual HR and ligands, we pretreated 
CD8 effectors with HR blocking antibodies prior to adoptive transfer, pretreated recipient mice with $\mathrm{HR}$ ligand blocking antibodies, or used mice that carried genetic deletions in either HR or HR ligands. $\alpha 4 \beta 1$ integrin, which recognizes VCAM-1, has been shown to act at the initial slow rolling step of the adhesion cascade, possibly in conjunction with CD44 (154), but also at the final integrinmediated step in lieu of LFA-1 $(227,228)$. Antibody blockade of $\alpha 4 \beta 1$ on CD8 T effectors almost completely eliminated their infiltration into both SC and IP tumors (Figure 17). The representation of these effectors in the spleen was unaffected by antibody pre-treatment, demonstrating that the lack of accumulation in the tumor was not a consequence of antibody-mediated cell killing. Antibody blockade of VCAM-1 on the tumor vasculature prior to transferring $\alpha 4 \beta 1+$ CD8 effector T-cells also substantially inhibited entry into SC tumors (Figure 18). This demonstrates that $\alpha 4 \beta 1 / \mathrm{VCAM}-1$ interactions are essential for CD8 T-cell entry into both SC and IP tumors despite differences in the level of VCAM-1 expression. Entry of effector CD8 T-cells into SC tumors was also completely inhibited using antibodies to LFA-1 (Figure 19). The nonredundancy of $\alpha 4 \beta 1$ and LFA-1, along with the involvement of activated LFA-1 in the terminal step of leukocyte adhesion (144), suggests that $\alpha 4 \beta 1$ acts in the initial slow rolling step to enable CD8 T effector entry into tumors. Interestingly, antibody blockade of CD44 on CD8 effectors also substantially inhibited their entry into both SC and IP tumors (Figure 20). It is likely that LFA-1 and CD44 act by binding to ICAM-1 and HA, respectively, as these well-established ligands are 
displayed on SC and IP tumor vasculature. The greater than $90 \%$ inhibition of infiltration observed with individual blockade of $\alpha 4 \beta 1$, CD 44 , and LFA-1 indicates that these three HRs act non-redundantly to mediate entry of IV primed CD8 effectors into both SC and IP tumors.

CXCR3, which interacts with CXCL9,10, and 11, mediates the transition from slow rolling to firm adhesion by activating the high affinity conformation of LFA-1 (220). To assess its importance, we used $\mathrm{CXCR}^{-/-}$mice that had been bred to a different TCR transgenic animal expressing a T-cell receptor specific for Tyrosinase + HLA-A2 $(203,229)$, and assessed infiltration of IV primed effectors into B16 tumors expressing a recombinant form of HLA-A2, AAD (205). Infiltration of both SC and IP B16-AAD tumors by CXCR3 ${ }^{-/}$effectors was reduced by more than $80 \%$ (Figure 21). In addition, WT effectors transferred into mice bearing 3-day old tumors effectively controlled tumor outgrowth for several weeks, but transferred $\mathrm{CXCR}^{-/-}$effectors had no discernable effect (Figure 22). Collectively these results illustrate that CXCR3 plays an essential role in the infiltration of CD8 effectors into tumors growing in multiple anatomical locations and that this is essential for control of tumor outgrowth.

\section{MAdCAM-1 does not mediate $\alpha 4 \beta 7^{+}$effector CD8 T-cell entry into IP tumors.}

Because VCAM-1 is expressed at low levels on IP tumor vasculature, we sought to determine whether MAdCAM-1 could provide an alternate route for entry of CD8 T-cells expressing $\alpha 4 \beta 7$ integrin. CD8 T-cell effectors primed by IP immunization are over $70 \% \alpha 4 \beta 7^{+}$(ref. (114)) (Figure 16). An additional 10\% 
express $\alpha 4$ in the absence of $\alpha 4 \beta 7$, and are thus $\alpha 4 \beta 1^{+}$. However, the level of $\alpha 4 \beta 1$ on the $\alpha 4 \beta 7^{+}$cells cannot be determined. Somewhat to our surprise, antibody blockade of MAdCAM-1 on IP tumor vasculature had no effect on infiltration of adoptively transferred IP primed effectors (Figure 23). On the other hand, antibody blockade of VCAM-1 inhibited infiltration of these effectors by about $80 \%$, and no additional effect was seen when VCAM-1 and MAdCAM1 were blocked simultaneously (Figure 24). In addition, treatment of effectors with either anti- $\alpha 4$, which would block both $\alpha 4 \beta 7$ and $\alpha 4 \beta 1$, or anti- $\alpha 4 \beta 7$, also inhibited IP primed effector infiltration into IP tumors (Figure 24). It has been reported that $\alpha 4 \beta 7$ can bind to VCAM-1 as well as MAdCAM-1 (142). Collectively, this suggests that IP primed effectors enter IP tumors through interactions between $\alpha 4 \beta 7$ and possibly $\alpha 4 \beta 1$ with VCAM-1 on IP tumor vasculature, and that MAdCAM-1 is uninvolved.

Because MAdCAM-1 was expressed on a higher fraction of IP tumor vasculature than VCAM-1, and MAdCAM-1 visualization did not require amplification, its lack of involvement in effector cell infiltration led us to question whether it was expressed on the luminal surface. To address this, we injected a mixture of fluorescent CD31 and MAdCAM-1 specific antibodies into the tail vein of IP tumor-bearing mice 30 minutes before harvesting tissue. The CD31 antibody decorated the vasculature of Peyer's Patches, axillary/brachial LN, and tumors, demonstrating that all were accessible to the injected antibodies. As expected, the MAdCAM-1 antibody decorated vasculature of Peyer's Patches but 
not that of axillary/brachial LNs. Importantly, it also did not stain the vasculature of IP tumors even following signal amplification (Figure 25). However, using the same in vivo injection approach, anti-VCAM-1 did stain the luminal surface of tumor vasculature (Figure 26). We conclude that $\alpha 4 \beta 7$ does not mediate IP primed effector entry into IP tumors through interaction with MAdCAM-1 because this HR ligand is not available on the luminal surface for interaction.

\section{E-Selectin is required for ESL+ effector CD8 T-cell entry into SC tumors.}

Cancer vaccines in humans are most commonly introduced by the intradermal route. In mice, activation of cells in the skin-draining LN generates effectors that express ESL. Over $50 \%$ of these cells express ESL in the absence of $\alpha 4 \beta 1$ (Figure 16). Since none of the available E-selectin antibodies completely abrogate interaction with $\mathrm{ESL}^{+}$cells (230), we used two alternate approaches to determine if ESL/E-selectin interactions mediated CD8 T-cell entry into SC tumors with E-selectin ${ }^{+}$vasculature. First, we transferred a 50/50 mix of SC and IP primed effectors into WT mice bearing SC or IP tumors. Infiltration of IP tumors by both SC and IP primed effectors was comparable, and also comparable to the infiltration of SC tumors by IP primed effectors. However, SC effectors infiltrated SC tumors to a substantially greater extent than did IP effectors (Figure 27). This is consistent with the idea that ESL/E-selectin interactions augment SC effector entry into SC tumors. To establish this definitively, we evaluated entry of SC primed CD8 T-cell effectors transferred into SC tumors grown in WT and E-selectin ${ }^{-/}$mice. The numbers of effectors 
infiltrating tumors grown in E-selectin ${ }^{-/}$mice were reduced by about half relative to the numbers in tumors growing in WT mice (Figure 28). Collectively, these results indicate that ESL/E-selectin interactions facilitate ESL+ CD8 T-cell entry into SC tumors with E-selectin+ vasculature, but are ineffective in facilitating entry of these effectors into tumors whose vasculature does not express this HR ligand. 
Figure 1
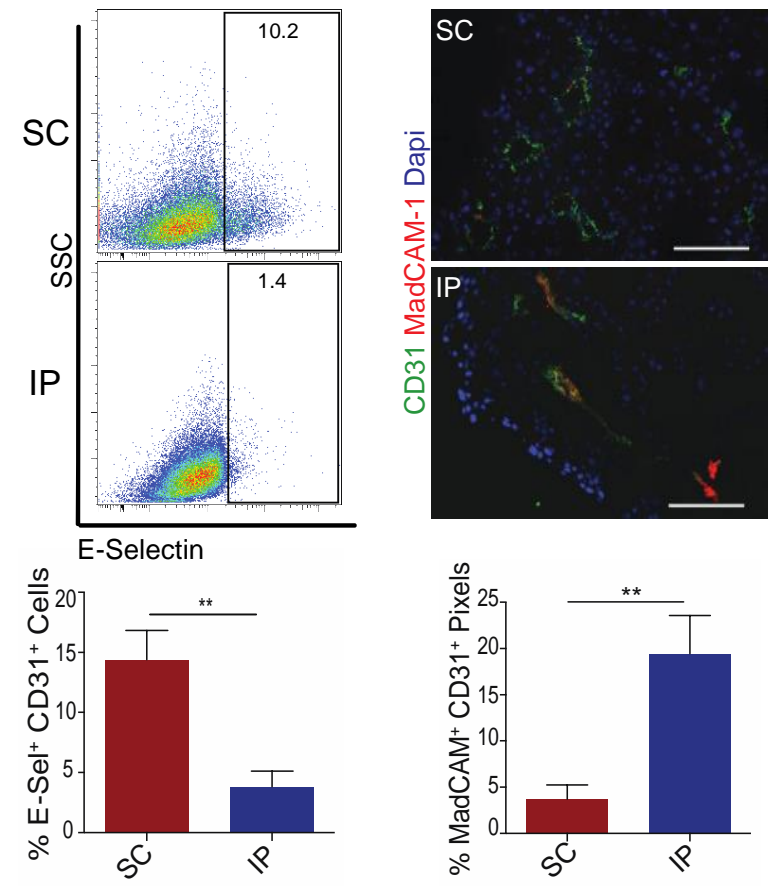
Figure 1: B16-OVA tumors were harvested 14 days after SC injection or 11 days after IP injection. Samples were either digested, enriched for $\mathrm{CD} 31^{+}$endothelial cells, and analyzed by flow cytometry, or frozen and processed for immunofluorescence microscopy. Representative flow cytometry and summary data for CD31+CD45 neg endothelial cells from SC or IP B16-OVA tumors stained for E-selectin ( $\mathrm{n}=3$ tumors per group). Representative images and summary data for CD31+ cells from SC or IP B16-OVA tumors stained for: MAdCAM-1 (Interrogated 5-10 random fields from 1 section of 3 tumors). Percentages were calculated using ImageJ to define CD31+ pixels and quantitating those positive for MAdCAM-1. All statistical analyses were performed using unpaired student's T-test. 


\section{Figure 2}

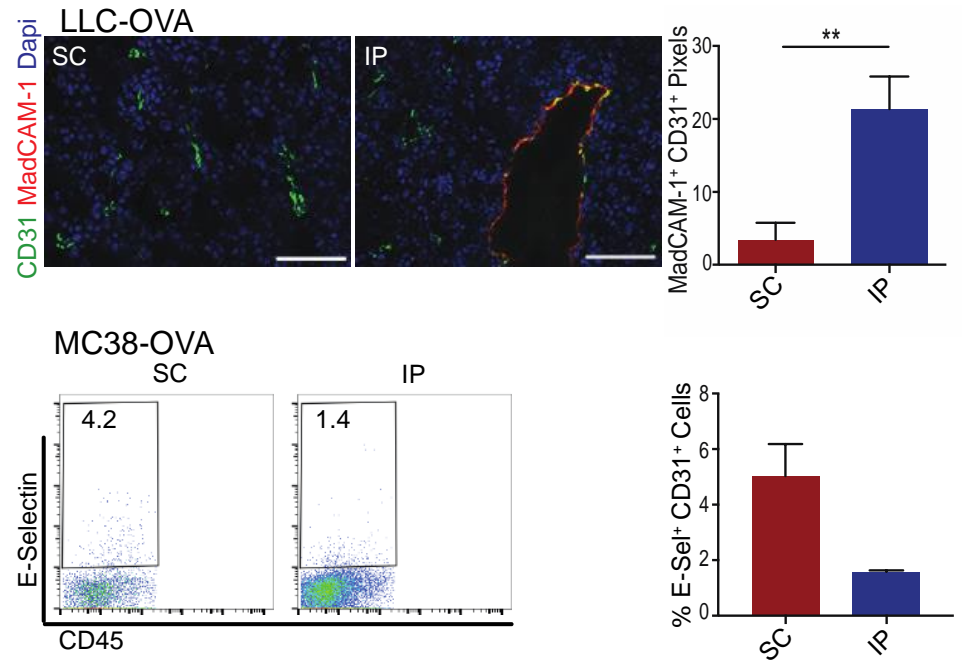


Figure 2: LLC-OVA or MC-38-OVA tumors were harvested on day 14 (SC) or day 11 (IP). LLC-OVA tumors were flash frozen and stained for MAdCAM-1 expression. Representative and summary data interrogating 8-10 random fields from single sections of 3 tumors each for the percent of $\mathrm{CD} 31^{+}$pixels that were MAdCAM $-1^{+}$. Percentages were calculated using ImageJ to define CD $31^{+}$pixels and quantitating those positive for MAdCAM-1. MC-38-OVA tumors were digested and stained for flow cytometry. Summary data ( $\mathrm{n}=2$ tumors per group) for the percent of $\mathrm{CD} 31^{+} \mathrm{CD} 45^{+}$cells that expressed E-Selectin. Statistical analysis performed using unpaired student's T-test. 
Figure 3
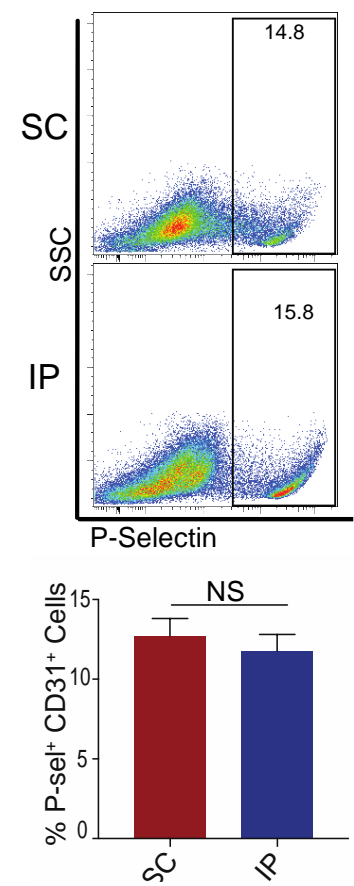
Figure 3: B16-OVA tumors were harvested 14 days after SC injection or 11 days after IP injection. Samples were digested, enriched for CD31+ endothelial cells, and analyzed by flow cytometry. Representative flow cytometry and summary data for $\mathrm{CD} 31^{+} \mathrm{CD} 45^{\text {neg }}$ endothelial cells from SC or IP B16-OVA tumors stained for $\mathrm{P}$-selectin ( $\mathrm{n}=3$ tumors per group). All statistical analyses were performed using unpaired student's T-test. 
Figure 4
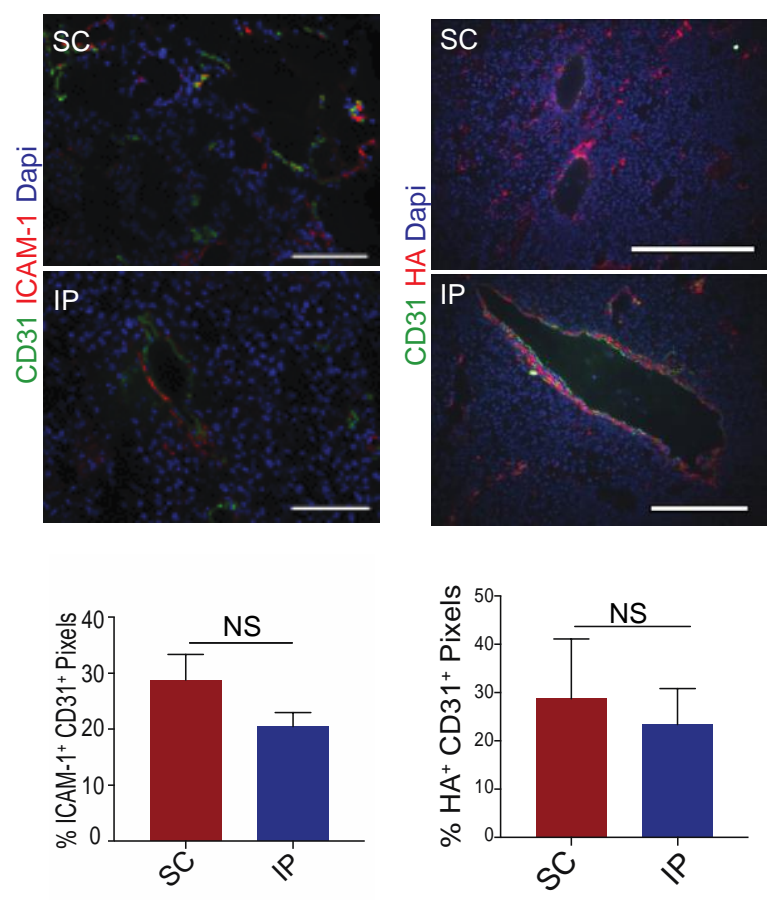
Figure 4: B16-OVA tumors were harvested 14 days after SC injection or 11 days after IP injection. Samples were frozen and stained for immunofluorescence microscopy. Representative images and summary data for CD $31^{+}$cells from SC or IP B16-OVA tumors stained for: ICAM-1 (Interrogated 5-10 random fields from 1 section of 3 tumors), and HA (Interrogated 5-10 random fields from 1 section of 3 tumors). Percentages were calculated using ImageJ to define CD $31^{+}$pixels and quantitating those positive for ICAM-1 or HA. All statistical analyses were performed using unpaired student's T-test. 
Figure 5

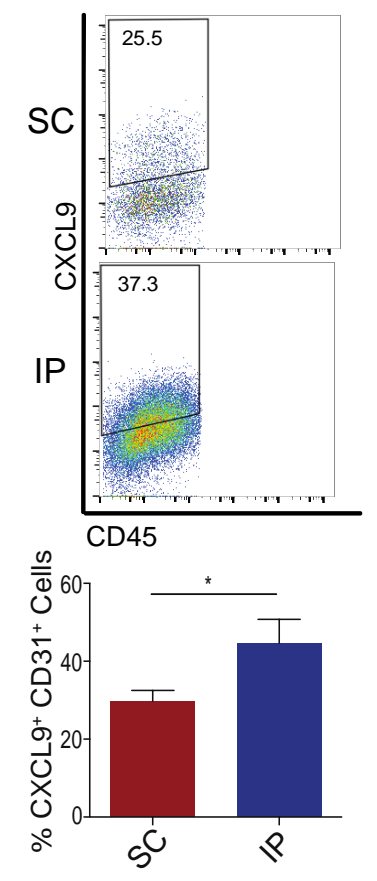


Figure 5: B16-OVA tumors were harvested 14 days after SC injection or 11 days after IP injection. Samples were digested, enriched for CD31+ endothelial cells, and analyzed by flow cytometry. Representative flow cytometry and summary data for CD31+CD45 neg endothelial cells from SC or IP B16-OVA tumors stained for intracellular CXCL9 ( $\mathrm{n}=7$ tumors per group). All statistical analyses were performed using unpaired student's T-test. 
Figure 6

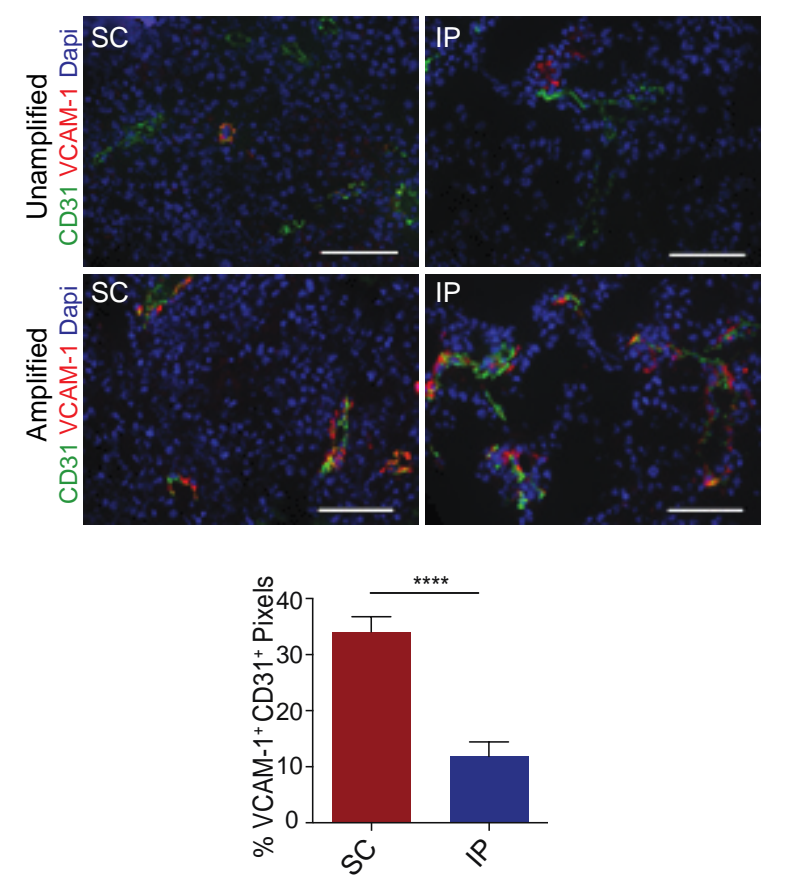


Figure 6: B16-OVA tumors were harvested 14 days after SC injection or 11 days after IP injection. Samples were frozen and processed for immunofluorescence microscopy. Representative images and summary data for CD $31^{+}$cells from SC or IP B16-OVA tumors stained for VCAM-1 (Interrogated 5-10 random fields from 1 section of 3 tumors). VCAM-1 expression on SC and IP B16-OVA tumors was determined either with or without tyramide amplification of the anti-VCAM-1 staining. Percentages were calculated using ImageJ to define CD31 ${ }^{+}$pixels and quantitating those positive for VCAM-1 on amplified sections. All statistical analyses were performed using unpaired student's T-test. 
Figure 7

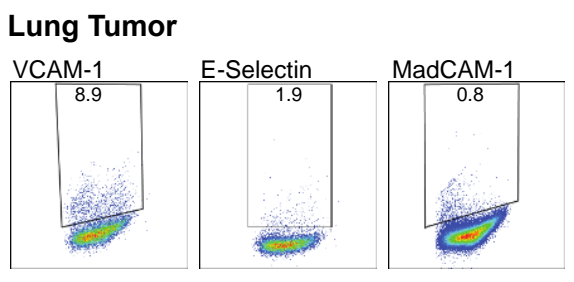

Brain Tumor
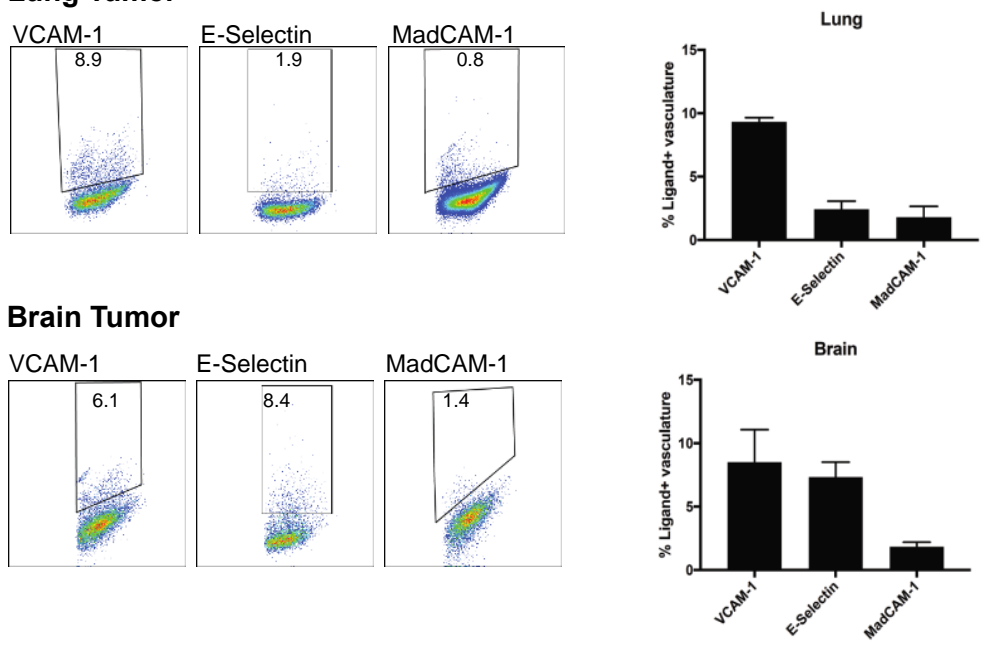
Figure 7:

B16-OVA tumors were harvested on day 21 (Lung) or day 13 (Brain) and dissociated and stained for flow cytometric analysis. Representative and summary data for expression of VCAM-1, E-Selectin, and MAdCAM-1 endothelial cells isolated from lung and brain tumors $(n=4)$. Plots are gated on CD31+CD45 cells. 
Figure 8

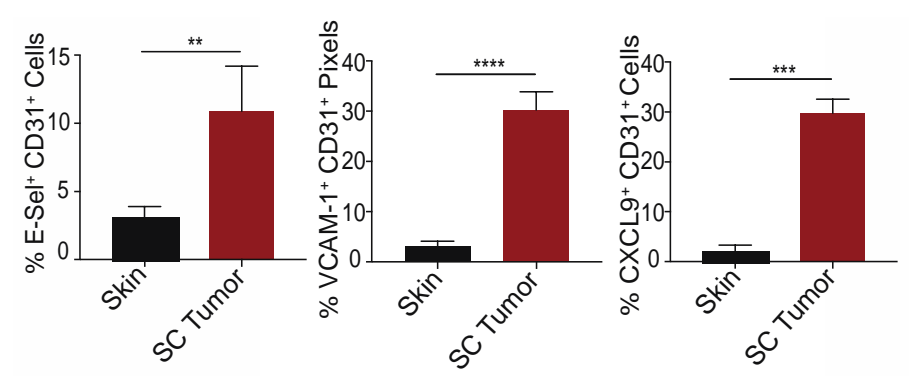


Figure 8: B16-OVA tumors were harvested 14 days after SC injection. Ears were harvested from non-tumor bearing mice. Samples were either digested, enriched for CD $31^{+}$endothelial cells, and analyzed by flow cytometry, or frozen and processed for immunofluorescence microscopy. E-selectin and CXCL9 expression on $\mathrm{CD} 31^{+} \mathrm{CD} 45^{\text {neg }}$ endothelial cells from skin and SC tumor was determined by flow cytometry ( $\mathrm{n}=3$ samples per group). VCAM- 1 expression on CD31+ pixels from skin and SC tumor was determined by immunofluorescence $(n=3)$. All statistical analyses were performed using unpaired student's T-test. 
Figure 9

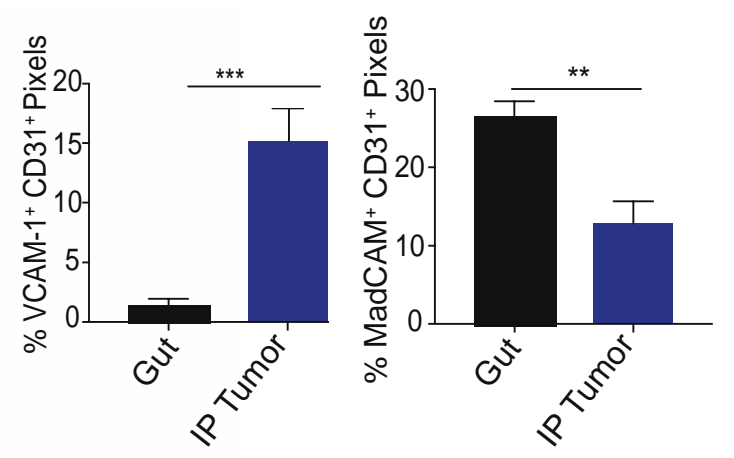


Figure 9: B16-OVA tumors were harvested 11 days after IP injection. Intestine was harvested from non-tumor bearing mice. Samples were frozen and processed for immunofluorescence microscopy. MAdCAM-1 and VCAM-1 expression on CD31+ cells from colon was determined by immunofluorescence (Interrogated 5 random fields from one section of 2 colons). Percentages were calculated using ImageJ to define CD31+ pixels and quantitating those positive for MAdCAM-1 or VCAM-1. All statistical analyses were performed using unpaired student's T-test. 
Figure 10

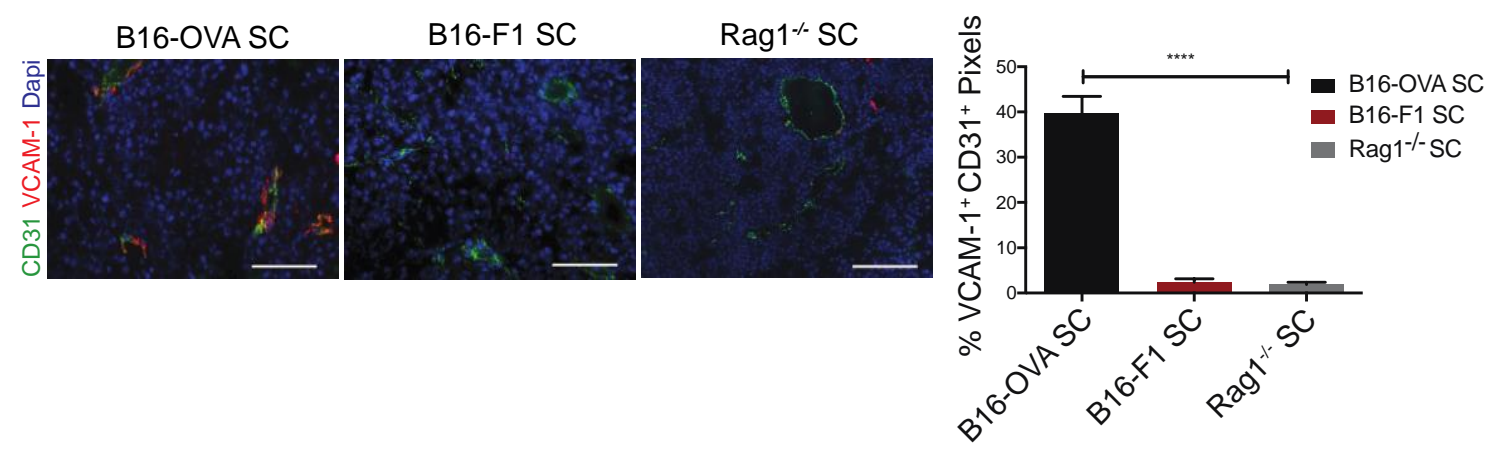


Figure 10: B16-OVA tumors were grown SC in WT B6 or Rag 1/- mice and B16F1 tumors were grown SC in WT B6 mice. Representative and summary data (Interrogated 10 random fields from one section of 3 tumors) showing VCAM-1 expression on $\mathrm{CD} 31^{+}$endothelial cells determined by immunofluorescence. Percentages were calculated using ImageJ to define CD31+ pixels and quantitating those positive for VCAM-1. All statistical analyses were performed using unpaired student's T-test. 
Figure 11

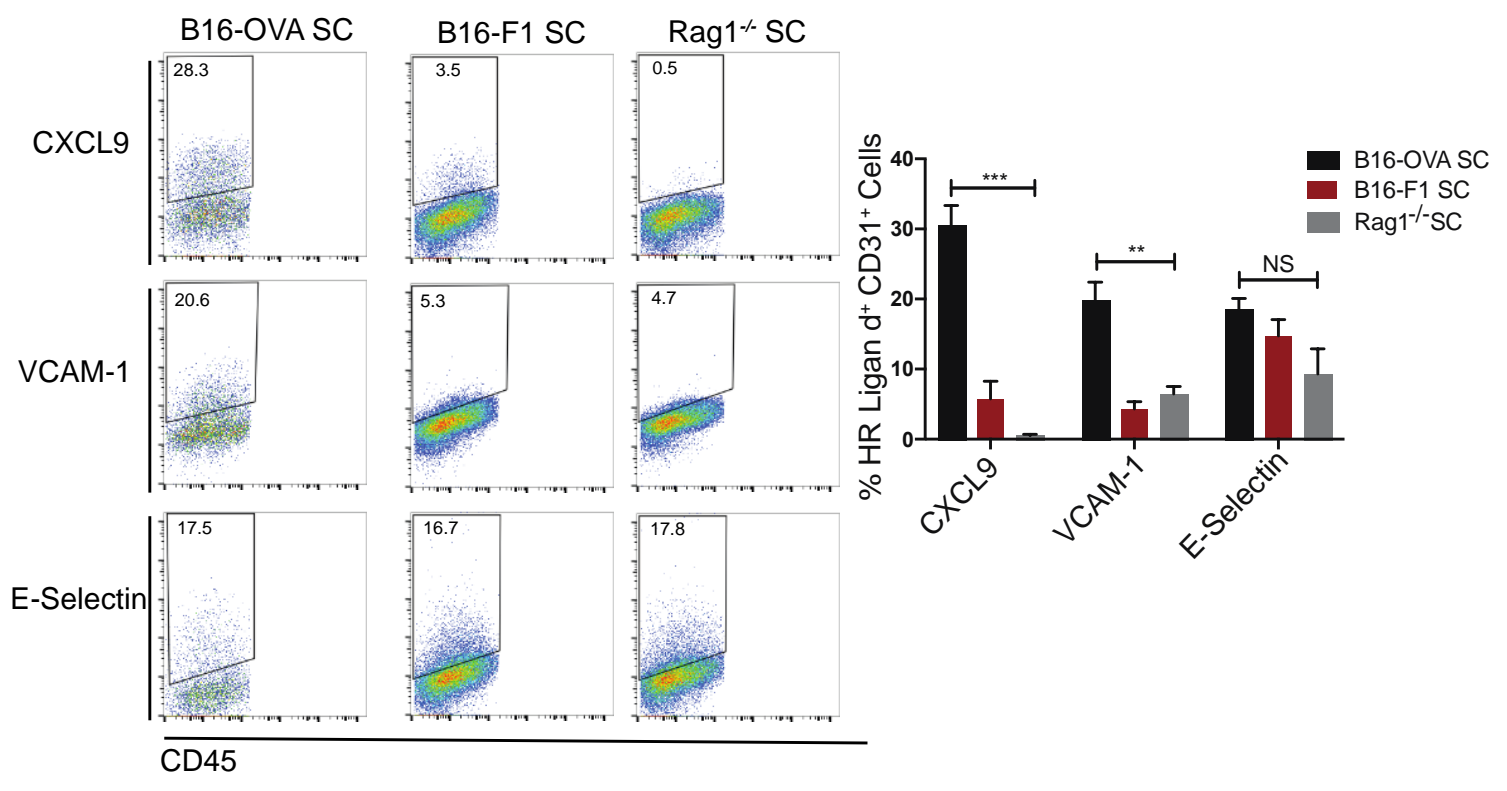


Figure 11: B16-OVA tumors were grown SC in WT B6 or Rag $1^{-/}$mice and B16F1 tumors were grown SC in WT B6 mice. Representative and summary data ( $n=3-4$ tumors per group) showing expression of CXCL9, VCAM-1, and Eselectin on gated $C D 31^{+} \mathrm{CD} 45^{\text {neg }}$ endothelial cells determined by flow cytometry. All statistical analyses were performed using unpaired student's T-test. 
Figure 12

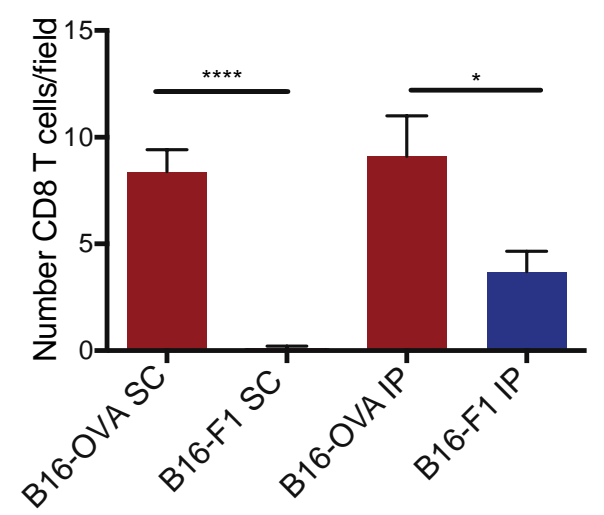


Figure 12: B16-OVA and B16-F1 tumors were harvested on day 14 (SC) or day 11 (IP) and flash frozen for immunofluorescence staining with anti-CD8.

Summary data interrogating 5 random 200X fields from single sections of 2 tumors to assess the number of CD8 T-cells. Statistical analysis performed using unpaired student's T-test. 
Figure 13

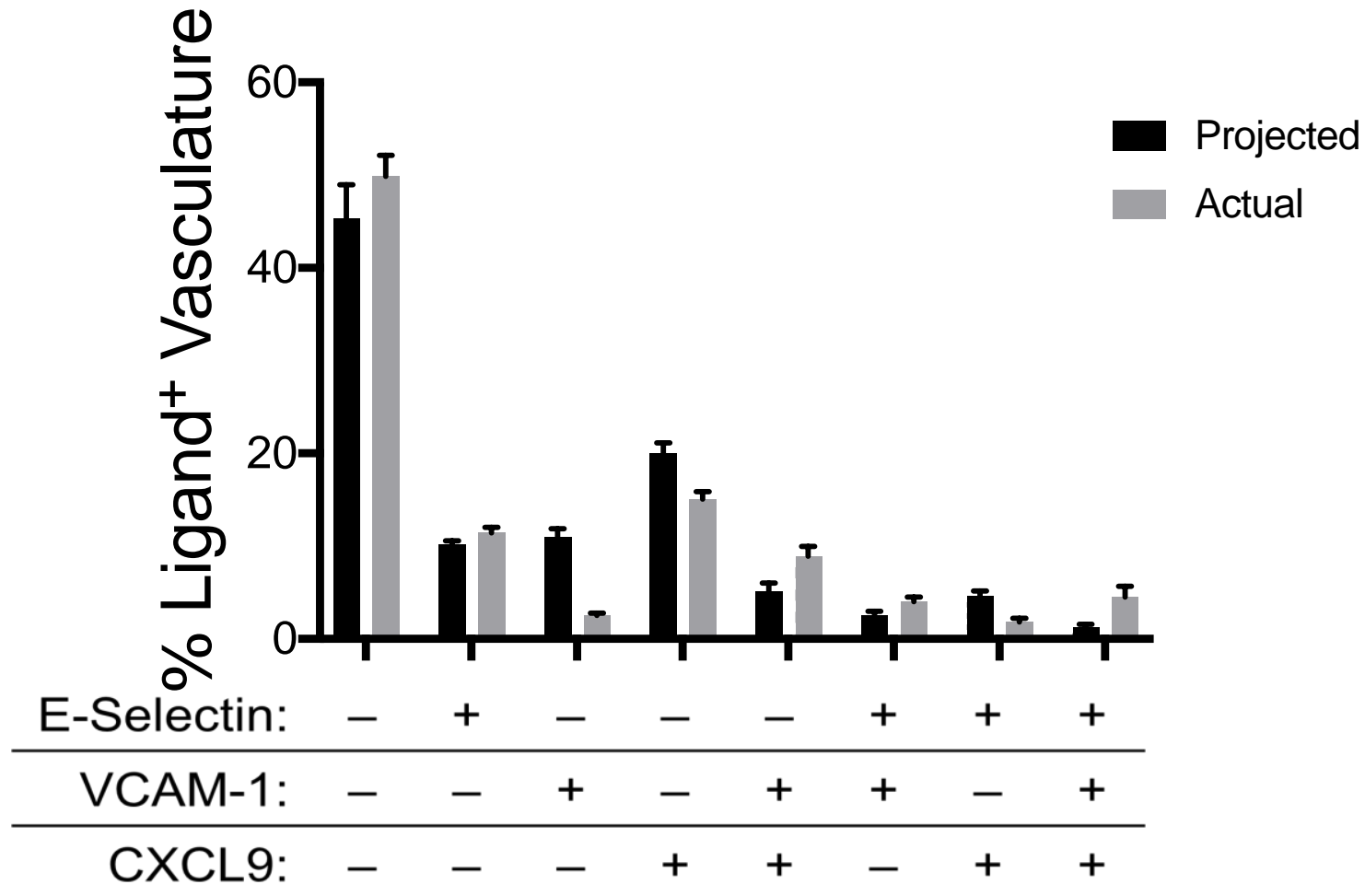


Figure 13: Expression of CXCL9, VCAM-1, and E-selectin on SC B16-OVA tumors was analyzed by flow cytometry. Summary data ( $n=4$ tumors) for the percent of positive CD31+ cells that are triple negative, single positive, double positive, or triple positive for CXCL9, VCAM-1, and E-selectin as projected by random chance and the actual percentages after FACS analysis. All statistical analysis performed using unpaired student's T-test. 
Figure 14
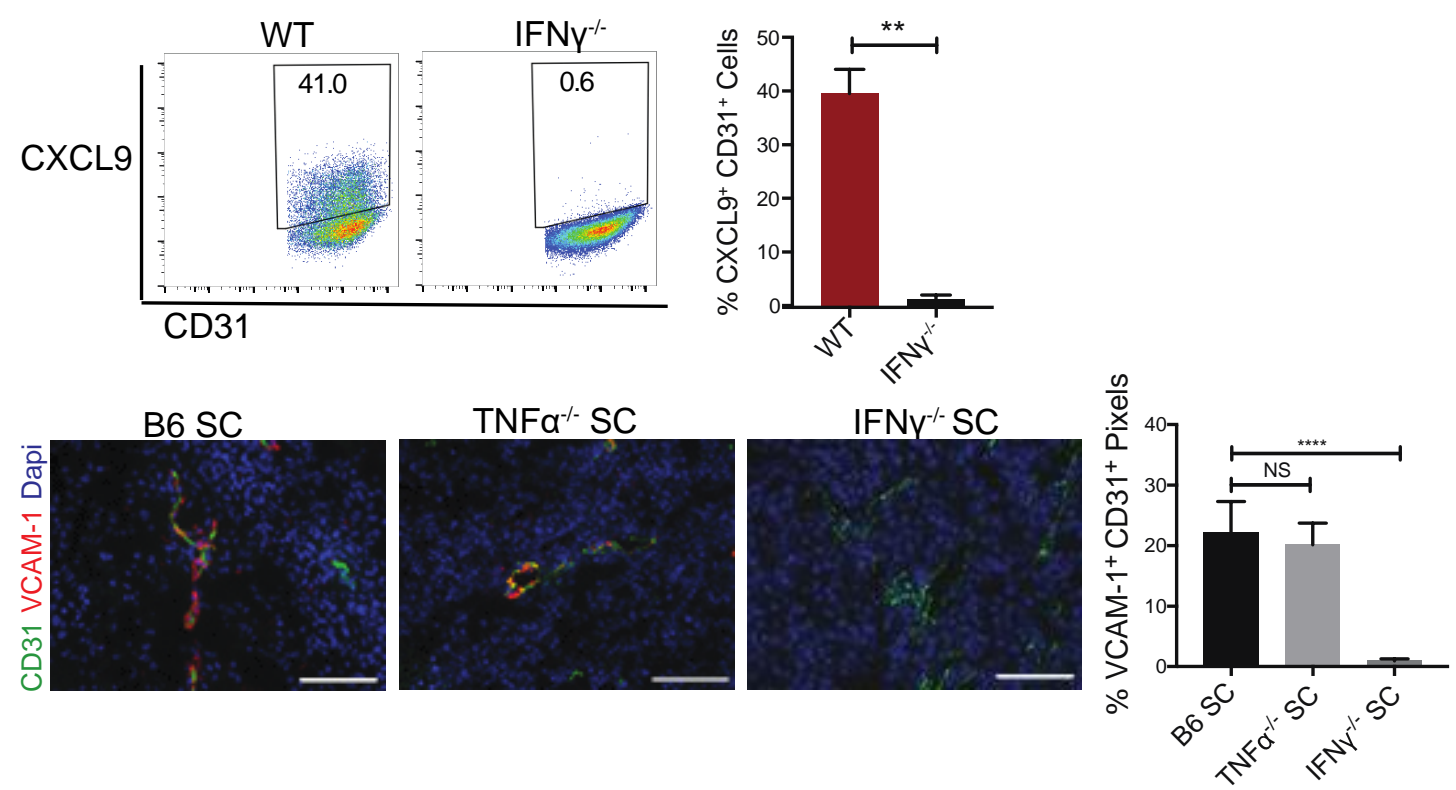
Figure 14: Tumors were grown SC in WT B6, IFN $\gamma^{-1-}$, or TNF $\alpha^{-1-}$ animals for $14 \mathrm{~d}$. upper, Representative and summary data ( $\mathrm{n}=3$ tumors per group) for CXCL9 expression in permeabilized $C D 31{ }^{+} C D 45^{\text {neg }}$ endothelial cells determined by flow cytometry). lower. Representative and summary data (Interrogated 10 random fields from one section of 3 tumors) for VCAM- 1 expression on CD31+ vasculature determined by immunofluorescence. Percentages were calculated using ImageJ to define CD31+ pixels and quantitating those positive for VCAM-1. All statistical analyses were performed using unpaired student's T-test. 
Figure 15
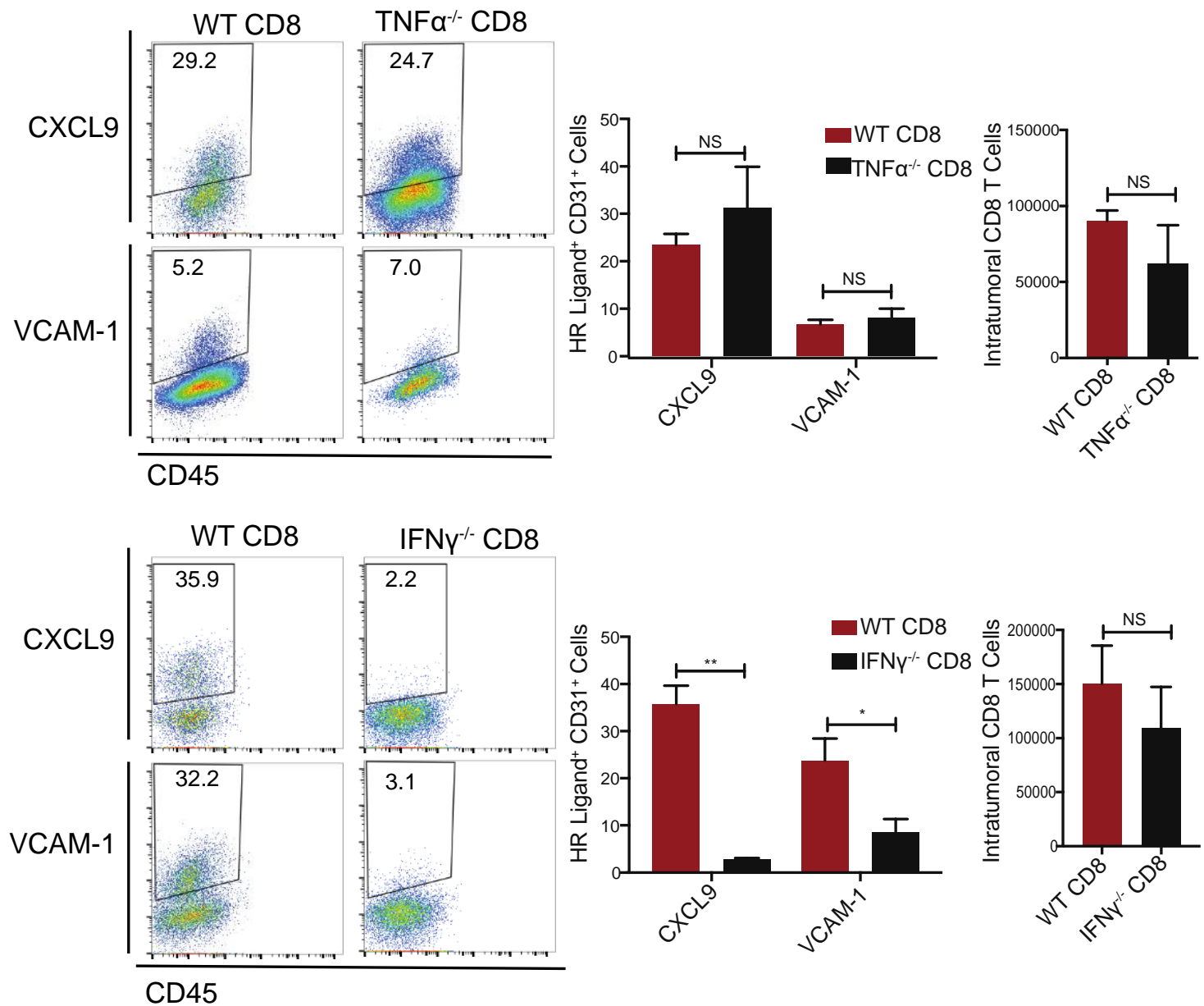
Figure 15: Rag1 ${ }^{-/-}$mice were repleted with CD8 T-cells from WT, IFN $\gamma^{-/}$, or $\mathrm{TNF}^{-1-}$ animals 3 days prior to SC B16-OVA injection. Tumors were harvested on day 14. CXCL9 and VCAM-1 expression on gated CD31+CD45 ${ }^{\text {neg }}$ endothelial cells were assessed by flow cytometry Representative and summary data ( $n=3$ tumors per group) are shown. All statistical analysis performed using unpaired student's T-test. 
Figure 16
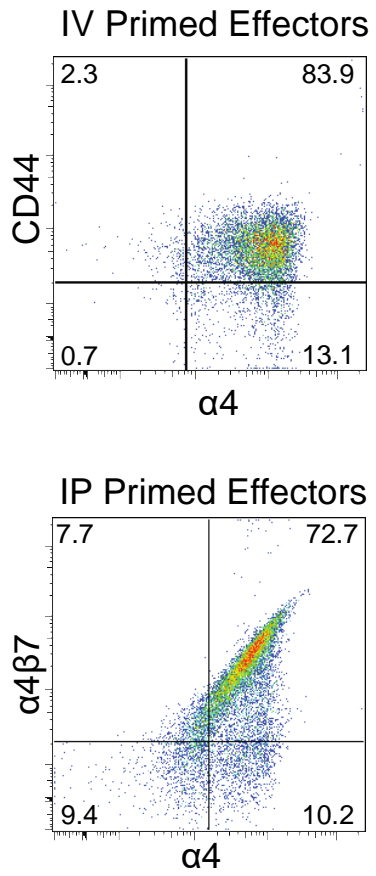

SC Primed Effectors

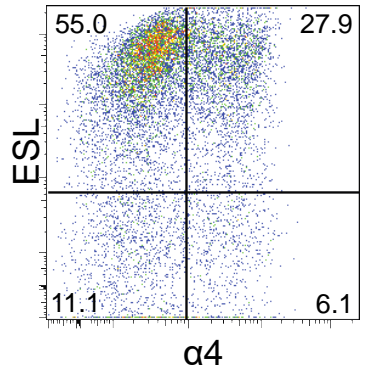


Figure 16: CD8 effector T-cells were generated using SIINFEKL pulsed BMDCs administered IV, IP, or SC as described in the legends to Figures 4 and 5.

Freshly isolated ex vivo effectors were stained with the indicated antibodies and analyzed by flow cytometry. Plots are gated on CD $45^{+} \mathrm{CD} 88^{+}$Thy $1.1^{+}$cells. 


\section{Figure 17}
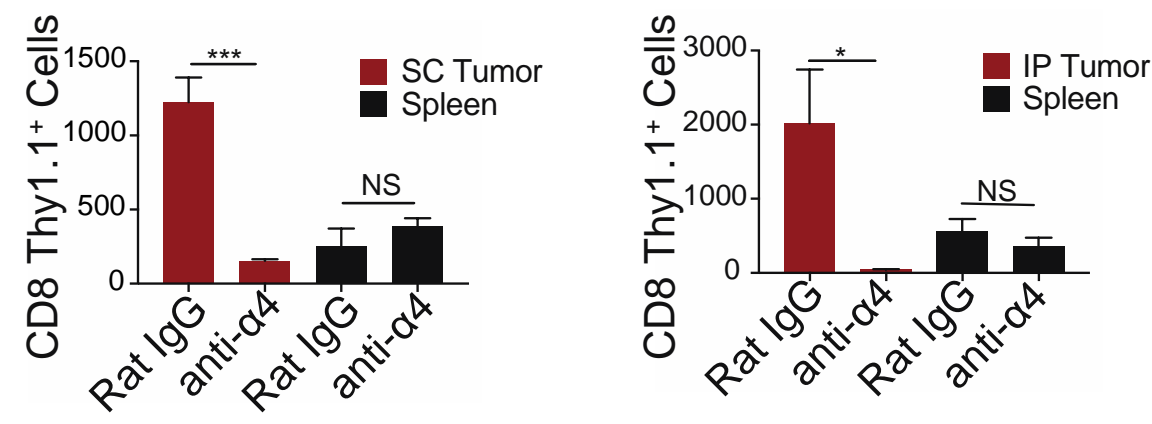
Figure 17: IV primed OT-1 Thy1.1 CD8 T-cell effectors were generated in WT B6 mice after adoptive transfer of $\mathrm{H}-2 \mathrm{~K}^{\mathrm{b}}+$ ovalbumin specific OT-I cells and immunization with peptide-pulsed BMDCs. After 4 days, cells were isolated and transferred into mice bearing 14 day old SC or 11 day old IP B16-OVA tumors. CD8 T-cells were incubated with anti- $\alpha 4$ blocking antibody for $30 \mathrm{~min}$ immediately prior to T-cell transfer. Tumors and spleens were harvested 18 hours later and infiltrating CD8 Thy $1.1^{+}$T-cells quantitated by flow cytometry. Infiltration data collected for entire tumor and $1 / 10^{\text {th }}$ of the spleen. All data shown are summary data ( $\mathrm{n}=3$ tumors per group). 
Figure 18

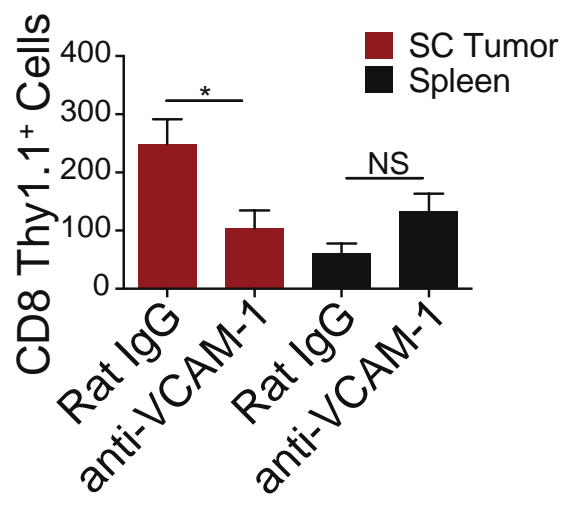


Figure 18: IV primed OT-1 Thy1.1 CD8 T-cell effectors were generated in WT B6 mice after adoptive transfer of $\mathrm{H}-2 \mathrm{~K}^{\mathrm{b}}+$ ovalbumin specific OT-I cells and immunization with peptide-pulsed BMDCs. After 4 days, cells were isolated and transferred into mice bearing 14 day old SC B16-OVA tumors. VCAM-1 blocking antibody was injected IP into tumor-bearing animals 6 hours prior to T-cell transfer. Tumors and spleens were harvested 18 hours later and infiltrating CD8 Thy $1.1^{+}$T-cells quantitated by flow cytometry. Infiltration data collected for entire tumor and $1 / 10^{\text {th }}$ of the spleen. All data shown are summary data ( $n=3$ tumors per group). 
Figure 19

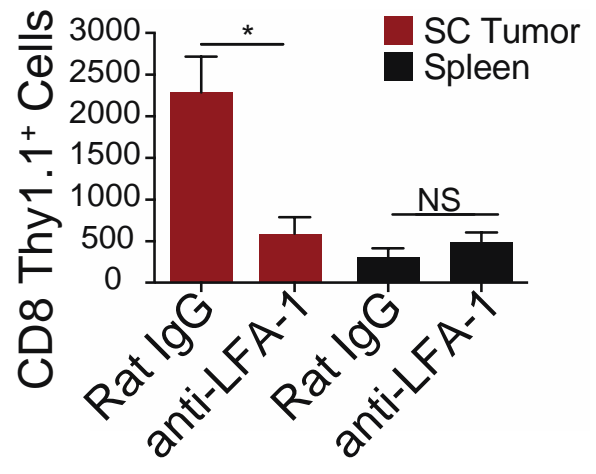


Figure 19: IV primed OT-1 Thy1.1 CD8 T-cell effectors were generated in WT B6 mice after adoptive transfer of $\mathrm{H}-2 \mathrm{~K}^{\mathrm{b}}+$ ovalbumin specific OT-I cells and immunization with peptide-pulsed BMDCs. After 4 days, cells were isolated and transferred into mice bearing 14 day old SC B16-OVA tumors. CD8 T-cells were incubated with anti-LFA-1 blocking antibody for 30 min immediately prior to T-cell transfer. Tumors and spleens were harvested 18 hours later and infiltrating CD8 Thy $1.1^{+}$T-cells quantitated by flow cytometry. Infiltration data collected for entire tumor and $1 / 10^{\text {th }}$ of the spleen. All data shown are summary data ( $n=3$ tumors per group). 
Figure 20
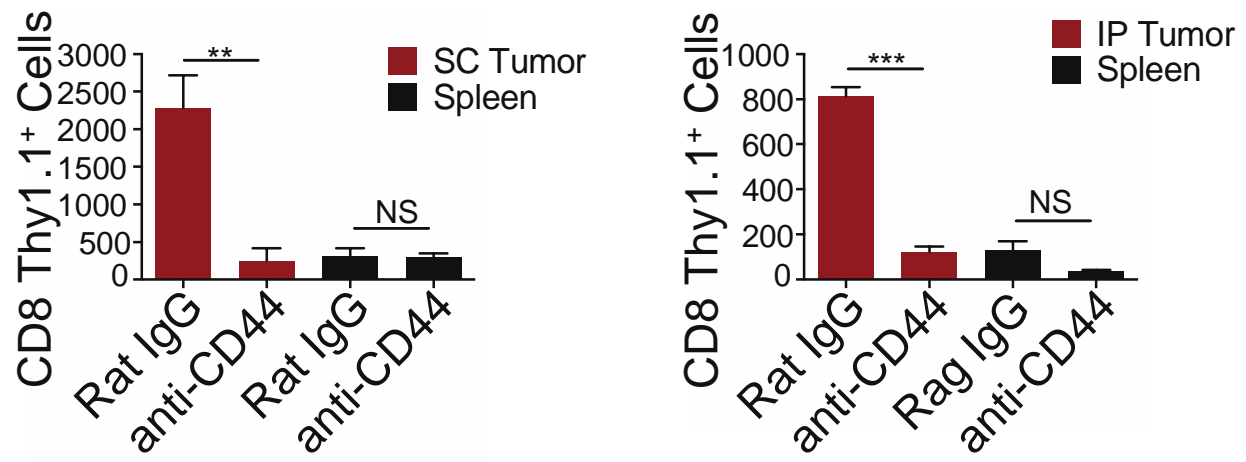
Figure 20: IV primed OT-1 Thy1.1 CD8 T-cell effectors were generated in WT B6 mice after adoptive transfer of $\mathrm{H}-2 \mathrm{~K}^{\mathrm{b}}+$ ovalbumin specific OT-I cells and immunization with peptide-pulsed BMDCs. After 4 days, cells were isolated and transferred into mice bearing 14 day old SC or 11 day old IP B16-OVA tumors. CD8 T-cells were incubated with anti-CD44 blocking antibody for 30 min immediately prior to T-cell transfer. Tumors and spleens were harvested 18 hours later and infiltrating CD8 Thy $1.1^{+} \mathrm{T}$-cells quantitated by flow cytometry. Infiltration data collected for entire tumor and $1 / 10^{\text {th }}$ of the spleen. All data shown are summary data ( $\mathrm{n}=3$ tumors per group). 
Figure 21

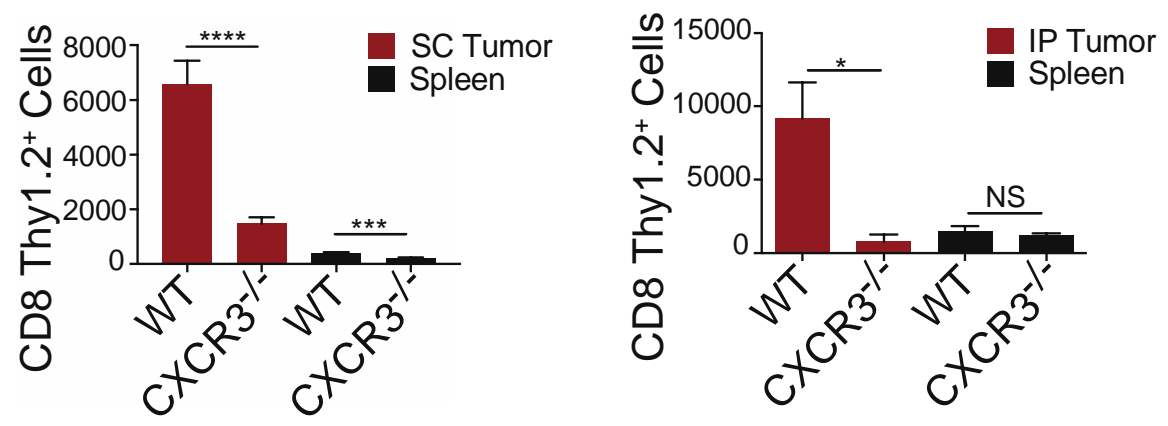


Figure 21: IV primed effector cells were generated in WT B6-AAD mice after adoptive transfer of AAD + tyrosinase specific FH TCR transgenic T-cells from either WT or CXCR3 ${ }^{-/-}$mice, by immunization with peptide-pulsed BMDC. After 4 days, FH T-cells were isolated and transferred into mice bearing $14 \mathrm{~d}$ old B16AAD tumors. Tumors and spleens were harvested $18 \mathrm{~h}$ later and infiltrating $\mathrm{FH}$ Thy 1.2 CD8 T-cells quantitated by flow cytometry. Infiltration data collected for entire tumor and $1 / 10^{\text {th }}$ of the spleen. All data shown are summary data $(n=5$ tumors per group). All statistics were performed using unpaired student's T-test. 
Figure 22

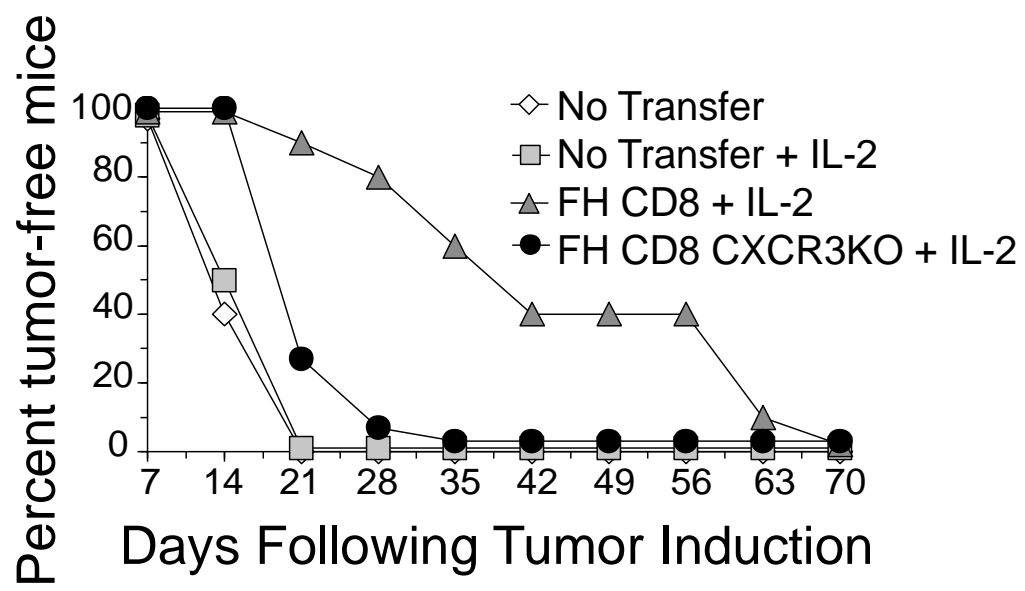


Figure 22: Adoptive transfer of 3 million purified TFH CD8 T-cells IV into AAD mice 3 days following SC B16-AAD tumor challenge. Animals receiving IL-2 support were injected IP with 1500CU every other day for 10 days. Mice that did not receive T-cells were either injected with IL-2 (No transfer + IL-2) or not (No transfer) and served as controls. Tumor measured by electronic caliper every other day. Mice without palpable tumors considered tumor free ( $n=10$ per group). All statistics were performed using unpaired student's T-test. 
Figure 23

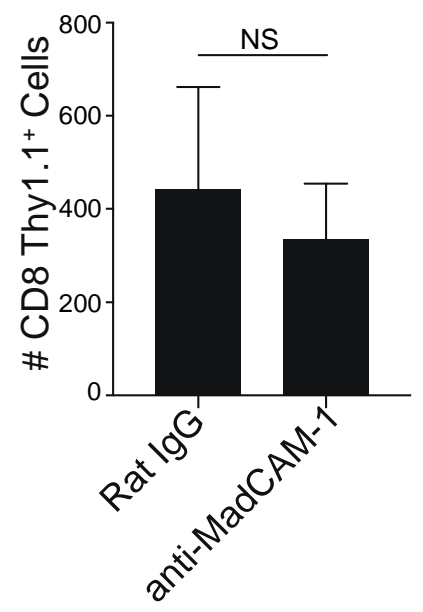


Figure 23: IP primed OT-1 Thy 1.1+ CD8 T-cell effectors were generated in WT B6 mice after adoptive transfer of $\mathrm{H}-2 \mathrm{~K}^{\mathrm{b}}+$ ovalbumin specific OT-I cells and immunization with peptide-pulsed BMDCs. After 4 days, cells were isolated and transferred into mice bearing 11 day old IP B16-OVA tumors. MAdCAM-1 blocking antibody was injected IP into tumor-bearing animals 6 hours prior to Tcell transfer. Tumors were harvested 18 hours later and infiltrating CD8 Thy $1.1^{+}$ T-cells quantitated by flow cytometry. All data shown are summary data $(n=3-4$ tumors per group). All statistics were performed using unpaired student's T-test. 
Figure 24

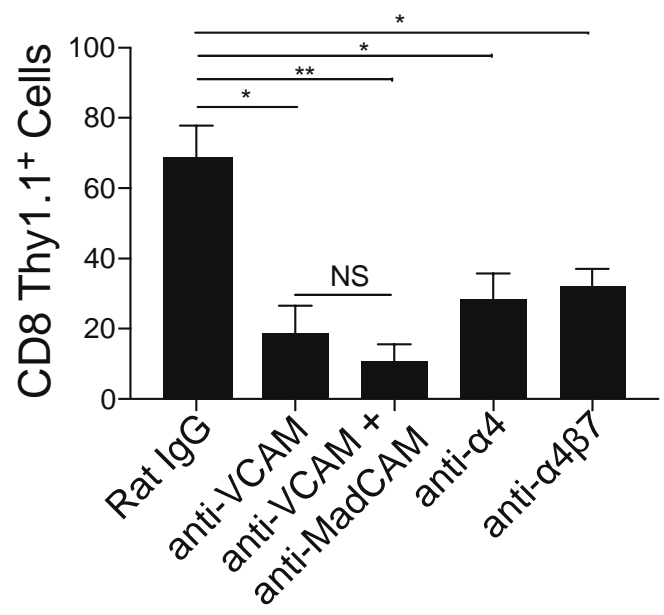


Figure 24: IP primed OT-1 Thy1.1+ CD8 T-cell effectors were generated in WT B6 mice after adoptive transfer of $\mathrm{H}-2 \mathrm{~K}^{\mathrm{b}}+$ ovalbumin specific OT-I cells and immunization with peptide-pulsed BMDCs. After 4 days, cells were isolated and transferred into mice bearing 11 day old IP B16-OVA tumors. The indicated blocking antibodies were incubated with CD8 T-cells for 30 min immediately prior to transfer (anti- $\alpha 4$, anti- $\alpha 4 \beta 7$ ), or injected IP into tumor-bearing animals 6 hours prior to T-cell transfer (anti-VCAM-1, anti-MAdCAM-1). Tumors were harvested 18 hours later and infiltrating CD8 Thy $1.1+\mathrm{T}$-cells quantitated by flow cytometry. All data shown are summary data ( $n=3-4$ tumors per group). All statistics were performed using unpaired student's T-test. 
Figure 25

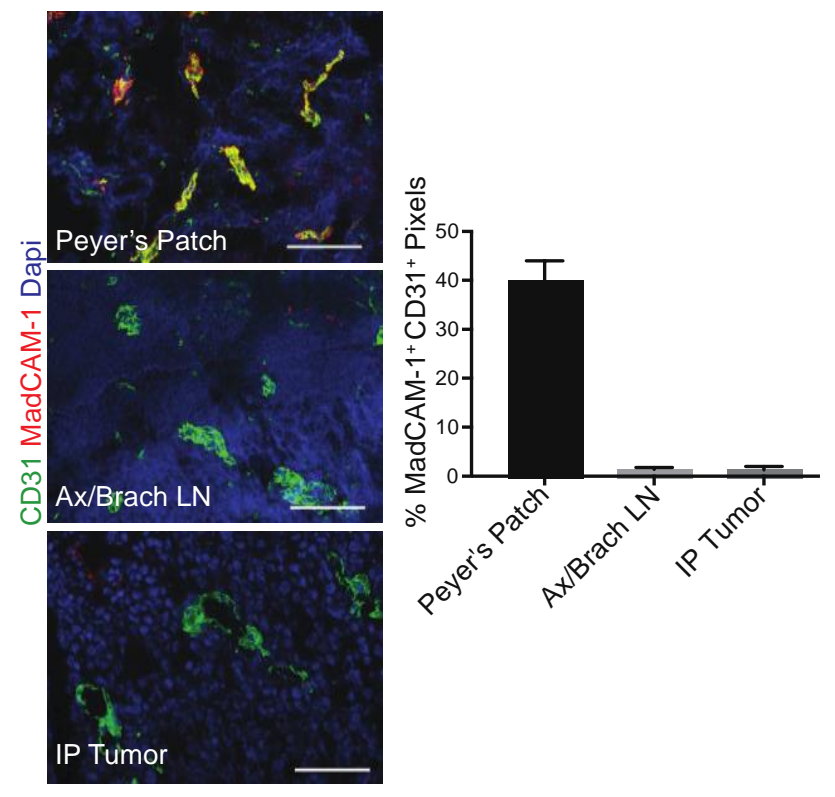


Figure 25: Animals bearing 11 day old IP tumors were injected IV with $100 \mu \mathrm{g}$ of anti-CD31 and 100 $\mu$ g of anti-MAdCAM-1 (Interrogating 10 random fields from one section each of 3 tumors). Antibodies were fluorescently labeled. Tumors and the indicated tissues were harvested after $30 \mathrm{~min}$ and vascular luminal expression was analyzed by immunofluorescence microscopy. All statistics were performed using unpaired student's T-test. 
Figure 26

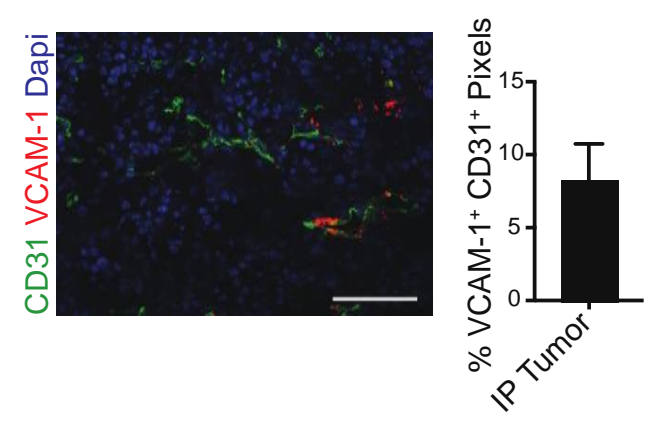


Figure 26: Animals bearing 11 day old IP tumors were injected IV with $100 \mu \mathrm{g}$ of anti-CD31 and 100 $\mu \mathrm{g}$ of anti-VCAM-1 (Interrogating 5-10 random fields from one section each of 2 tumors). Antibodies were fluorescently labeled. Tumors and the indicated tissues were harvested after 30 min and vascular luminal expression was analyzed by immunofluorescence microscopy. All statistics were performed using unpaired student's T-test. 


\section{Figure 27}

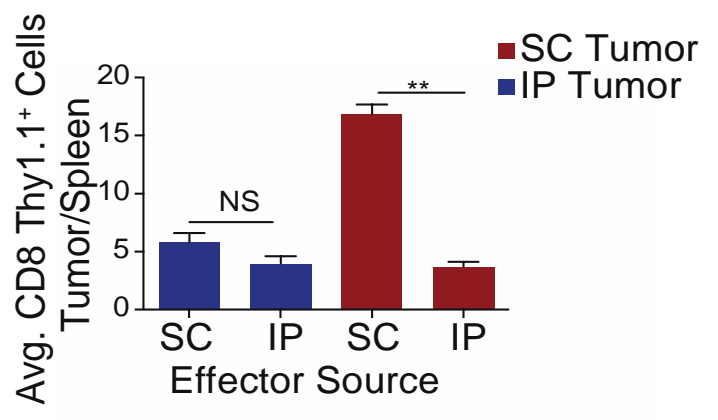


Figure 27: SC and IP primed OT-I CD8 T-cell effectors were generated as described in the legends to Figures 4 and 5. A 50:50 mix of SC and IP primed effectors were transferred into B6 mice bearing day 14 SC or day 11 IP tumors. Tumors and spleens were harvested $18 \mathrm{hrs}$ later and infiltration of Thy $1.1{ }^{+} \mathrm{CD} 8$ effector T-cells was analyzed by flow cytometry. Infiltration data collected for entire tumor and $1 / 10^{\text {th }}$ of the spleen. All data shown are summary data $(n=3$ tumors per group). 
Figure 28

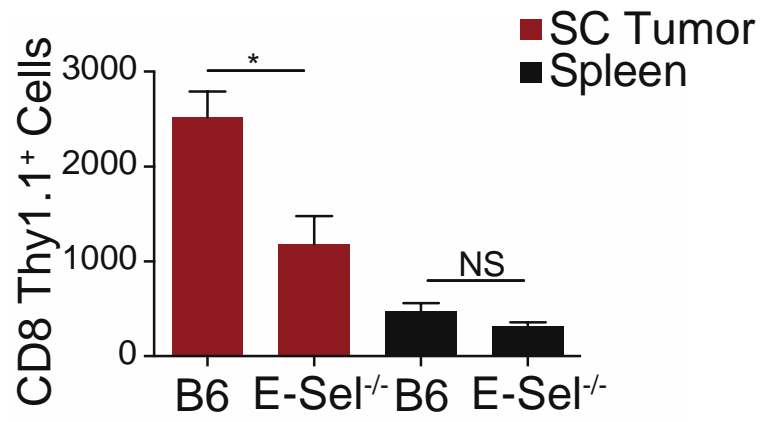


Figure 28: SC primed effectors were transferred into WT B6 WT B6 or Eselectin $^{-/}$mice bearing 14 day SC B16-OVA tumors ( $\mathrm{n}=3$ tumors per group). The number of Thy $1.1^{+}$CD8 T-cells that entered tumors and spleens was enumerated $18 \mathrm{~h}$ later. Infiltration data collected for entire tumor and $1 / 10^{\text {th }}$ of the spleen. All statistics were done using unpaired student's T-test. 
Figure 29

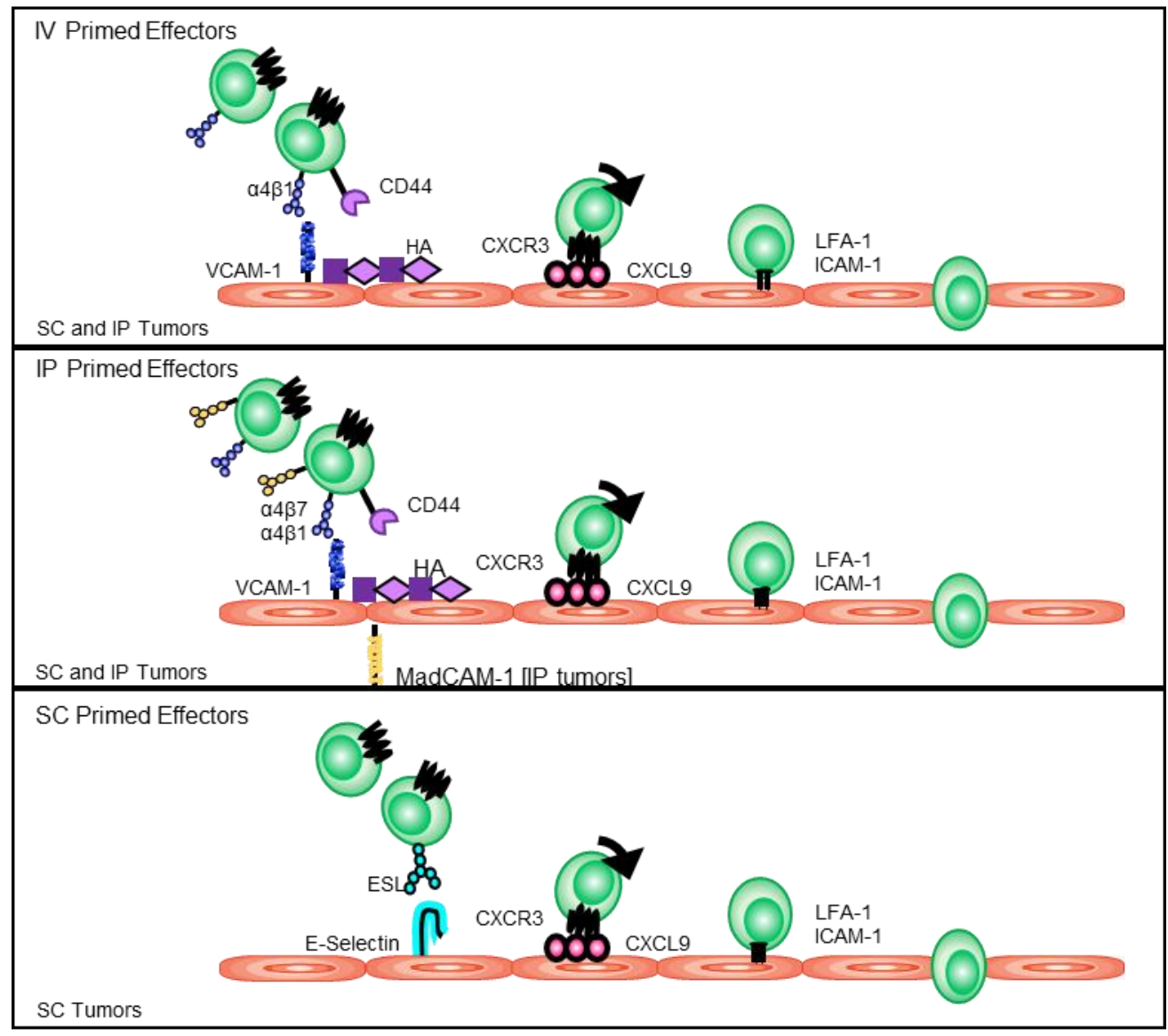




\section{Figure 29:}

Summary of major conclusions regarding mechanisms of entry of CD8 effectors into tumors. top, IV primed effectors expressing $\alpha 4 \beta 1$, CD44, CXCR3, and LFA-1 enter through vasculature of SC and IP tumors expressing VCAM-1, HA, CXCL9, and ICAM-1. Expression of VCAM-1 and CXCL9 is controlled by IFN $\gamma$ released by previously infiltrated CD8 effectors. middle, IP primed effectors expressing $\alpha 4 \beta 7$, in addition to molecules expressed on IV primed effectors, utilize the same HR ligands to enter SC and IP tumors, but are unable to utilize MAdCAM-1 that is selectively expressed on IP tumor vasculature due to its lack of lumenal expression. bottom, SC primed effectors expressing ESL in the presence or absence of $\alpha 4 \beta 1$, in addition to CXCR3 and LFA-1, show augmented entry into SC tumors that selectively express E-selectin on vasculature. 


\section{Discussion}

While some tumors are well-infiltrated by CD8 T-cells others are very poorly infiltrated $(24,26,30,36,206,207)$. One possible explanation for this distinction is differences in the expression of HR ligands on tumor-associated vasculature, in conjunction with the cohort of HR expressed on T-cells. This study characterized vascular HR ligand expression in murine tumors growing in distinct anatomic locations, the factors controlling ligand expression, and the molecular requirements for CD8 T-cell entry (Figure 29). These results identify both tumor anatomical location and immune microenvironment as important elements controlling expression of these molecules. While E-selectin augmented CD8 Tcell entry selectively into SC tumors, MAdCAM-1 was irrelevant because it was not expressed on the vascular luminal surface. Importantly, VCAM-1 through its interaction with $\alpha 4 \beta 1$ and likely $\alpha 4 \beta 7$, and one or more ligands for CXCR3 supported broad-based infiltration of CD8 T-cells into both anatomic locations. Overall our results identify mechanisms that control CD8 T-cell infiltration into tumors growing in different anatomic locations, and point towards strategies to enhance infiltration for therapeutic purposes.

Several previous studies have evaluated the expression of individual HR ligands on tumor-associated vasculature. Human skin-associated tumors have been shown to express a low level of E-selectin (162), murine SC B16-F10 tumors express low levels of E-selectin (176), ICAM-1 (176), and CXCL9 $(220,221)$, and intracranial B16-OVA tumors express a low level of VCAM-1 
(219). Expression of VCAM-1 correlates with increased T-cell representation in pancreatic islet cell carcinoma, glioblastoma, and melanoma $(91,96,175)$. Genetic expression of VCAM-1, ICAM-1, and MAdCAM-1 in human colorectal cancers is variable and correlates with the extent of T-cell infiltration and patient survival (184). In this study, we showed that patterns of E-selectin and MAdCAM1 expression on the vasculature of multiple different murine SC and IP tumors mimicked those on skin and gut vasculature, respectively $(121,123,137,231)$. VCAM-1, CXCL9, and ICAM-1 were expressed on tumor vasculature in both locations, in keeping with their broad expression on inflamed tissues. Our observation that expression of E-selectin and MAdCAM-1 on tumor vasculature is dependent on anatomic location is consistent with the sprouting model of angiogenesis (232), in which vasculature branches from healthy normal tissue vasculature toward areas of hypoxia. Signaling differences in skin and gut vascular endothelial cells that lead to differences in HR ligand expression are not understood (190). In addition, the observation that MAdCAM-1 expression is confined to the abluminal surface has not been previously reported and indicates that there are factors controlling its polarity that remain to be identified. Thus, although tumor-associated vasculature is generally considered to be aberrant, our work reveals that it retains tissue-associated characteristics.

Previous studies have pointed to a low level of HR ligand expression on poorly immunogenic tumors $(162,176,219)$. When expression is augmented using pro-inflammatory stimuli, these molecules facilitate, or are at least 
associated with, enhanced entry of CD8 T-cells into tumors. In this study, we showed that expression of VCAM-1 and CXCL9 on the vasculature of B16-F1 tumors grown in WT mice and B16-OVA tumors grown in Rag-- mice was very low, and that the immune response to tumor-associated OVA in WT mice was sufficient to drive increased expression of these ligands without therapeutic intervention. The expression of VCAM-1 and CXCL9 on tumor endothelial cells was coordinately controlled by IFN $\gamma$ released from CD8 T-cells, and was significantly higher than that of normal tissue vasculature. However, expression of E-selectin, although higher than that of normal tissue, was not significantly influenced by adaptive immunity. MAdCAM-1 expression was actually lower on tumor vasculature compared to gut. We and others have established that HR ligand expression can also be upregulated in response to checkpoint blockade inhibitors (Hailemichael, et al unpublished; Wilson, et al unpublished). Increased HR ligand expression is associated with increased T-cell representation in the tumor microenvironment and improved tumor control (233). We have established that expression of HR ligands, including VCAM-1 and ICAM-1, is also upregulated in response to the checkpoint blockade inhibitor anti-CTLA-4 which increased CD8 T-cell representation in the tumor (Hailemichael, et al unpublished; Wilson, et al unpublished). Collectively these studies suggest that the level of HR ligand expression on most tumors will limit CD8 effector T-cell entry, but can be enhanced by augmenting the endogenous immune response, 
directly activating tumor vascular endothelial cells, or manipulating the immunosuppressive tumor microenvironment.

A somewhat surprising observation was that infiltration of WT and IFN $\gamma^{-1-}$ CD8 T-cells into tumors grown in Rag $1^{-/}$animals was similar, despite the lack of HR ligand expression on tumors infiltrated by IFN $\gamma^{-/-}$CD8 T-cells. This suggests that initial infiltration of these cells, presumably involving these same HR ligands, is driven by another mechanism, and in Rag $1^{-/-}$mice this is most likely an innate immune cell. These results suggest $\mathrm{HR}$ ligand expression on tumor vasculature must be sustained through continual restimulation by IFN $\gamma$ from intratumoral CD8 effectors. In turn suggesting the existence of a positive feedback loop in which newly infiltrating T-cells that release IFN $\gamma$ maintain or increase expression of HR ligands, leading to recruitment of additional CD8 effectors that perpetuate the process. This positive feedback loop may be down-modulated by the immunosuppressive microenvironment of tumors that inhibits the activity of CD8 effectors, and upregulated by therapeutic interventions that maintain or increase intratumoral effector activity, or augment the magnitude of the immune response. In the same way, directly increasing HR ligand expression on tumor vasculature has the potential to amplify this positive feedback loop by supporting increased infiltration of active CD8 effectors, further increasing HR ligand expression, and augmenting intratumoral immunity and tumor control.

In this study, we also established that $\alpha 4 \beta 1$, CD 44, CXCR3, and LFA-1 played non-redundant roles in enabling effector CD8 T-cell entry into both SC 
and IP tumors. Given that LFA-1 interaction with ICAM-1 is the most common mediator of firm adhesion, and it had been previously shown to mediate CD8 Tcell entry into therapeutically treated tumors (176), its importance in mediating entry in the present study was not unexpected. An earlier clinical study pointed to CXCR3 as a positive prognostic indicator in melanoma patients, and its ligands CXCL9,10, and 11 have been identified as part of a 12 chemokine gene signature associated with enhanced patient survival and response to immunotherapy $(170,178)$. Previous studies have shown either CXCL9 or CXCL10 to be of central importance in CD8 T-cell entry into SC or intracranial B16 tumors $(218,220)$. Our results confirm and extend this earlier work by showing that CXCR3 is the only chemokine receptor needed for CD8 T-cell entry into B16 tumors growing in IP as well as SC locations, that it was necessary for T-cell mediated tumor control, and that CXCL9 expression was dependent on adaptive immunity.

While elevated expression of CD44 is a marker of T-cell activation and memory, its role in T-cell entry into tissues has been evaluated in only a small number of studies. It was found that CD44 acted cooperatively with $\alpha 4 \beta 1$ to mediate T-cell entry into the peritoneum $(227,228,234)$. Interestingly it was also found that this pathway acted in lieu of LFA-1 to support the firm adhesion step preceding extravasation (227). We found that either $\alpha 4 \beta 1$ or CD44 blockade completely inhibited T-cell entry into both SC and IP tumors, but $\alpha 4 \beta 1$ and LFA-1 played essential independent roles in enabling entry. Based on this latter 
observation and this earlier work, we propose that $\alpha 4 \beta 1$ and CD44 coordinately mediate initial slow rolling and CXCR3 activates the high affinity form of LFA-1 to mediate the final firm adhesion step. Taken together, our work establishes that this is a general mechanism supporting CD8 T-cell entry into a variety of tumors growing in different anatomic locations. The importance of VCAM- 1 is emphasized by the fact that it supports entry of $\alpha 4 \beta 1^{+} T$-cells even when expressed at relatively low levels on IP tumor vasculature, and that it may also enable infiltration of T-cells expressing $\alpha 4 \beta 7$. In contrast, molecules such as Eselectin and MAdCAM-1, with their limited tissue distribution and lack of luminal expression, are of much more limited value.

In keeping with this, we suggest intradermal vaccination, the most common route of vaccine administration, may limit the effectiveness of cancer vaccines for metastatic lesions in non-skin-associated sites. At least in mice, this route of immunization leads to T-cells with predominant expression of ESL, and only a minor cohort expressing $\alpha 4 \beta 1$ (114). Intravenous vaccination generates effectors that uniformly express $\alpha 4 \beta 1$, and should be evaluated as a route for administration of cancer vaccines. Similarly, the HR expressed on TIL or PBL activated for use in CAR-T, Bi-specific antibody, or recombinant TCR based adoptive cell therapy approaches are rarely examined. Given the massive numbers of such cells that are administered for therapeutic effect, and the generally higher success rates in treating liquid tumors where infiltration is not 
constrained by vasculature, we believe there are significant opportunities to optimize HR expression to improve the success of this approach.

Effectors primed in a route consistent with infiltration into multiple anatomic locations are only one side of a two-sided coin. HR ligand expression on tumor vasculature must be high enough to support entry of primed effectors. While the partially inflamed phenotype of tumor vasculature supports infiltration of some lymphocytes into tumors, infiltration could be greatly increased if HR ligand expression was enhanced on tumor vessels. Enhanced expression of ligands on tumor vasculature may augment the success of current therapies by creating tumor vasculature that supports the entry of a greater percentage of transferred cells thereby increasing the number of patients that respond. Adoptive cell therapies have shown efficacy in melanoma patients with preexisting CD8 T-cell infiltrate (69). Cytokines secreted by these pre-existing CD8 T-cells likely drive increased vascular HR ligand expression setting up a microenvironment permissive to infiltration of newly transferred cells. Enhancing ligand expression through a tumor vasculature-targeted approach, can jumpstart a feedback loop whereby ligand expression enhances CD8 T-cell infiltration and even patients without pre-existing CD8 T-cell infiltrate may respond to therapy. Based on their ability to enable entry of cells into tumors in multiple sites, VCAM1 or CXCL9 would be logical ligands to enhance. In addition to Adoptive cell therapy, many current first-line therapies, including radiotherapy and checkpoint blockade inhibitors, are also most effective in patients with pre-existing CD8 T- 
cell infiltrate (66-68). Therefore, this detailed understanding of the requirements for CD8 T-cell entry into tumors in multiple anatomic locations, combined with targeted upregulation of ligand expression on tumor vasculature, could enhance the efficacy of multiple melanoma therapies.

This chapter was adapted from Woods, A.N., Wilson, A.L., Srivinisan, N., Zeng, J., Dutta, A.B., Peske, J.D., Tewalt, E.F., Gregg, R.K., Ferguson, A.R., and Engelhard, V.H. Cancer Immunology Research (2017). Differential expression of homing receptor ligands on tumor associated vasculature that control CD8 effector T cell entry. 


\section{Appendix: Effect of anti-CTLA-4 +/- gp100/IFA}

\section{Vaccination on CD8 T-cell accumulation in tumors and}

\section{HR ligand expression on tumor vasculature}

\section{Introduction}

Naïve T-cell differentiation and proliferation into antigen-specific activated effectors requires two distinct signals (235). The first signal is the antigen-specific interaction between the TCR and antigen presented on an MHC molecule by the antigen presenting cell. The second signal, or co-stimulation, is the interaction between CD28 on the T-cell and B7 molecules (CD80 and CD86) on the APC. When a T-cell receives both signals it is considered activated and begins clonal expansion. These activated cells can then traffic to the site of antigen exposure and kill infected or transformed cells. Cytotoxic T lymphocyte associated antigen 4 (CTLA-4), a cell surface molecule closely resembling CD28, is found on T-cells and acts as a strong negative regulator of T-cell activation when bound to B7 molecules on the surface of APCs (236).

Because CD8 T-cells are such a powerful tool for fighting cancer, mechanisms of peripheral tolerance or inhibitory checkpoints have become popular targets for immunotherapy. Checkpoint blockade therapies, including blockade of CTLA-4 and programmed death protein 1 (PD-1), can be curative therapies for cancer patients by releasing T-cell inhibition and enabling them to fight (237-239). Ipilimumab, an injectable anti-CTLA-4 antibody, received FDA 
approval for the treatment of melanoma patients in 2011 (237). Unfortunately, while successful in some patients, many patients receive little to no clinical benefit from Ipilimumab and other checkpoint blockade therapies $(240,241)$.

Resistance to anti-CTLA-4 therapy may be due to poor pre-existing antitumor immunity $(74,242)$ or defects in IFN $\gamma$ gene pathways (243). One approach to increasing the clinical efficacy of anti-CTLA-4 and other checkpoint blockade therapies is to combine with vaccination. Gp100 peptide is a melanocyte differentiation antigen commonly used in clinical trials to vaccinate melanoma patients in hopes of generating large numbers of gp100-specific T-cells (Pmel-1) to mount an anti-tumor response $(244,245)$. Conceptually, combining the vaccine with the checkpoint blockade therapy will significantly enhance the immune response and in turn clinical response rate. The vaccination increases the number of tumor-specific CD8 T-cells in the patient and the checkpoint blockade therapy allows for co-stimulation through CD28 signaling thereby creating a large number of T-cells that are activated and able to fight the cancer cells. Interestingly, in a study of 676 melanoma patients, vaccination with gp100 peptide in Incomplete Freund's Adjuvant (IFA) combined with anti-CTLA-4 therapy showed no therapeutic benefit over anti-CTLA-4 monotherapy (237). Instead, the addition of the gp100/IFA vaccine had a negative effect on the efficacy of the CTLA-4 checkpoint blockade therapy, reducing both the overall response rate and the disease control rate to Ipilimumab (237). 
Gp100 peptide vaccine along with many other trial cancer vaccines, is generally formulated with IFA. IFA, water-in-oil emulsion of antigen, is used in vaccine formulations to safely and effectively bolster the efficacy of vaccines. Vaccination with gp100 in IFA has been shown to create a persistent antigen depot at the vaccination site where CD8 T-cells are activated. This antigen depot sequesters the cells thus rendering them unable to traffic to the site of tumor growth (246). These cells eventually become exhausted and die lending minimal efficacy to the gp100/IFA vaccine.

In this study, a collaboration with the lab of Dr. Willem Overwijk at MD Anderson, we tested that hypothesis that the gp100/IFA vaccination site sequesters both antigen-specific (Pmel-1) and non-antigen specific (non-Pmel-1) CD8 T-cells thereby reducing the efficacy of anti-CTLA-4 checkpoint blockade therapy. The number of Pmel-1 and non-Pmel-1 CD8 T-cells in the tumor and at the vaccination site was quantified to determine if cells were trafficking to the tumor or being sequestered. In addition to CD8 T cell counts, expression of ICAM-1 and VCAM-1, two aforementioned mediators of CD8 T-cell homing to tumors, was measured on CD31+ vasculature at the gp100/IFA vaccination site and on tumor-associated vasculature in mice treated with gp100/IFA alone or in combination with IP administered anti-CTLA-4 to determine the impact of combined therapy on HR ligand induction. The data collected indicates that the persisting antigen depot at the gp100/IFA vaccination site induced sequestration of cells, both antigen specific and non-specific. This sequestration at the 
vaccination site subsequently resulted in lower infiltration into the tumor thus preventing the initiation of a positive feedback loop whereby infiltrating CD8 effectors secreting inflammatory cytokines would increase the expression of VCAM-1 and ICAM-1 on the tumor-associated vasculature thereby creating a more permissive environment for increased CD8 T-cell accumulation.

\section{Results}

Expression of vascular ligands at the vaccination site is unchanged by CD8

\section{T-cell accumulation.}

In the work described above, we have established that the presence of CD8 T-cells in the tumor microenvironment increases the expression of HR ligand on tumor-associated vasculature. Previous work has demonstrated that gp100/IFA vaccination leads to an accumulation of CD8 T-cells at the vaccination site. Therefore, we sought to determine how HR ligand expression changed on skin vasculature following vaccination with gp100 in IFA and CD8 T-cell sequestration.

We found no significant change in the expression of ICAM-1 or VCAM-1 on vasculature at the vaccination site following SC injection of IFA alone or in combination with gp100/IFA even following a significant increase in the number of antigen-specific (Pmel-1) and non-specific (non-Pmel-1) CD8 T-cells in the area (Figure 30 and 31). Concurrent gp100/IFA vaccination and anti-CTLA-4 treatment led to a greater increase in non-Pmel-1 specific T effectors at the vaccination site compared to gp100/IFA alone but this did not subsequently 
increase ICAM-1 or VCAM-1 expression (Figure 30 and 31). P-mel-1+ T effectors continued to accumulate at the vaccination site following the addition of anti-IFN $\gamma$ to the combined gp100/IFA anti-CTLA-4 treatment (Figure 31). ICAM-1 and VCAM-1 expression was not changed with the addition of anti-IFN $\gamma$ to the treatment regimen. These results indicate that expression of ICAM-1 and VCAM1 at the vaccination site is not sensitive to the increased presence of effector Tcells and therefore that these cells are likely accumulating due to the IFA at the vaccine site and not due to increased HR ligand expression. 
Figure 30

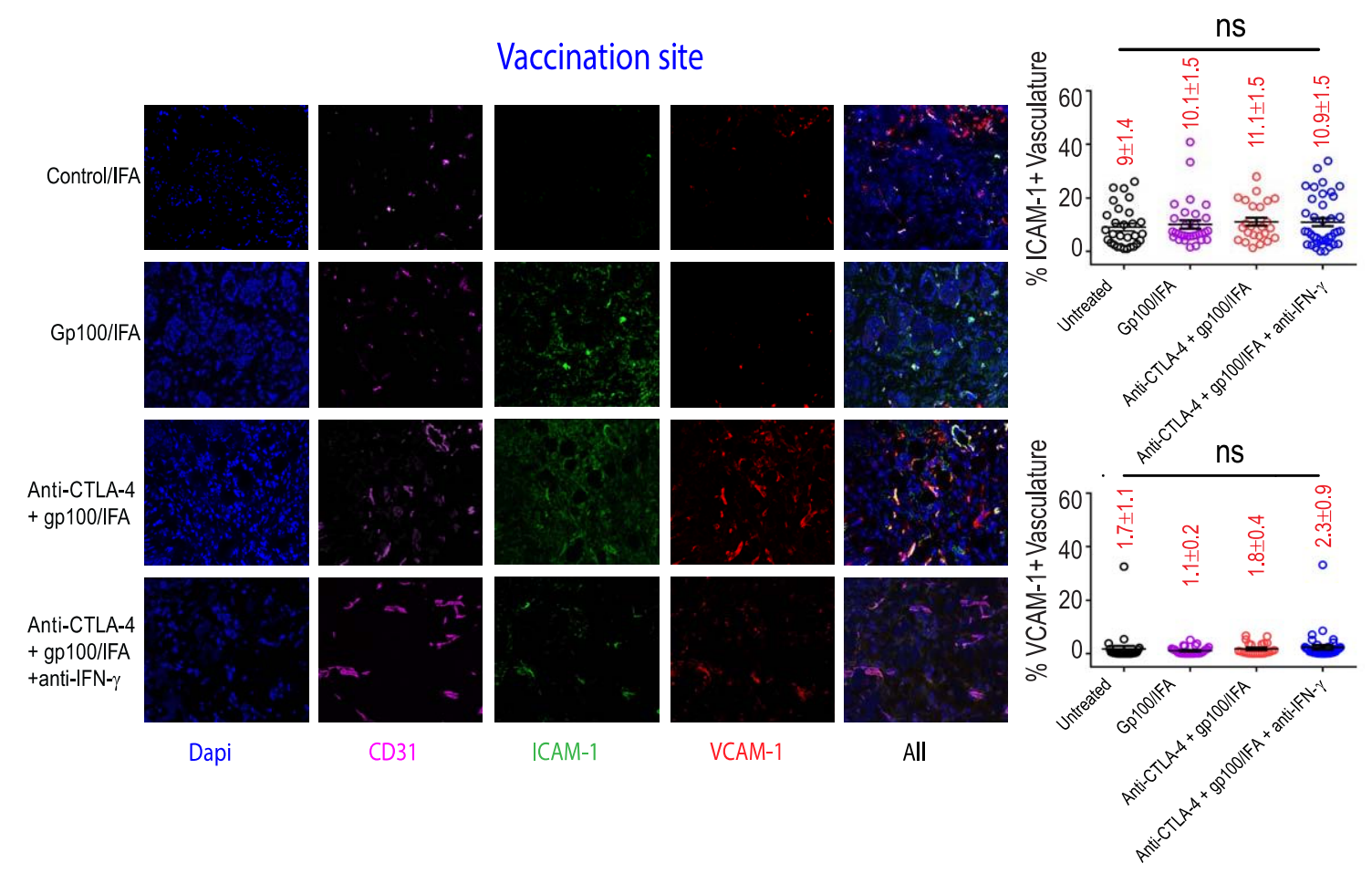


Figure 30: Pmel-1 T-effectors were adoptively transferred into mice immunized SC with gp100/IFA. In addition to the gp100/IFA, a cohort of mice was treated IP with anti-CTLA4 +/- anti-IFNy. Expression of VCAM-1 and ICAM-1 on CD31+ vasculature from the gp100/IFA vaccination site was determined using immunofluorescence microscopy. Representative and summary data shown for all fields from $n=3$ mice per treatment group. All statistical analyses were performed using unpaired student's T-test. 
Figure 31
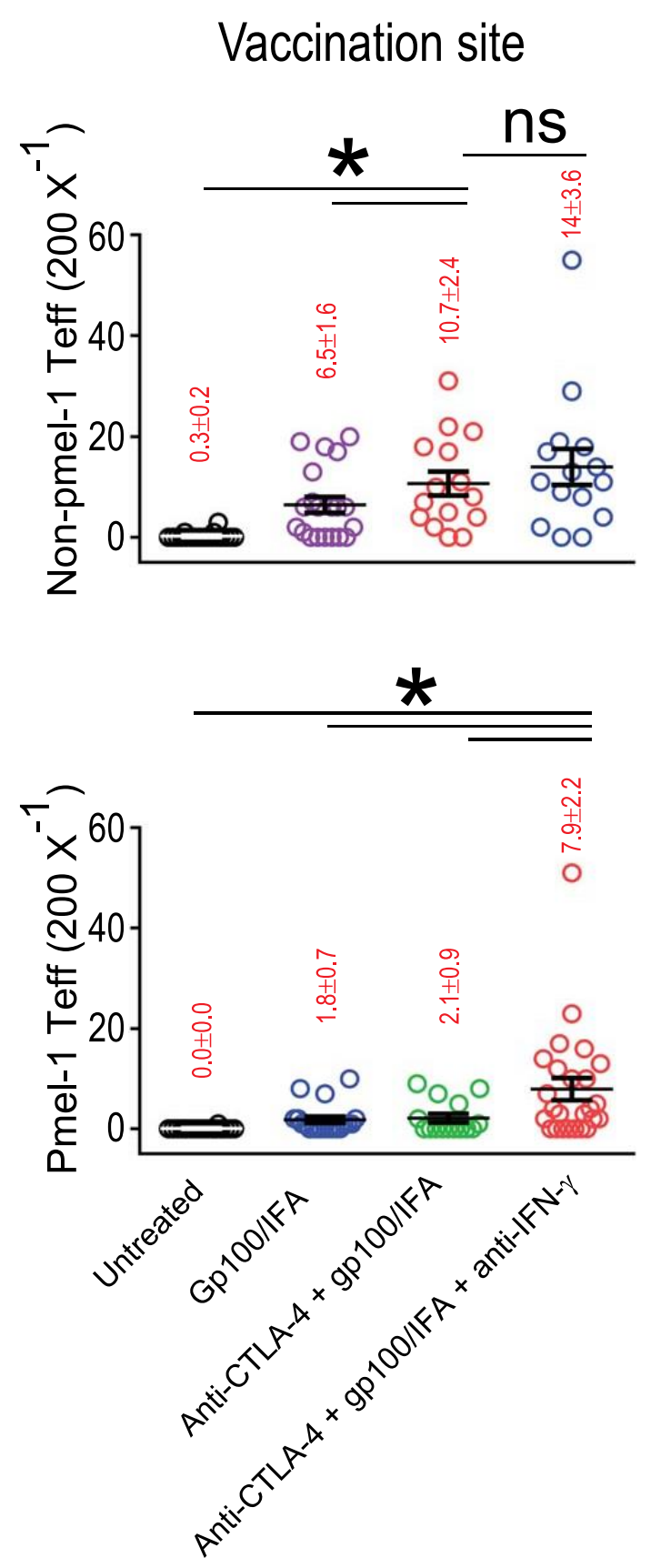
Figure 31: Pmel-1 T effectors were adoptively transferred into mice immunized SC with gp100/IFA. A cohort of mice was also treated IP with anti-CTLA4 +/- antiIFNY. Number of Pmel-1 and non-Pmel-1 T-effectors at the gp100/IFA vaccination site was enumerated by counting cells on immunofluorescence images. Representative and summary data shown for all fields from $n=3$ mice per treatment group. All statistical analyses were performed using unpaired student's T-test. 


\section{Anti-CTLA-4 increases vascular HR ligand expression on tumor-associated} vasculature.

Because the expression of ICAM-1 and VCAM-1 on vasculature at the vaccine site was unchanged in response to combined vaccination and checkpoint blockade therapy, we asked how these therapies affected expression of HR ligands on tumor-associated vasculature. Anti-CTLA-4 treatment significantly increased the expression of both ICAM-1 and VCAM-1 on tumor-associated vasculature compared to that of control (IFA only) treated mice or mice vaccinated with gp100/IFA alone (Figure 32). This increased ligand expression in treated tumors correlated with an increase in both antigen-specific (Pmel-1) and non-antigen-specific (non-Pmel-1) CD8 T-cell accumulation (Figure 33). ICAM-1 and VCAM-1 expression was highest in tumors treated with anti-CTLA-4 alone. This increase was negated by the addition of anti-IFN $\gamma$ to the treatment regimen indicating that the increase in ICAM-1 and VCAM-1 following anti-CTLA4 treatment was IFNy driven (Figure 32). Effector T-cell representation was also lower in tumors from mice that received anti-IFN $\gamma$ (Figure 33). These results support the positive feedback model whereby infiltrating effectors secrete IFNY thereby increasing HR ligand expression on the tumor-associated vasculature and, in-turn, supporting increased effector infiltration into the tumor. The decrease in ligand expression and lower numbers of effectors in tumors from the anti-CTLA-4 + gp100/IFA treatment group compared to the anti-CTLA-4 alone group supports the conclusion that gp100/IFA sequesters cells at the vaccination 
site thereby preventing them from making it to the tumor site and exerting their effector function there. 
Figure 32

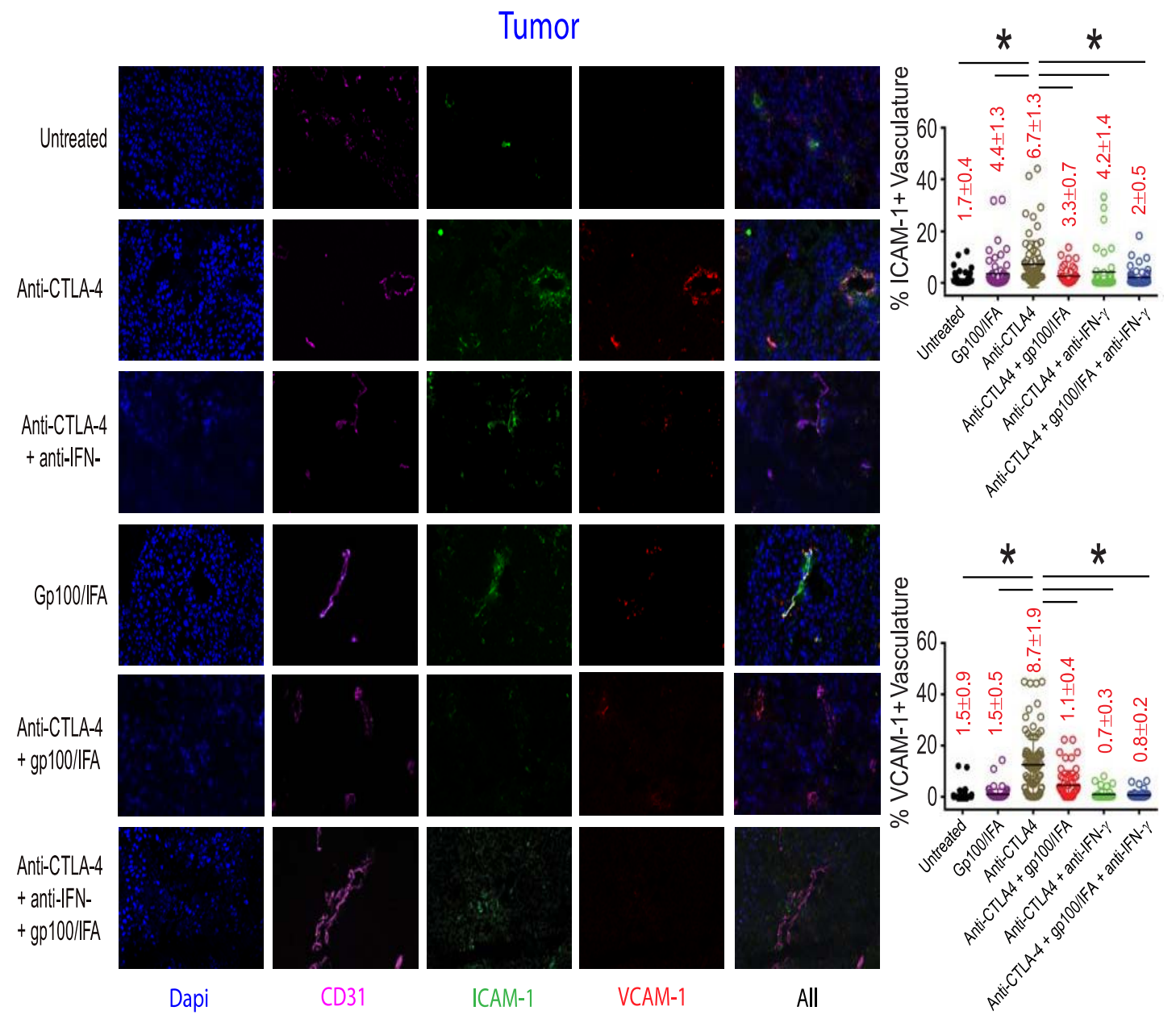


Figure 32: Pmel-1 T-effectors were adoptively transferred into mice immunized SC with gp100/IFA. A cohort of mice was also treated IP with anti-CTLA4 +/- antiIFNy. Expression of VCAM-1 and ICAM-1 on CD31+ tumor was determined using immunofluorescence microscopy. Representative and summary data shown for $n=10$ random fields from $n=3$ mice per treatment group. All statistical analyses were performed using unpaired student's T-test. 
Figure 33
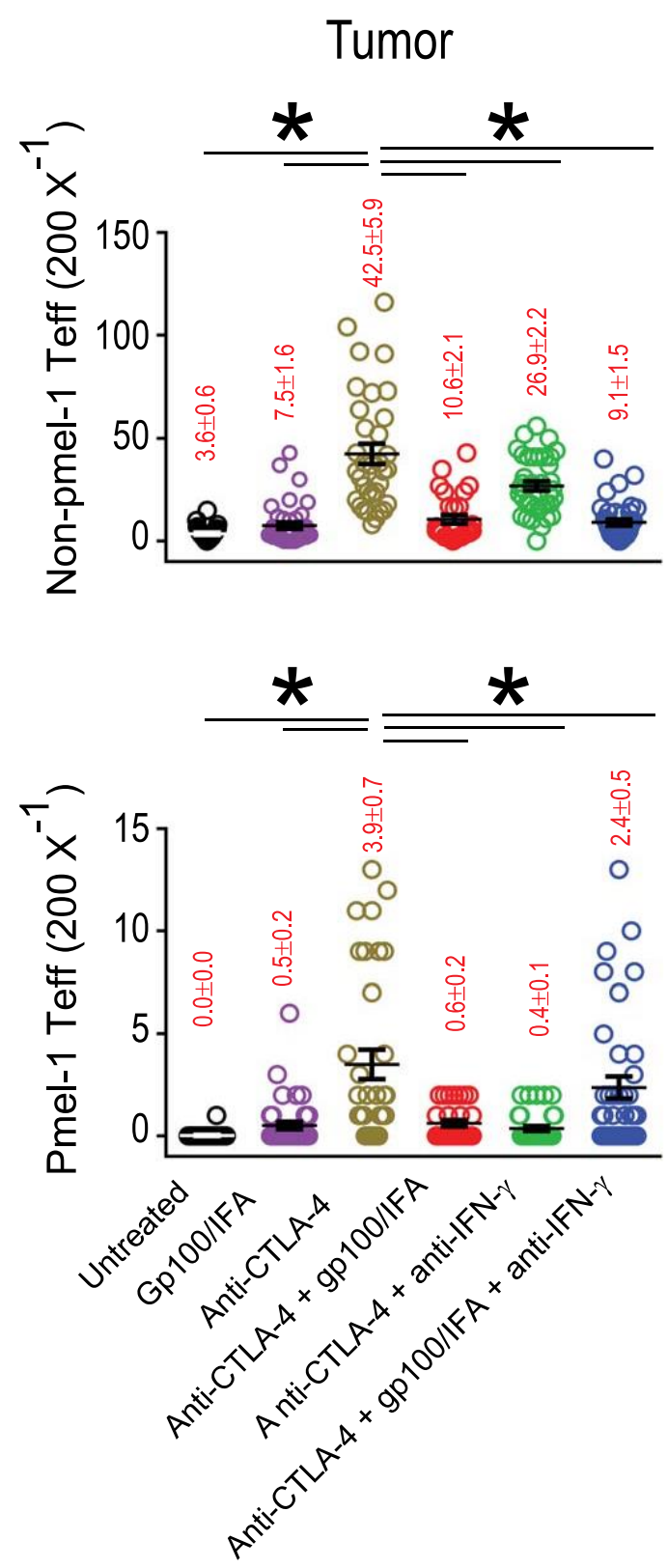
Figure 33: Pmel-1 T-effectors were adoptively transferred into mice immunized SC with gp100/IFA. A cohort of mice was also treated IP with anti-CTLA4 +/- antiIFNy. Number of tumor-infiltrating Pmel-1 and non-Pmel-1 T-effectors was enumerated by counting cells on immunofluorescence images. Representative and summary data shown for all fields from $n=3$ mice per treatment group. All statistical analyses were performed using unpaired student's T-test. 


\section{Discussion}

CTLA-4 checkpoint blockade therapy is a milestone in the treatment of cancer, but currently clinical benefit is limited to only a small subset of cancer patients. CTLA-4 blockade therapy is most effective in the presence of preexisting tumor-specific T-cells $(242,247)$. Unfortunately, the poor immunogenicity of many tumors leads to inadequate CD8+ T-cell mediated antitumor immunity. Cancer vaccination strategies could be used to induce expansion of the tumor-specific T-cell pool. While progress has been made in clinical cancer vaccine formulations, delivery, and ability to potentiate anti-cancer immune responses (248-252) robust clinical evidence of increased efficacy to checkpoint blockade therapy combined with vaccination is currently lacking. We showed, based on T-cell infiltration and HR ligand induction, peptide vaccine in IFA failed to synergize with anti-CTLA-4 checkpoint blockade therapy due to sequestration of T-cells at the vaccination site.

We found that anti-CTLA-4 therapy alone induced the highest levels of HR ligand expression on tumor-associated vasculature and CD8 T-cell accumulation in the tumor in an IFNy-dependent manner. When gp100/IFA was given concurrently with anti-CTLA-4 therapy, HR ligand induction and CD8 T-cell accumulation at the tumor site was greatly reduced. We believe this was due to the observed increase in CD8 T-cells at the vaccination site. Interestingly, these effector T-cells had antigen specificities other than the gp100 vaccine antigen, yet became sequestered at the gp100 vaccination site. Neutralization of IFN- - , a 
CD8+ T-cell effector cytokine able to induce expression of the ligands ICAM-1 and VCAM-1, reduced CD8+ T-cell accumulation at the tumor, shifting them to the vaccination site. Together, our data are consistent with a scenario where circulating effector T-cells infiltrate tumor tissue and encounter cognate antigen, causing the release of IFN- $\gamma$, which increases expression of adhesion molecules such as ICAM-1 and VCAM-1 by endothelial cells, thereby supporting infiltration of additional effector T-cells. This supports a cycle of T-cell infiltration, target cell lysis, cytokine secretion and local inflammation. When the vaccine is persistently present, as in the case of gp100 peptide emulsified in non-biodegradable IFA, this process results in sequestration of effector T-cells at the vaccination site (246). Importantly, non-gp100 specific effector T-cells induced by anti-CTLA-4 checkpoint blockade also become sequestered. Mechanistically, preventing the formation of a persistent, chronically inflamed vaccination site by altering vaccine formulation offers a path towards the use of vaccines that synergize with antiCTLA-4 checkpoint blockade therapy and significantly improved clinical efficacy.

Overall, our results indicate that gp100/IFA vaccination induces persistent inflammation at the vaccination site that recruits, functionally impairs and eventually destroys tumor-specific effector T-cells induced by anti-CTLA-4 checkpoint blockade therapy. Non-persistent vaccine formulations can reverse these undesirable effects and synergize with anti-CTLA-4 checkpoint blockade, overcoming primary resistance to checkpoint blockade therapy and greatly enhancing both response rates and complete cure rates. These results provide 
explanation for the lack of synergy between anti-CTLA-4 therapy and gp100/IFA vaccination in patients with melanoma. They also highlight the importance of vaccine formulation in future clinical trials of combination therapy with checkpoint blockade and vaccination and point the way to increase the therapeutic efficacy of checkpoint blockade for patients with cancer.

This chapter was an adapted excerpt from: Yared Hailemichael, Amber Woods, Tihui Fu, Qiuming He, Michael C. Nielsen, Farah Hasan, Jason Roszik, Zhilan Xiao, Christina Vianden, Hiep Khong, Manisha Singh, Meenu Sharma, Faisal Faak, Derek Moore, Zhimin Dai, Scott M. Anthony, Kimberly S. Schluns, Padmanee Sharma, Victor H. Engelhard, Willem W. Overwijk. JCI Insights (In submission). Cancer vaccine formulation dictates synergy with CTLA-4 and PDL1 checkpoint blockade therapy. 


\section{Conclusions and Future Directions}

While a small number of studies had identified individual HR that could contribute to T-cell infiltration into some tumors, and several suggestive correlations had been identified, a comprehensive analysis of the molecules that mediate entry of CD8 T-cells into any one kind of tumor, and how this varies with anatomical location, had not yet been conducted. To determine which HR/HR ligand interactions are required for CD8 T-cell entry into tumors we first systematically identified which HR ligands are expressed on the vasculature of tumors growing in different anatomic locations. Immunofluorescence and flow cytometry were used to directly compare HR ligand expression on B16 melanoma vasculature to that of adjacent tissue vasculature. We found that ligand expression varies depending on site of tumor growth but the HR ligands VCAM-1, CXCL9, and ICAM-1 were expressed regardless of tumor location. Eselectin and MAdCAM-1 expression mimicked patterns of expression seen on adjacent tissue vasculature. We then used blocking antibodies and knockout mice to show that $\alpha 4 \beta 1 / V C A M-1, C D 44 / H A, C X C R 3 / C X C L 9 / 10$, and LFA1/ICAM-1 interactions are required for CD8 T-cell entry into tumors growing both SC and IP. This is the first study to also begin to investigate the impact of checkpoint blockade therapy on the expression of HR ligands on tumorassociated vasculature.

Our findings suggest the existence of a positive feedback loop that drives expression of HR ligands on tumor associated vasculature, which depends upon 
cytokine-secreting immune cells in tumors (Figure 34). We hypothesize that the loop is initiated by early infiltration of innate immune cells, which leads to transient upregulation of HR ligands on tumor vasculature. We think it most likely that NK cells are the relevant innate population, but this requires further investigation. This initial HR ligand expression supports the infiltration of a small number of CD8 T cells. These activated effector T-cells secrete IFNy, thus driving more sustained HR ligand expression on the tumor endothelium. This supports the ongoing infiltration of additional effectors. However, we believe that this feedback loop will ultimately be limited by one or more immunosuppressive mechanisms operating within the tumor microenvironment (Figure 35). Without continued infiltration and secretion of pro-inflammatory cytokines by activated effectors, HR ligand expression returns to very low levels and no longer supports CD8 T cell infiltration. Testable predictions of this model include: 1) NK cell depletion should prevent both HR ligand upregulation and T-cell infiltration; 2) Late stage tumors that are well infiltrated will nonetheless show only low levels of HR ligand expression in association with an exhausted T-cell phenotype.

Reversal of immunosuppression should lead to re-expression of HR ligands and resumption of T-cell infiltration. 
Figure 34: Positive Feedback Loop

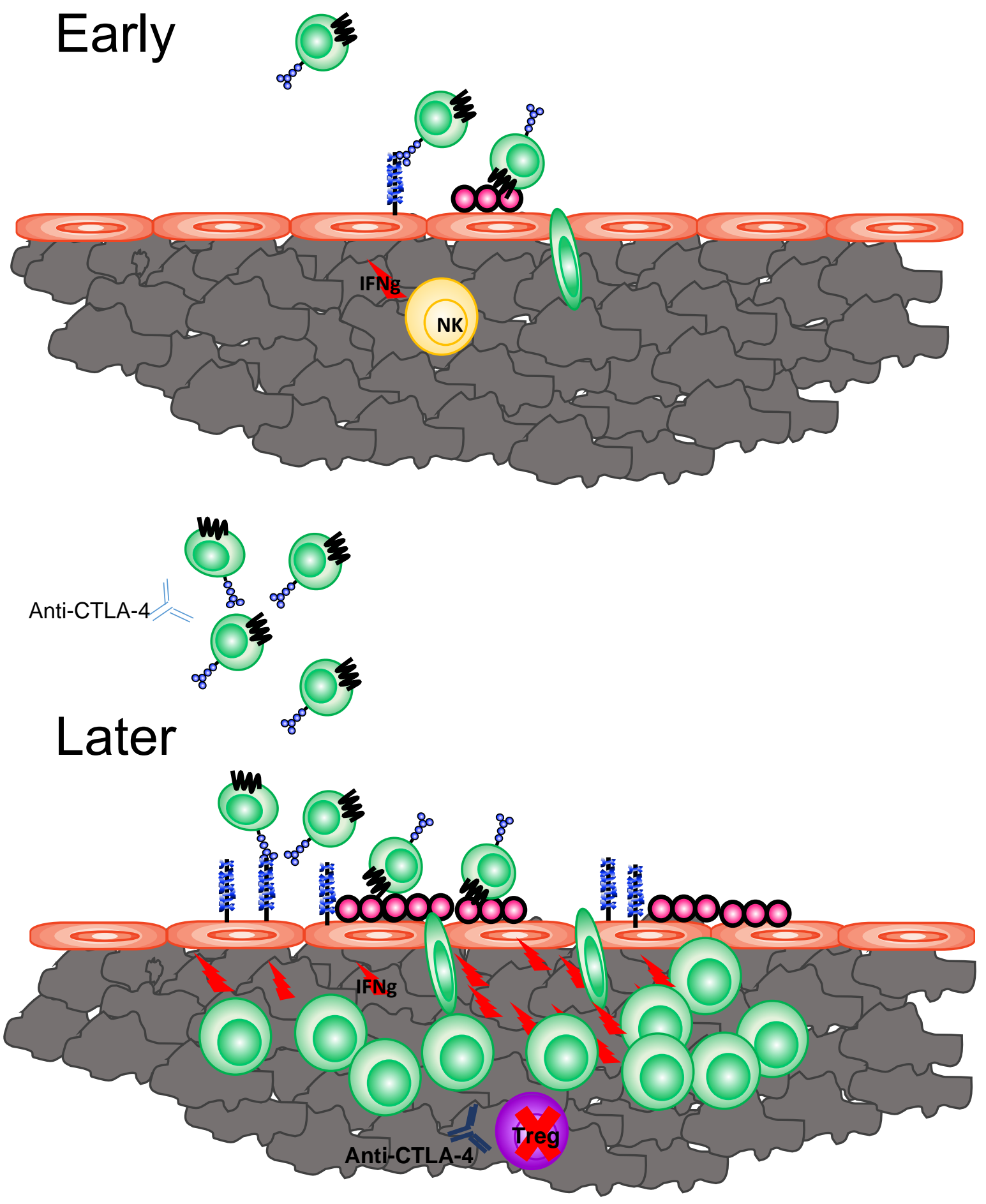


Figure 34: HR Ligand Induction on Tumor Vasculature

Early in tumor development innate immune cells, likely NK cells, infiltrate tumors and secrete IFNy. This IFNy increases the level of HR ligand expression on tumor vasculature. This increased HR ligand expression supports the entry of a small number of activated effectors. Later, these activated effectors secrete additional IFNy which sustains the expression of HR ligands on the tumorassociated vasculature. This supports the entry of additional CD8 T-cells. Blockade of CTLA-4 allows for increased CD8 T-cell activation and expansion in the $L N$ thereby increasing the number of cells available to traffic to the tumor. Alternatively, CTLA-4 blockade results in the killing of Tregs in the tumor microenvironment therefore decreasing immunosuppression within the tumor. The continued infiltration and IFNy secretion by CD8 T-cells is required to maintain elevated $\mathrm{HR}$ ligand expression on the tumor vasculature and to support infiltration into tumors. 
Figure 35: Factors Limiting CD8 T-cell Trafficking
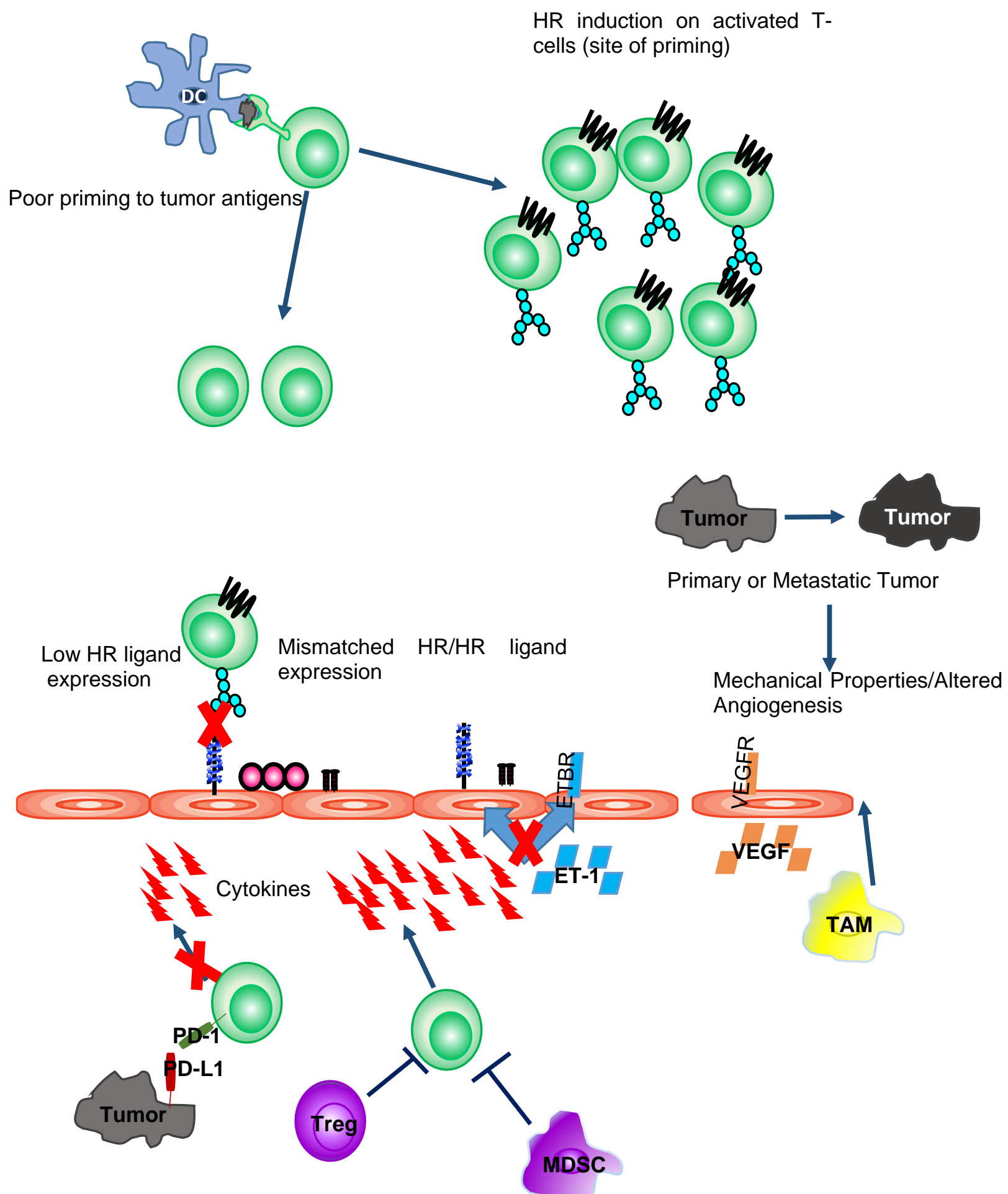
Figure 35: Factors limiting CD8 T-cell trafficking

Many factors can negatively impact the expression of $\mathrm{HR}$ ligands on tumor vasculature, thereby limiting CD8 T-cell infiltration into tumors. Poor T-cell priming in the LN, due to low immunogenicity of the tumor, results in fewer activated effectors. Priming in the incorrect LN can generate effectors that do not express the proper HR for trafficking to tumors growing in specific anatomic locations. At the tumor, low HR ligand expression or mismatched HR/HR ligands can inhibit T-cell entry. CD8 T-cell secretion of pro-inflammatory cytokines can be inhibited by regulatory T-cells, Myeloid Derived Suppressor Cells, and PD-1/PDL1 interactions between tumor cells and CD8 T-cells (263). Endothelin-1 $(171,263)$ interactions with its receptors on endothelial cells can inhibit cytokineinduced upregulation of the HR ligands ICAM-1 and VCAM-1 on tumorassociated vasculature. Additionally, tumor associated macrophages (264), VEGF, and the metastatic nature of the tumor (265) can significantly impact angiogenesis thus disrupting the mechanical properties of the vasculature and disrupting lymphocyte adhesion. 
In addition to the HR/ligand interactions that mediated CD8 T-cell entry into tumors growing in both SC and IP sites, we found that there was an additional interaction that could mediate CD8 T-cell entry into SC tumors. Using two different experimental approaches, this work has shown that E-selectin is capable of mediating CD8 T-cell entry into SC tumors. The first was the use of Eselectin $^{-/}$mice and the second was a comparison of the trafficking of SC and IP primed effectors into tumors growing in SC and IP sites. The conclusions drawn from these experiments could be strengthened by analyzing the profile of effectors capable of entering SC tumors and showing that ESL single positive cells were unable to enter SC tumors grown in E-selectin ${ }^{-/}$mice and that the SC effectors found in SC tumor bearing animals were $\mathrm{ESL}^{+}$. While our work has attributed ESL/E-selectin interactions to specifically mediating entry into SC tumors, E-selectin was also expressed at a low level on the vasculature of brain tumors. Localized E-selectin expression on only SC tumor vasculature suggests this interaction has limited capacity to improve CD8 T-cell entry into tumors, but expression at additional tumor sites could enhance this capacity.

The cells and cytokines required to drive expression of HR ligands on tumor vasculature were also investigated as a part of this study. Using knockout mice and adoptive transfers, we found that IFNy, and not TNFa, secreted by CD8 T-cells in the tumor microenvironment was required to drive expression of VCAM-1 and CXCL9 on the vasculature of SC B16 melanomas. We have shown that without CD8 T-cells or IFNy, VCAM-1 and CXCL9 expression decreases 
significantly. The next step is to use in-vitro assays to determine if IFNy stimulation is sufficient upregulate VCAM-1 and CXCL9 expression on tumorderived endothelial cells. These in-vitro experiments would provide insight into how tumor vasculature would respond if treated with intra-tumoral injections of IFNy. For these experiments, endothelial cells would be isolated from B16-F1 tumors using enzyme-mediated digestion and magnetic bead separation. Isolated endothelial cells would then be cultured in the presence of IFNY or TNFa, collected after 4, 8,12, 18, or $24 \mathrm{hrs}$, stained for VCAM-1 and CXCL9, and analyzed by flow cytometry. We have shown B16-F1 tumors have very low HR ligand expression and therefore, presumably, an increased capacity for HR ligand upregulation. Assessing expression at multiple time-points will allow determination of the optimal time for VCAM-1 and CXCL9 upregulation on tumorderived endothelium $(215,226,253,254)$. Based on the results from the Rag $1^{1-}$ experiments, IFNY should be sufficient to drive increased VCAM-1 and CXCL9 expression on the tumor endothelial cells while TNFa alone should have no effect on the expression of these molecules. This is in contrast to what is found in the literature suggesting that TNFa and IFNy are both capable of inducing VCAM-1 expression on endothelial cells $(150,226)$. Culturing these cells in the presence of both TNFa and IFNy would enable us to determine whether TNFa can enhance CXCL9 or VCAM-1 expression induced by IFNy $(215,253,254)$. Next, it would be interesting to determine if IFNY stimulation can increase the level of VCAM-1 and CXCL9 expressed on endothelial cells from B16-OVA tumors. These molecules 
are expressed on $20-30 \%$ of vascular endothelial cells from B16-OVA tumors at baseline. Therefore, this in-vitro stimulation could provide insight into the maximum possible expression of these molecules on tumor-associated vasculature. We can also use this approach to determine if endothelial cells isolated from other tissues, and tumors growing in different anatomic sites, have the same responsiveness to stimulation with these cytokines. These in-vitro cultures can also allow us to determine the $1 / 2$ life of ligand expression on tumorderived endothelial cells which will help us to determine when HR ligand expression is highest following treatments such as anti-CTLA-4. Additionally, we can use these studies to analyze dose response to IFNy stimulation for tumor endothelial cell production of VCAM-1 and CXCL9. Collectively, this data will provide a more detailed and complete understanding of how tumor endothelial cells from different anatomic locations are capable of responding to stimulation from CD8 T-cell-secreted cytokines.

While VCAM-1 and CXCL9 expression is dependent on adaptive immune cells in the tumor microenvironment, E-selectin expression is seemingly unaltered by adaptive immunity. E-selectin expression was not different in wellinfiltrated B16-OVA tumors compared to the poorly-infiltrated B16-F1 tumors. There was a trend towards lower E-selectin expression when B16-OVA tumors were grown in Rag $1^{-/-}$mice, but it did not reach the level of significance. Additional experiments are needed to determine first if E-selectin expression on tumor vasculature is controlled by cells in the tumor microenvironment and, if so, 
what cells and cytokines drive this expression. One possibility is that E-selectin is expressed on SC tumor vasculature because the vasculature of the skin expresses E-selectin, not due to immune driven induction. In this scenario, the Eselectin expression seen in SC tumors is simply a product of tumor location. This situation does not seem likely based on the differences in E-selectin expression on skin and SC tumor vasculature seen in Figure 8. Alternatively, E-selectin expression may be impacted or controlled by cytokines in the tumor microenvironment, similar to VCAM-1 and CXCL9. Addition of cytokines to invitro cultures of endothelial cells isolated from SC B16 tumors would elucidate which cytokines are sufficient to drive E-selectin expression on tumor-derived vasculature. The literature suggests that E-selectin expression can be driven by TNFa or Lta3 through binding the TNFR $(129,255)$. Previous work in the lab has shown that PNAd expression on IP tumor vasculature is driven by Lta3 signaling through the TNFR (233). Because both Lta3 and TNFa signal through the TNFR, growing tumors in $\mathrm{TNFR}^{-/}$mice would allow us to assess the impact of Lta3 and TNFa signaling on E-selectin expression. Growing tumors in TNFa ${ }^{-/-}$mice would allow us to specifically assess the importance of TNFa in driving E-selectin expression. In addition to which cytokines may be driving E-selectin expression on SC tumor vasculature, which cells in the tumor microenvironment are secreting these cytokines remains unknown. Our work indicates that adaptive immune cells are not driving E-selectin expression on tumor-associated vasculature, therefore innate immune cells would likely be the cytokine source. 
To test whether innate immune cells, such as NK cells, innate lymphoid cells (iLC), or other myeloid cells in the tumor microenvironment are driving E-selectin expression on the vasculature of SC B16-OVA tumors we can implant B16-OVA tumors SC into NOD/SCID or NSG mice (256). These mice lack both B and Tcells as well as NK cells and the II-2R y chain ${ }^{-/}$in NSG mice additionally eliminates iLC (257) and will therefore enable assessment of E-selectin expression on the vasculature of tumors in the absence of NK cells and iLC. If NSG mice are found to have decreased ligand expression we can replete with NK cells to determine if NK cells are sufficient to drive E-selectin expression on SC tumor vasculature. E-selectin, though thought to only be expressed on skin vasculature was also found on the vasculature of brain tumors. This suggests that under the right conditions, with stimulation from the correct cells and cytokines, E-selectin expression may be induced on the vasculature of tumors growing in locations other than the skin. Induction of E-selectin in other sites may increase efficacy of intradermally administered vaccines which likely induce a significant number of ESL single positive effectors.

The next remaining question regarding HR ligand expression on tumorassociated vasculature is whether the drivers and patterns of HR ligand expression on IP tumor vasculature are the same as those found in SC tumors. We have shown that in SC tumors CXCL9 and VCAM-1 expression can be driven by IFNy secreted by CD8 T-cells. These molecules were co-localized on CD31+ endothelial cells more frequently than would be predicted by random 
chance. This co-localization indicates coordinated control of VCAM-1 and CXCL9 expression. Meanwhile, E-selectin expression is independently controlled. A similar analysis was not conducted for IP tumor vasculature, but could provide additional insights into the differences in SC and IP tumor microenvironments. While we would hypothesize that VCAM-1 and CXCL9 would continue to be coordinately controlled. MAdCAM-1 could be independently controlled similar to what is seen with E-selectin or it could be coordinately controlled, and if induced on the luminal surface, MAdCAM-1 and VCAM-1 could work together to increase infiltration into IP tumors. An analysis of the differences in the cytokine profiles for SC and IP B16-OVA tumors using a Luminex panel would also increase our understanding of the differences in these two tumors. We know from previous work that NK cells are similarly represented in SC and IP tumors but these cells secrete significantly more IFN $\gamma$ and TNF $\alpha$ in SC tumors compared to IP (233), but a comprehensive analysis of the cytokine milieu from SC and IP tumors has not been conducted. It would also be interesting to repeat the IFNY ${ }^{-1}, \mathrm{TNFa}^{--}$, and Rag repletion experiments in IP tumors to determine if the same cytokines are driving ligand expression regardless of tumor location or if tumor location impacts vascular responsiveness to cytokine stimulation. This would also determine whether the unexpected inability of TNFa to drive VCAM-1 expression is tumorspecific or anatomic site-specific.

A very surprising finding was the lack of luminal expression of MAdCAM-1 on IP B16-OVA tumor-associated vasculature. Whether this phenomenon is 
specific to B16-OVA or holds true for other tumor types, such as LLC-OVA or MC38-OVA remains to be determined. IV injection of labeled CD31 and MAdCAM-1 antibodies into LLC-OVA or MC38-OVA IP tumor-bearing mice would determine if MAdCAM-1 expression is abluminal in multiple tumor types or only B16-OVA. What cytokines drive MAdCAM-1 expression on the tumor vasculature, what controls the polarity of expression, and whether the polarity can be changed are additional questions that remain to be addressed. Studies using IFNY ${ }^{--}$and $\mathrm{TNFa}^{-/-}$mice could begin to determine what is driving MAdCAM1 expression on IP tumor vasculature. Determining what impacts the polarity of $\mathrm{HR}$ ligand expression on tumor endothelium is a little more tricky. One possibility is that the cytokine-secreting cells are inside the tumor not in the vessel lumen and MAdCAM-1 expression is induced only in direct proximity to the cytokine. Immunofluorescence staining of in-vitro cultures could determine if this hypothesis is correct. While the abluminal expression of MAdCAM-1 is an intriguing phenomenon with a potentially novel mechanism, this route of investigation may not be as clinically relevant as other future directions described herein.

To this point, all analysis of HR ligand expression has assessed HR ligand expression on CD31+CD45- endothelial cells isolated from tumors. In this study, the expression of CXCL9 was determined by intracellular staining of magnetic bead enriched endothelial cells. Because CXCL9 is a secreted chemokine, CD $31^{+}$cells are not necessarily the only cellular source of CXCL9 available to 
mediate CD8 T-cell entry into tumors. In different inflammatory contexts fibroblasts $(258,259)$, macrophages, neutrophils $(258,260)$, and even tumor cells (261) have been found to produce CXCL9. Therefore, the CXCL9 measurements in this study are quite possibly underestimates of the actual CXCL9 levels in SC and IP B16 tumors. Therefore, isolating fibroblasts, DCs, neutrophils, and tumor cells from B16-OVA tumors and assessing intracellular CXCL9 levels would be a very interesting next step. It is extremely possible that the CD $31^{+}$endothelial cells, of which approximately $30 \%$ express CXCL9, are only a minor source of CXCL9 in the tumor microenvironment. Additionally, CXCL9 is only one CXCR3 ligand. Levels of CXCL10 expression in SC and IP tumors have not been analyzed but would provide an even clearer picture of what is available for CXCR3 binding.

While this work has comprehensively analyzed HR ligand expression on SC and IP B16 melanomas, it has yet to determine if the differences in HR ligand expression seen in implantable mouse tumors are also seen on human primary and metastatic melanomas. Therefore, it would be very interesting to correlate the results of this study to clinical specimens. To do this, tissue samples from primary skin melanoma lesions, as well as tissue samples from bowel metastasis would need to be stained for VCAM-1, CXCL9, E-selectin, and MAdCAM-1. We would expect to see VCAM-1 and CXCL9 on samples isolated both from the skin and bowel while E-selectin expression would be restricted to the skin lesions and MAdCAM-1 to the bowel lesions. If E-selectin and MAdCAM-1 are found on 
tumors from both locations this may indicate that control of expression is different in human melanomas and implantable mouse tumors. Importantly, this work would confirm our finding that VCAM-1 and CXCL9 are widely expressed, regardless of the site of tumor growth, and therefore important molecules for CD8 T-cell infiltration into human tumors.

Understanding which molecules are expressed on B16 melanoma vasculature in different anatomic locations and which interactions are capable of mediating CD8 T-cell entry into tumors, provides a foundation to work towards increased CD8 T-cell infiltration into tumors. The representation of CD8 T-cells in tumors is a strong prognostic factor and predictor of response to immunotherapy, therefore this line of study is a very important future direction for the work described in this thesis. Because VCAM-1 and CXCL9 are widely expressed and required for entry into both SC and IP tumors increasing their expression has the potential to significantly improve CD8 T-cell entry into tumors in multiple anatomic locations. Two potential strategies for increasing HR ligand expression on tumor-associated vasculature are concentrated administration of inflammatory stimuli and tumor-endothelium targeted HR ligand induction. The first approach would be to intra-tumorally inject IFNy and show that this increases HR ligand expression resulting in increased CD8 T-cell accumulation in the tumor. If it does not, then the number of T-cells generated in response to the tumor may be the limiting factor and therefore vaccination would be necessary to boost the T-cell response. Based on our findings, intradermal, or SC vaccination, is not the best 
vaccination route to induce $\alpha 4 \beta 1$ expression on the effector CD8 T-cells and therefore IV vaccination should be explored. Because injection of IFNY could have numerous off-target effects, targeted upregulation of $\mathrm{HR}$ ligands on the tumor vasculature is likely a better approach. Tumor vasculature can be targeted using many different approaches including use of tumor-endothelium targeted microbubbles and engineered adeno-associated viruses that localize to specific tumor targets (199). These methods could deliver a tumor vasculature-modifying drug or cytokine directly, shRNA sequences to knockdown inhibitory molecules, or even protein-coding nucleic acid sequences. These could potentially be the endothelial expressed ligands themselves (e.g. E-selectin, VCAM-1, CXCL10), or an upstream cytokine known to induce their expression (e.g. TNF $\alpha$, IFN $\gamma$, LT $\alpha$ ). Specific upregulation of one or more HR ligands on the tumor vasculature is a promising approach to increasing CD8 T-cell infiltration. If the experiments described above find CXCL9 levels in the tumor are significantly higher than initially thought, this would indicate that VCAM-1 is the limiting factor for CD8 Tcell trafficking into tumors. Therefore, VCAM-1 should be the focus of studies aimed at increasing ligand expression on tumor vasculature. Targeted expression of VCAM-1 on the tumor-associated vasculature, in combination with IV vaccination is likely a promising approach to improve CD8 T-cell representation in tumors.

As discussed in the appendix, the next big step for this line of work is to determine how current melanoma therapies impact HR ligand expression on 
tumor-associated vasculature. Our work with the Overwijk lab at MD Anderson has scratched the surface of this, but much more work remains. In addition to the collaborative work described in the appendix, I have worked closely with another member of our lab to more extensively investigate the impact of anti-CTLA-4 treatment on CD8 T-cell representation in B16 melanomas and HR ligand expression on tumor vasculature. This preliminary work indicates that only a small percent of mice treated IP with anti-CTLA-4 respond to treatment, as determined by an increase in CD8 T-cell numbers in the tumor microenvironment. This response rate is similar to what is seen clinically (262). There are two proposed mechanisms of action for anti-CTLA-4. The first is increased T-cell priming in the $L N$ and the second is through altering Treg representation/function in the tumor (236). Therefore, we seek to determine which of these two mechanisms is playing a role in the responses seen in our mice. On day 13 post-tumor implant, anti-CTLA-4 treated tumors were found to have increased numbers, but not frequencies, of effector CD8 T-cells and Tregs. The functionality of the Tregs in these tumors was not assessed. Future experiments using magnetic bead enrichment will enable us to determine if the function of these Tregs has been altered by anti-CTLA-4 treatment. In addition to the Tregs, the CD8 T-cell numbers were increased in response to anti-CTLA-4, and this increase was associated with decreased tumor burden, but interestingly, a higher proportion of those CD8 T-cells expressed PD-1. Therefore, we need to determine if PD-1 is a marker of activation or exhaustion in this setting. The 
current data at day 13 shows no difference in PD-1 MFI, but a higher frequency of PD-1 expressing CD8 T-cells in anti-CTLA-4 treated tumors. To better understand what is happening here, we need to analyze PD-1 expression on CD8 T-cells from tumors on day 10 instead of day 13. This earlier time-point should help us to determine if these cells are becoming exhausted. In addition to the T-cell analysis, we have assessed HR ligand expression on anti-CTLA-4 treated and control tumors. VCAM-1 expression is enhanced, CXCL9 expression trends upward, and E-selectin expression is unchanged following treatment with anti-CTLA-4. Our current hypothesis is that day 13 tumor harvest misses peak CXCL9 expression. The earlier day 10 harvest will hopefully enable us to see a statistically significant increase in CXCL9 expression induced by the anti-CTLA-4 treatment. Based on the completed experiments, we propose that anti-CTLA-4 is functioning in the LN leading to sustained infiltration of cells into the tumor from the LN which drives enhanced ligand expression and thereby supports increased infiltration in a positive feedback loop. The impact of combining anti-CTLA-4 and anti-PD-1 checkpoint blockade therapy on HR ligand expression has not been tested but would also be a very exciting avenue to explore.

The thorough characterization of HR ligand expression on tumor vasculature at a baseline state, paves the way for understanding these same concepts in response to the many therapies being tested for improving clinical efficacy of cancer treatment. In addition to the anti-CTLA-4 experiments, we are interested in investigating the effect of priming the immune response or depleting 
negative regulators on CD8 T-cell trafficking into tumors. If mice are treated with anti-CD40, or other agonists such as CpG, what HR are induced on the activated CD8 T-cells? Does site of agonist injection impact HR induction on CD8 T-cells? Does priming the immune response in tumor-bearing mice enhance HR ligand expression on the tumor-associated vasculature? Do these treatments synergize with checkpoint blockade to enhance CD8 T-cell entry into tumors? These questions and many more can be explored by treating mice SC, IP, or IV with molecules like anti-CD40 and assessing the phenotype of activated CD8 T-cells and the HR ligands expressed on tumor vasculature. While priming the immune response is one potential route for changing CD8 T-cell trafficking in tumor bearing animals, removing immuno-suppressive cells and factors or improving vascular structure is another approach that has the potential to significantly change CD8 T-cell trafficking (Figure 35). What is the impact of Treg depletion on HR ligand expression on tumor vasculature? Does Treg depletion synergize with anti-CTLA-4 to improve response rate? Assessing both the priming and depleting approaches to improving CD8 T-cell trafficking will determine if there are specific advantages/disadvantages to using a priming approach versus a depleting approach to change the tumor microenvironment. Does blockade of VEGF or Endothelin-1 increase improve HR ligand expression and synergize with adoptive cell therapies or checkpoint blockade? These experiments could provide additional insights into which immune-based therapies or combinations of therapies are likely to be most effective. 
The work in this thesis has demonstrated the importance of HR expression on CD8 T-cells and HR ligand expression on tumor vasculature for effective CD8 T-cell infiltration into tumors. It highlights the differences in HR ligand expression based on site of tumor growth, the importance of CD8 T-cells in setting up a positive feedback loop to drive increased HR ligand expression on tumor vasculature, and the ability of anti-CTLA-4 therapy to drive increases in HR ligand expression on tumor vasculature and CD8 T-cell representation in tumors. CD8 T-cell trafficking serves as a critical barrier to the success of immune-based therapies for cancer including cancer vaccines, checkpoint blockade, and adoptive transfer therapies. This enhanced understanding of the molecular requirements for CD8 T-cell entry into tumors growing in different anatomic locations has the potential to be applied clinically to enhance the efficacy of cancer immunotherapies and to one-day lead to a cure. 


\section{References}

1. Coley $\mathrm{W}$. The treatment of malignant tumors by repeated inoculations of erysipelas. With a report of ten original cases. LWW. 1893;105:487-510.

2. Wiemann B, Starnes CO. Coley's toxins, tumor necrosis factor and cancer research: a historical perspective. Pharmacol Ther. 1994;64:529-64.

3. Kaplan DH, Shankaran V, Dighe AS, Stockert E, Aguet M, Old LJ, et al. Demonstration of an interferon gamma-dependent tumor surveillance system in immunocompetent mice. Proc Natl Acad Sci U S A. 1998;95:7556-61.

4. Smyth MJ, Thia KY, Street SE, MacGregor D, Godfrey DI, Trapani JA. Perforinmediated cytotoxicity is critical for surveillance of spontaneous lymphoma. J Exp Med. 2000;192:755-60.

5. Smyth MJ, Crowe NY, Godfrey DI. NK cells and NKT cells collaborate in host protection from methylcholanthrene-induced fibrosarcoma. Int Immunol. 2001;13:459-63.

6. Shankaran V, Ikeda H, Bruce AT, White JM, Swanson PE, Old LJ, et al. IFNgamma and lymphocytes prevent primary tumour development and shape tumour immunogenicity. Nature. 2001;410:1107-11.

7. Coussens LM, Tinkle CL, Hanahan D, Werb Z. MMP-9 supplied by bone marrowderived cells contributes to skin carcinogenesis. Cell. 2000;103:481-90.

8. Lin EY, Nguyen AV, Russell RG, Pollard JW. Colony-stimulating factor 1 promotes progression of mammary tumors to malignancy. J Exp Med. 2001;193:727-40.

9. Turk MJ, Guevara-Patiño JA, Rizzuto GA, Engelhorn ME, Houghton AN. Concomitant tumor immunity to a poorly immunogenic melanoma is prevented by regulatory $\mathrm{T}$ cells. J Exp Med. 2004;200:771-82.

10. Yang L, DeBusk LM, Fukuda K, Fingleton B, Green-Jarvis B, Shyr Y, et al. Expansion of myeloid immune suppressor $\mathrm{Gr}+\mathrm{CD} 11 \mathrm{~b}+$ cells in tumor-bearing host directly promotes tumor angiogenesis. Cancer Cell. 2004;6:409-21.

11. De Palma M, Venneri MA, Galli R, Sergi LS, Politi LS, Sampaolesi M, et al. Tie2 identifies a hematopoietic lineage of proangiogenic monocytes required for tumor vessel formation and a mesenchymal population of pericyte progenitors. Cancer Cell. 2005;8:211-26.

12. Clark WH Jr, Elder DE, Guerry D 4th, Braitman LE, Trock BJ, Schultz D, et al. Model predicting survival in stage I melanoma based on tumor progression. J Natl Cancer Inst. 1989;81:1893-904. 
13. Lauder I, Aherne W. The significance of lymphocytic infiltration in neuroblastoma. $\mathrm{Br}$ J Cancer. 1972;26:321-30.

14. Palma L, Di Lorenzo N, Guidetti B. Lymphocytic infiltrates in primary glioblastomas and recidivous gliomas. Incidence, fate, and relevance to prognosis in 228 operated cases. J Neurosurg. 1978;49:854-61.

15. Vesely M, Kershaw M, Schreiber R, Smyth M. Natural innate and adaptive immunity to cancer. Annu Rev Immunol. 2011;29:235-71.

16. Fridman $\mathrm{WH}$, Pagès $\mathrm{F}$, Sautès-Fridman $\mathrm{C}$, Galon J. The immune contexture in human tumours: impact on clinical outcome. Nat Rev Cancer. 2012;12:298-306.

17. Tran DQ, Ramsey $H$, Shevach EM. Induction of FOXP3 expression in naive human CD4+FOXP3 T cells by T-cell receptor stimulation is transforming growth factorbeta dependent but does not confer a regulatory phenotype. Blood. 2007;110:2983-90.

18. Wang J, loan-Facsinay A, van der Voort EIH, Huizinga TWJ, Toes REM. Transient expression of FOXP3 in human activated nonregulatory CD4+ T cells. Eur $\mathrm{J}$ Immunol. 2007;37:129-38.

19. Wilke CM, Kryczek I, Wei S, Zhao E, Wu K, Wang G, et al. Th17 cells in cancer: help or hindrance? Carcinogenesis. 2011;32:643-9.

20. Bailey SR, Nelson MH, Himes RA, Li Z, Mehrotra S, Paulos CM. Th17 Cells in Cancer: The Ultimate Identity Crisis. Front Immunol. 2014;5:276.

21. Diederichsen ACP, Hjelmborg J v B, Christensen PB, Zeuthen J, Fenger C. Prognostic value of the CD4+/CD8+ ratio of tumour infiltrating lymphocytes in colorectal cancer and HLA-DR expression on tumour cells. Cancer Immunol Immunother. 2003;52:423-8.

22. Ino $\mathrm{Y}$, Yamazaki-Itoh R, Shimada K, Iwasaki M, Kosuge T, Kanai $\mathrm{Y}$, et al. Immune cell infiltration as an indicator of the immune microenvironment of pancreatic cancer. $\mathrm{Br}$ J Cancer. 2013;108:914-23.

23. Preston CC, Maurer MJ, Oberg AL, Visscher DW, Kalli KR, Hartmann LC, et al. The ratios of CD8+ T cells to CD4+CD25+ FOXP3+ and FOXP3- T cells correlate with poor clinical outcome in human serous ovarian cancer. PloS One. 2013;8:e80063.

24. Sato E, Olson SH, Ahn J, Bundy B, Nishikawa H, Qian F, et al. Intraepithelial CD8+ tumor-infiltrating lymphocytes and a high $\mathrm{CD} 8+$ /regulatory $\mathrm{T}$ cell ratio are associated with favorable prognosis in ovarian cancer. Proc Natl Acad Sci U S A. 2005;102:18538-43.

25. Nakano O, Sato M, Naito Y, Suzuki K, Orikasa S, Aizawa M, et al. Proliferative activity of intratumoral CD8+ T-lymphocytes as a prognostic factor in human renal cell 
carcinoma clinicopathologic demonstration of antitumor immunity. Cancer Res. $2001 ; 61: 5132-6$.

26. Galon J, Costes A, Sanchez-Cabo F, Kirilovsky A, Mlecnik B, Lagorce-Pagès C, et al. Type, density, and location of immune cells within human colorectal tumors predict clinical outcome. Science. 2006;313:1960-4.

27. Pagès F, Kirilovsky A, Mlecnik B, Asslaber M, Tosolini M, Bindea G, et al. In situ cytotoxic and memory $T$ cells predict outcome in patients with early-stage colorectal cancer. J Clin Oncol. 2009;27:5944-51.

28. Galon J, Angell HK, Bedognetti D, Marincola FM. The continuum of cancer immunosurveillance: prognostic, predictive, and mechanistic signatures. Immunity. 2013;39:11-26.

29. Angell H, Galon J. From the immune contexture to the Immunoscore: the role of prognostic and predictive immune markers in cancer. Curr Opin Immunol. 2013;25:261-7.

30. Erdag G, Schaefer JT, Smolkin ME, Deacon DH, Shea SM, Dengel LT, et al. Immunotype and immunohistologic characteristics of tumor-infiltrating immune cells are associated with clinical outcome in metastatic melanoma. Cancer Res. 2012;72:1070-80.

31. Rosenberg SA, Yang JC, Topalian SL, Schwartzentruber DJ, Weber JS, Parkinson $\mathrm{DR}$, et al. Treatment of 283 consecutive patients with metastatic melanoma or renal cell cancer using high-dose bolus interleukin 2 [see comments]. J Am Med Assoc. 1994;271:907-13.

32. Schwartzentruber DJ, Lawson DH, Richards JM, Conry RM, Miller DM, Treisman J, et al. gp100 peptide vaccine and interleukin-2 in patients with advanced melanoma. $\mathrm{N}$ Engl J Med. 2011;364:2119-27.

33. Sullivan RJ, Hoshida Y, Brunet J, Tahan S, Aldridge J, Kwabi C, et al. A single center experience with high-dose (HD) IL-2 treatment for patients with advanced melanoma and pilot investigation of a novel gene expression signature as a predictor of response. J Clin Oncol [Internet]. 2009 [cited 2015 Mar 21];27:15s. Available from: http://meetinglibrary.asco.org/content/34743-65

34. Wang E, Miller LD, Ohnmacht GA, Mocellin S, Perez-Diez A, Petersen D, et al. Prospective molecular profiling of melanoma metastases suggests classifiers of immune responsiveness. Cancer Res. 2002;62:3581-6.

35. Weiss GR, Grosh WW, Chianese-Bullock KA, Zhao Y, Liu H, Slingluff CL, et al. Molecular insights on the peripheral and intratumoral effects of systemic high-dose rlL-2 (aldesleukin) administration for the treatment of metastatic melanoma. Clin Cancer Res. 2011;17:7440-50. 
36. Gajewski TF, Louahed J, Brichard VG. Gene signature in melanoma associated with clinical activity. Cancer J. 2010;16:399-403.

37. Ulloa-Montoya F, Louahed J, Dizier B, Gruselle O, Spiessens B, Lehmann FF, et al. Predictive gene signature in MAGE-A3 antigen-specific cancer immunotherapy. J Clin Oncol. 2013;31:2388-95.

38. Ji R-R, Chasalow SD, Wang L, Hamid O, Schmidt H, Cogswell J, et al. An immuneactive tumor microenvironment favors clinical response to ipilimumab. Cancer Immunol Immunother. 2012;61:1019-31.

39. Herbst RS, Soria J-C, Kowanetz M, Fine GD, Hamid O, Gordon MS, et al. Predictive correlates of response to the anti-PD-L1 antibody MPDL3280A in cancer patients. Nature. 2014;515:563-7.

40. Tumeh PC, Harview CL, Yearley JH, Shintaku IP, Taylor EJM, Robert L, et al. PD-1 blockade induces responses by inhibiting adaptive immune resistance. Nature. 2014;515:568-71.

41. Halama N, Michel S, Kloor M, Zoernig I, Benner A, Spille A, et al. Localization and density of immune cells in the invasive margin of human colorectal cancer liver metastases are prognostic for response to chemotherapy. Cancer Res. 2011;71:5670-7.

42. Halama N, Michel S, Kloor M, Zoernig I, Pommerencke T, von Knebel Doeberitz M, et al. The localization and density of immune cells in primary tumors of human metastatic colorectal cancer shows an association with response to chemotherapy. Cancer Immun. 2009;9:1.

43. Morris M, Platell C, lacopetta B. Tumor-infiltrating lymphocytes and perforation in colon cancer predict positive response to 5-fluorouracil chemotherapy. Clin Cancer Res. 2008;14:1413-7.

44. Yasuda K, Nirei T, Sunami E, Nagawa H, Kitayama J. Density of CD4(+) and CD8(+) $\mathrm{T}$ lymphocytes in biopsy samples can be a predictor of pathological response to chemoradiotherapy (CRT) for rectal cancer. Radiat Oncol. 2011;6:1-6.

45. Denkert C, Loibl S, Noske A, Roller M, Müller BM, Komor M, et al. Tumor-associated lymphocytes as an independent predictor of response to neoadjuvant chemotherapy in breast cancer. J Clin Oncol. 2010;28:105-13.

46. Loi S, Sirtaine N, Piette F, Salgado R, Viale G, Eenoo FV, et al. Prognostic and predictive value of tumor-infiltrating lymphocytes in a phase III randomized adjuvant breast cancer trial in node-positive breast cancer comparing the addition of docetaxel to doxorubicin with doxorubicin-based chemotherapy. J Clin Oncol. 2013;31:860-7. 
47. West NR, Milne K, Truong PT, Macpherson N, Nelson BH, Watson PH. Tumorinfiltrating lymphocytes predict response to anthracycline-based chemotherapy in estrogen receptor-negative breast cancer. Breast Cancer Res. 2011;13:R126.

48. Balermpas P, Michel Y, Wagenblast J, Seitz O, Weiss C, Rödel F, et al. Tumourinfiltrating lymphocytes predict response to definitive chemoradiotherapy in head and neck cancer. Br J Cancer. 2014;110:501-9.

49. Liu H, Zhang T, Ye J, Li H, Huang J, Li X, et al. Tumor-infiltrating lymphocytes predict response to chemotherapy in patients with advance non-small cell lung cancer. Cancer Immunol Immunother. 2012;61:1849-56.

50. Beverly B, Kang SM, Lenardo MJ, Schwartz RH. Reversal of in vitro T cell clonal anergy by IL-2 stimulation. Int Immunol. 1992;4:661-71.

51. Margolin KA. Interleukin-2 in the treatment of renal cancer. Semin Oncol. 2000;27:194-203.

52. Keir ME, Butte MJ, Freeman GJ, Sharpe AH. PD-1 and its ligands in tolerance and immunity. Annu Rev Immunol. 2008;26:677-704.

53. Blank C, Brown I, Peterson AC, Spiotto M, Iwai Y, Honjo T, et al. PD-L1/B7H-1 inhibits the effector phase of tumor rejection by $T$ cell receptor (TCR) transgenic CD8+ T cells. Cancer Res. 2004;64:1140-5.

54. Dong H, Strome SE, Salomao DR, Tamura H, Hirano F, Flies DB, et al. Tumorassociated B7-H1 promotes T-cell apoptosis: a potential mechanism of immune evasion. Nat Med. 2002;8:793-800.

55. Topalian SL, Hodi FS, Brahmer JR, Gettinger SN, Smith DC, McDermott DF, et al. Safety, activity, and immune correlates of anti-PD-1 antibody in cancer. N Engl J Med. 2012;366:2443-54.

56. Pardoll DM. The blockade of immune checkpoints in cancer immunotherapy. Nat Rev Cancer. 2012;12:252-64.

57. Cha E, Klinger M, Hou Y, Cummings C, Ribas A, Faham M, et al. Improved survival with $\mathrm{T}$ cell clonotype stability after anti-CTLA-4 treatment in cancer patients. Sci Transl Med. 2014;6:238ra70-238ra70.

58. Kvistborg P, Philips D, Kelderman S, Hageman L, Ottensmeier C, Joseph-Pietras D, et al. Anti-CTLA-4 therapy broadens the melanoma-reactive CD8+ T cell response. Sci Transl Med. 2014;6:254ra128-254ra128.

59. Bulliard Y, Jolicoeur R, Windman M, Rue SM, Ettenberg S, Knee DA, et al. Activating Fc $y$ receptors contribute to the antitumor activities of immunoregulatory receptortargeting antibodies. J Exp Med. 2013;210:1685-93. 
60. Simpson TR, Li F, Montalvo-Ortiz W, Sepulveda MA, Bergerhoff K, Arce F, et al. Fcdependent depletion of tumor-infiltrating regulatory $T$ cells co-defines the efficacy of anti-CTLA-4 therapy against melanoma. J Exp Med. 2013;210:1695-710.

61. Hamid O, Schmidt H, Nissan A, Ridolfi L, Aamdal S, Hansson J, et al. A prospective phase II trial exploring the association between tumor microenvironment biomarkers and clinical activity of ipilimumab in advanced melanoma. J Transl Med. 2011;9:204.

62. Casares N, Pequignot MO, Tesniere A, Ghiringhelli F, Roux S, Chaput N, et al. Caspase-dependent immunogenicity of doxorubicin-induced tumor cell death. $\mathrm{J}$ Exp Med. 2005;202:1691-701.

63. Formenti SC, Demaria S. Combining radiotherapy and cancer immunotherapy: a paradigm shift. J Natl Cancer Inst. 2013;105:256-65.

64. Lugade AA, Moran JP, Gerber SA, Rose RC, Frelinger JG, Lord EM. Local radiation therapy of B16 melanoma tumors increases the generation of tumor antigenspecific effector cells that traffic to the tumor. J Immunol. 2005;174:7516-23.

65. Zitvogel L, Kepp O, Kroemer G. Immune parameters affecting the efficacy of chemotherapeutic regimens. Nat Rev Clin Oncol. 2011;8:151-60.

66. Demaria S, Kawashima N, Yang AM, Devitt ML, Babb JS, Allison JP, et al. Immunemediated inhibition of metastases after treatment with local radiation and CTLA-4 blockade in a mouse model of breast cancer. Clin Cancer Res. 2005;11:728-34.

67. Demaria S, Ng B, Devitt ML, Babb JS, Kawashima N, Liebes L, et al. Ionizing radiation inhibition of distant untreated tumors (abscopal effect) is immune mediated. Int $\mathrm{J}$ Radiat Oncol Biol Phys. 2004;58:862-70.

68. Postow MA, Callahan MK, Barker CA, Yamada Y, Yuan J, Kitano S, et al. Immunologic correlates of the abscopal effect in a patient with melanoma. $\mathrm{N}$ Engl $\mathrm{J}$ Med. 2012;366:925-31.

69. Restifo NP, Dudley ME, Rosenberg SA. Adoptive immunotherapy for cancer: harnessing the T cell response. Nat Rev Immunol. 2012;12:269-81.

70. Beatty GL, Haas AR, Maus MV, Torigian DA, Soulen MC, Plesa G, et al. Mesothelinspecific chimeric antigen receptor mRNA-engineered $T$ cells induce antitumor activity in solid malignancies. Cancer Immunol Res. 2014;2:112-20.

71. Peske JD, Thompson ED, Gemta L, Baylis RA, Fu Y-X, Engelhard VH. Effector lymphocyte-induced lymph node-like vasculature enables naive $\mathrm{T}$-cell entry into tumours and enhanced anti-tumour immunity. Nat Commun. 2015;6:7114.

72. Yu P, Lee Y, Liu W, Krausz T, Chong A, Schreiber H, et al. Intratumor depletion of CD4+ cells unmasks tumor immunogenicity leading to the rejection of late-stage tumors. J Exp Med. 2005;201:779-91. 
73. Champiat S, Ferté C, Lebel-Binay S, Eggermont A, Soria JC. Exomics and immunogenics. Oncoimmunology. 2014;3:e27817.

74. Snyder A, Makarov V, Merghoub T, Yuan J, Zaretsky JM, Desrichard A, et al. Genetic basis for clinical response to CTLA-4 blockade in melanoma. $\mathrm{N}$ Engl $\mathrm{J}$ Med. 2014;371:2189-99.

75. Fuertes MB, Kacha AK, Kline J, Woo S-R, Kranz DM, Murphy KM, et al. Host type I IFN signals are required for antitumor CD8+ T cell responses through CD8\{alpha\}+ dendritic cells. J Exp Med. 2011;208:2005-16.

76. Deng L, Liang H, Xu M, Yang X, Burnette B, Arina A, et al. STING-dependent cytosolic DNA sensing promotes radiation-induced type i interferon-dependent antitumor immunity in immunogenic tumors. Immunity. 2014;41:843-52.

77. Woo S-R, Fuertes MB, Corrales L, Spranger S, Furdyna MJ, Leung MYK, et al. STING-dependent cytosolic DNA sensing mediates innate immune recognition of immunogenic tumors. Immunity. 2014;41:830-42.

78. Spranger S, Bao R, Gajewski T. Melanoma-intrinsic $\beta$-catenin signaling prevents T cell infiltration and anti-tumor immunity. J Immunother Cancer. 2014;2:015.

79. Wang T, Niu G, Kortylewski M, Burdelya L, Shain K, Zhang S, et al. Regulation of the innate and adaptive immune responses by Stat-3 signaling in tumor cells. Nat Med. 2004;10:48-54.

80. Gabrilovich DI, Ostrand-Rosenberg S, Bronte V. Coordinated regulation of myeloid cells by tumours. Nat Rev Immunol. 2012;12:253-68.

81. Pylayeva-Gupta Y, Lee KE, Hajdu CH, Miller G, Bar-Sagi D. Oncogenic Kras-induced GM-CSF production promotes the development of pancreatic neoplasia. Cancer Cell. 2012;21:836-47.

82. Vonderheide $\mathrm{RH}$, Bayne LJ. Inflammatory networks and immune surveillance of pancreatic carcinoma. Curr Opin Immunol. 2013;25:200-5.

83. Mullins DW, Sheasley SL, Ream RM, Bullock TN, Fu YX, Engelhard VH. Route of immunization with peptide-pulsed dendritic cells controls the distribution of memory and effector T cells in lymphoid tissues and determines the pattern of regional tumor control. J Exp Med. 2003;198:1023-34.

84. Chang C-J, Tai K-F, Roffler S, Hwang L-H. The Immunization Site of CytokineSecreting Tumor Cell Vaccines Influences the Trafficking of Tumor-Specific $T$ Lymphocytes and Antitumor Efficacy against Regional Tumors. J Immunol. 2004;173:6025-32.

85. Hangalapura BN, Oosterhoff D, Gupta T, de Groot J, Wijnands PGJTB, van Beusechem VW, et al. Delivery route, MyD88 signaling and cross-priming events 
determine the anti-tumor efficacy of an adenovirus based melanoma vaccine. Vaccine. 2011;29:2313-21.

86. Sandoval F, Terme M, Nizard M, Badoual C, Bureau M-F, Freyburger L, et al. Mucosal Imprinting of Vaccine-Induced CD8+ T Cells Is Crucial to Inhibit the Growth of Mucosal Tumors. Sci Transl Med. 2013;5:172ra20-172ra20.

87. Lurquin $\mathrm{C}$, Lethé $\mathrm{B}$, Plaen ED, Corbière V, Théate I, Baren N van, et al. Contrasting frequencies of antitumor and anti-vaccine $T$ cells in metastases of a melanoma patient vaccinated with a MAGE tumor antigen. J Exp Med. 2005;201:249-57.

88. Marincola FM, Wang E, Herlyn M, Seliger B, Ferrone S. Tumors as elusive targets of T-cell-based active immunotherapy. Trends Immunol. 2003;24:334-41.

89. Thurner B, Haendle I, Roder C, Dieckmann D, Keikavoussi P, Jonuleit H, et al. Vaccination with MAGE-3A1 peptide-pulsed mature, monocyte-derived dendritic cells expands specific cytotoxic T cells and induces regression of some metastases in advanced stage IV melanoma. J Exp Med. 1999;190:1669-78.

90. Weiss VL, Lee TH, Song H, Kouo TS, Black CM, Sgouros G, et al. Trafficking of high avidity HER-2/neu-specific T cells into HER-2/neu-expressing tumors after depletion of effector/memory-like regulatory T cells. PLoS ONE. 2012;7:e31962.

91. Quezada SA, Peggs KS, Simpson TR, Shen Y, Littman DR, Allison JP. Limited tumor infiltration by activated $T$ effector cells restricts the therapeutic activity of regulatory T cell depletion against established melanoma. J Exp Med. 2008;205:2125-38.

92. Bernhard H, Neudorfer J, Gebhard K, Conrad H, Hermann C, Nährig J, et al. Adoptive transfer of autologous, HER2-specific, cytotoxic T lymphocytes for the treatment of HER2-overexpressing breast cancer. Cancer Immunol Immunother Cll. 2008;57:271-80.

93. Economou JS, Belldegrun AS, Glaspy J, Toloza EM, Figlin R, Hobbs J, et al. In vivo trafficking of adoptively transferred interleukin-2 expanded tumor-infiltrating lymphocytes and peripheral blood lymphocytes. Results of a double gene marking trial. J Clin Invest. 1996;97:515-21.

94. Fisher B, Packard BS, Read EJ, Carrasquillo JA, Carter CS, Topalian SL, et al. Tumor localization of adoptively transferred indium-111 labeled tumor infiltrating lymphocytes in patients with metastatic melanoma. J Clin Oncol. 1989;7:250-61.

95. Ganss R, Hanahan D. Tumor microenvironment can restrict the effectiveness of activated antitumor lymphocytes. Cancer Res. 1998;58:4673-81.

96. Garbi N, Arnold B, Gordon S, Hämmerling GJ, Ganss R. CpG motifs as proinflammatory factors render autochthonous tumors permissive for infiltration and destruction. J Immunol. 2004;172:5861-9. 
97. Griffith KD, Read EJ, Carrasquillo JA, Carter CS, Yang JC, Fisher B, et al. In vivo distribution of adoptively transferred indium-111-labeled tumor infiltrating lymphocytes and peripheral blood lymphocytes in patients with metastatic melanoma. J Natl Cancer Inst. 1989;81:1709-17.

98. Kershaw MH, Westwood JA, Parker LL, Wang G, Eshhar Z, Mavroukakis SA, et al. A phase I study on adoptive immunotherapy using gene-modified $T$ cells for ovarian cancer. Clin Cancer Res. 2006;12:6106-15.

99. Pockaj BA, Sherry RM, Wei JP, Yannelli JR, Carter CS, Leitman SF, et al. Localization of 111 indium-labeled tumor infiltrating lymphocytes to tumor in patients receiving adoptive immunotherapy. Augmentation with cyclophosphamide and correlation with response. Cancer. 1994;73:1731-7.

100. Bourquin C, Borch P von der, Zoglmeier C, Anz D, Sandholzer N, Suhartha N, et al. Efficient Eradication of Subcutaneous but Not of Autochthonous Gastric Tumors by Adoptive $\mathrm{T}$ Cell Transfer in an SV40 T Antigen Mouse Model. J Immunol. 2010;185:2580-8.

101. Sackstein R. The lymphocyte homing receptors: gatekeepers of the multistep paradigm. Curr Opin Hematol. 2005;12:444-50.

102. Butcher EC. Leukocyte-endothelial cell recognition: Three (or more) steps to specificity and diversity. Cell. 1991;67:1033-6.

103. Ley K, Laudanna C, Cybulsky MI, Nourshargh S. Getting to the site of inflammation: the leukocyte adhesion cascade updated. Nat Rev Immunol. 2007;7:678-89.

104. Mora JR, von Andrian UH. T-cell homing specificity and plasticity: new concepts and future challenges. Trends Immunol. 2006;27:235-43.

105. Campbell DJ, Debes GF, Johnston B, Wilson E, Butcher EC. Targeting T cell responses by selective chemokine receptor expression. Semin Immunol. 2003;15:277-86.

106. Dudda JC, Lembo A, Bachtanian E, Huehn J, Siewert C, Hamann A, et al. Dendritic cells govern induction and reprogramming of polarized tissue-selective homing receptor patterns of $\mathrm{T}$ cells: important roles for soluble factors and tissue microenvironments. Eur J Immunol. 2005;35:1056-65.

107. Hammerschmidt SI, Ahrendt M, Bode U, Wahl B, Kremmer E, Förster R, et al. Stromal mesenteric lymph node cells are essential for the generation of gut-homing T cells in vivo. J Exp Med. 2008;205:2483-90.

108. Johansson-Lindbom B, Svensson M, Wurbel MA, Malissen B, Marquez G, Agace W. Selective generation of gut tropic T cells in gut-associated lymphoid tissue (GALT): requirement for GALT dendritic cells and adjuvant. J Exp Med. 2003;198:963-9. 
109. Masopust D, Schenkel JM. The integration of T cell migration, differentiation and function. Nat Rev Immunol. 2013;13:309-20.

110. Mora JR, Cheng G, Picarella D, Briskin M, Buchanan N, von Andrian UH. Reciprocal and dynamic control of CD8 T cell homing by dendritic cells from skin- and gutassociated lymphoid tissues. J Exp Med. 2005;201:303-16.

111. Mora JR, Bono MR, Manjunath N, Weninger W, Cavanagh LL, Rosemblatt M, et al. Selective imprinting of gut-homing T cells by Peyer's patch dendritic cells. Nature. 2003;424:88-93.

112. Sigmundsdottir H, Pan J, Debes GF, Alt C, Habtezion A, Soler D, et al. DCs metabolize sunlight-induced vitamin D3 to "program" $T$ cell attraction to the epidermal chemokine CCL27. Nat Immunol. 2007;8:285-93.

113. Campbell DJ, Butcher EC. Rapid acquisition of tissue-specific homing phenotypes by CD4(+) T cells activated in cutaneous or mucosal lymphoid tissues. J Exp Med. 2002;195:135-41.

114. Ferguson AR, Engelhard VH. CD8 T cells activated in distinct lymphoid organs differentially express adhesion proteins and coexpress multiple chemokine receptors. J Immunol. 2010;184:4079-86.

115. Sheasley-O'Neill SL, Brinkman CC, Ferguson AR, Dispenza MC, Engelhard VH. Dendritic cell immunization route determines integrin expression and lymphoid and nonlymphoid tissue distribution of CD8 T cells. J Immunol. 2007;178:1512-22.

116. Brinkman CC, Sheasley-O'Neill SL, Ferguson AR, Engelhard VH. Activated CD8 T cells redistribute to antigen-free lymph nodes and exhibit effector and memory characteristics. J Immunol. 2008;181:1814-24.

117. Austrup F, Vestweber D, Borges E, Lohning M, Brauer R, Herz U, et al. P- and Eselectin mediate recruitment of T-helper-1 but not T-helper-2 cells into inflammed tissues. Nature. 1997;385:81-3.

118. Berg EL, Yoshino T, Rott LS, Robinson MK, Warnock RA, Kishimoto TK, et al. The cutaneous lymphocyte antigen is a skin lymphocyte homing receptor for the vascular lectin endothelial cell-leukocyte adhesion molecule 1. J Exp Med. $1991 ; 174: 1461-6$.

119. Borges E, Tietz W, Steegmaier M, Moll T, Hallmann R, Hamann A, et al. P-selectin glycoprotein ligand-1 (PSGL-1) on T helper 1 but not on T helper 2 cells binds to $P$ selectin and supports migration into inflamed skin. J Exp Med. 1997;185:573-8.

120. Fuhlbrigge RC, King SL, Dimitroff CJ, Kupper TS, Sackstein R. Direct real-time observation of $\mathrm{E}$ - and P-selectin-mediated rolling on cutaneous lymphocyteassociated antigen immobilized on Western blots. J Immunol. 2002;168:5645-51. 
121. Fuhlbrigge RC, Kieffer JD, Armerding D, Kupper TS. Cutaneous lymphocyte antigen is a specialized form of PSGL-1 expressed on skin-homing $\mathrm{T}$ cells. Nature. 1997;389:978-81.

122. Brinkman CC, Rouhani SJ, Srinivasan N, Engelhard VH. Peripheral tissue homing receptors enable $T$ cell entry into lymph nodes and affect the anatomical distribution of memory cells. J Immunol. 2013;191:2412-25.

123. Chong BF, Murphy JE, Kupper TS, Fuhlbrigge RC. E-selectin, thymus- and activation-regulated chemokine/CCL17, and intercellular adhesion molecule-1 are constitutively coexpressed in dermal microvessels: a foundation for a cutaneous immunosurveillance system. J Immunol. 2004;172:1575-81.

124. Kupper TS, Fuhlbrigge RC. Immune surveillance in the skin: mechanisms and clinical consequences. Nat Rev Immunol. 2004;4:211-22.

125. Hallahan D, Clark ET, Kuchibhotla J, Gewertz BL, Collins T. E-Selectin Gene Induction by lonizing Radiation Is Independent of Cytokine Induction. Biochem Biophys Res Commun. 1995;217:784-95.

126. Kaplanski G, Fabrigoule M, Boulay V, Dinarello CA, Bongrand P, Kaplanski S, et al. Thrombin induces endothelial type II activation in vitro: IL-1 and TNF-alphaindependent IL-8 secretion and E-selectin expression. J Immunol. 1997;158:543541.

127. Matsumoto M, Shigeta A, Furukawa Y, Tanaka T, Miyasaka M, Hirata T. CD43 collaborates with P-selectin glycoprotein ligand-1 to mediate E-selectin-dependent T cell migration into inflamed skin. J Immunol. 2007;178:2499-506.

128. Matsumoto M, Atarashi K, Umemoto E, Furukawa $Y$, Shigeta A, Miyasaka M, et al. CD43 functions as a ligand for E-Selectin on activated $T$ cells. J Immunol. 2005;175:8042-50.

129. Yao L, Setiadi H, Xia L, Laszik Z, Taylor FB, McEver RP. Divergent inducible expression of P-selectin and E-selectin in mice and primates. Blood. 1999;94:38208.

130. Zarbock A, Ley K, McEver RP, Hidalgo A. Leukocyte ligands for endothelial selectins: specialized glycoconjugates that mediate rolling and signaling under flow. Blood. 2011;118:6743-51.

131. Hariri G, Zhang Y, Fu A, Han Z, Brechbiel M, Tantawy MN, et al. Radiation-guided P-selectin antibody targeted to lung cancer. Ann Biomed Eng. 2008;36:821-30.

132. Barthel SR, Gavino JD, Descheny L, Dimitroff CJ. Targeting selectins and selectin ligands in inflammation and cancer. Expert Opin Ther Targets. 2007;11:1473-91.

133. Homey B, Alenius $\mathrm{H}$, Muller A, Soto H, Bowman EP, Yuan W, et al. CCL27-CCR10 interactions regulate T cell-mediated skin inflammation. Nat Med. 2002;8:157-65. 
134. Andrew DP, Ruffing N, Kim CH, Miao W, Heath H, Li Y, et al. C-C chemokine receptor 4 expression defines a major subset of circulating nonintestinal memory $\mathrm{T}$ cells of both Th1 and Th2 potential. J Immunol. 2001;166:103-11.

135. Campbell JJ, Haraldsen G, Pan J, Rottman J, Qin S, Ponath P, et al. The chemokine receptor CCR4 in vascular recognition by cutaneous but not intestinal memory $\mathrm{T}$ cells. Nature. 1999;400:776-80.

136. Morales J, Homey B, Vicari AP, Hudak S, Oldham E, Hedrick J, et al. CTACK, a skinassociated chemokine that preferentially attracts skin-homing memory T cells. Proc Natl Acad Sci U S A. 1999;96:14470-5.

137. Rott LS, Briskin MJ, Andrew DP, Berg EL, Butcher EC. A fundamental subdivision of circulating lymphocytes defined by adhesion to mucosal addressin cell adhesion molecule-1. Comparison with vascular cell adhesion molecule-1 and correlation with beta 7 integrins and memory differentiation. J Immunol. 1996;156:3727-36.

138. Ericsson A, Kotarsky K, Svensson M, Sigvardsson M, Agace W. Functional characterization of the CCL25 promoter in small intestinal epithelial cells suggests a regulatory role for caudal-related homeobox $(\mathrm{Cdx})$ transcription factors. J Immunol. 2006;176:3642-51.

139. Ando $T$, Jordan $P$, Wang $Y$, Itoh $M$, Joh $T$, Sasaki $M$, et al. MAdCAM-1 expression and regulation in murine colonic endothelial cells in vitro. Inflamm Bowel Dis. 2005;11:258-64.

140. Chen J, Salas A, Springer TA. Bistable regulation of integrin adhesiveness by a bipolar metal ion cluster. Nat Struct Mol Biol. 2003;10:995-1001.

141. Berlin C, Bargatze RF, Campbell JJ, von Andrian UH, Szabo MC, Hasslen SR, et al. alpha 4 integrins mediate lymphocyte attachment and rolling under physiologic flow. Cell. 1995;80:413-22.

142. Berlin C, Berg EL, Briskin MJ, Andrew DP, Kilshaw PJ, Holzmann B, et al. Alpha 4 beta 7 integrin mediates lymphocyte binding to the mucosal vascular addressin MAdCAM-1. Cell. 1993;74:185-95.

143. de Château M, Chen S, Salas A, Springer TA. Kinetic and mechanical basis of rolling through an integrin and novel $\mathrm{Ca2}+$-dependent rolling and $\mathrm{Mg} 2+-$ dependent firm adhesion modalities for the $\alpha 4 \beta 7-M A d C A M-1$ interaction. Biochemistry (Mosc). $2001 ; 40: 13972-9$.

144. Salas A, Shimaoka M, Chen S, Carman CV, Springer T. Transition From Rolling to Firm Adhesion Is Regulated by the Conformation of the I Domain of the Integrin Lymphocyte Function-associated Antigen-1. J Biol Chem. 2002;277:50255-62.

145. Cook-Mills JM, Marchese ME, Abdala-Valencia H. Vascular cell adhesion molecule1 expression and signaling during disease: regulation by reactive oxygen species and antioxidants. Antioxid Redox Signal. 2011;15:1607-38. 
146. Hubbard AK, Rothlein R. Intercellular adhesion molecule-1 (ICAM-1) expression and cell signaling cascades. Free Radic Biol Med. 2000;28:1379-86.

147. Kaplanski G, Marin V, Fabrigoule M, Boulay V, Benoliel A-M, Bongrand P, et al. Thrombin-Activated Human Endothelial Cells Support Monocyte Adhesion In Vitro Following Expression of Intercellular Adhesion Molecule-1 (ICAM-1; CD54) and Vascular Cell Adhesion Molecule-1 (VCAM-1; CD106). Blood. 1998;92:1259-67.

148. Lawrence MB, Springer TA. Leukocytes roll on a selectin at physiologic flow rates: distinction from and prerequisite for adhesion through integrins. Cell. 1991;65:85973.

149. Mollà M, Gironella M, Miquel R, Tovar V, Engel P, Biete A, et al. Relative roles of ICAM-1 and VCAM-1 in the pathogenesis of experimental radiation-induced intestinal inflammation. Int J Radiat Oncol • Biol • Phys. 2003;57:264-73.

150. Wang X, Michie SA, Xu B, Suzuki Y. Importance of IFN-gamma-mediated expression of endothelial VCAM-1 on recruitment of CD8+ T cells into the brain during chronic infection with Toxoplasma gondii. J Interferon Cytokine Res Off J Int Soc Interferon Cytokine Res. 2007;27:329-38.

151. Baron JL, Madri JA, Ruddle NH, Hashim G, Janeway CA. Surface expression of alpha 4 integrin by CD4 T cells is required for their entry into brain parenchyma. $J$ Exp Med. 1993;177:57-68.

152. Calzascia T, Masson F, Di Berardino-Besson W, Contassot E, Wilmotte R, urrandLions $\mathrm{M}$, et al. Homing phenotypes of tumor-specific CD8 T cells are predetermined at the tumor site by crosspresenting APCs. Immunity. 2005;22:175-84.

153. Kenyon NJ, Liu R, O’Roark EM, Huang W, Peng L, Lam KS. An alpha4beta1 integrin antagonist decreases airway inflammation in ovalbumin-exposed mice. Eur $\mathrm{J}$ Pharmacol. 2009;603:138-46.

154. Alon R, Kassner PD, Carr MW, Finger EB, Hemler ME, Springer TA. The integrin VLA-4 supports tethering and rolling in flow on VCAM-1. J Cell Biol. 1995;128:1243-53.

155. Coursey TG, Bohat R, Barbosa FL, Pflugfelder SC, de Paiva CS. Desiccating stressinduced chemokine expression in the epithelium is dependent on upregulation of NKG2D/RAE-1 and release of IFN- $y$ in experimental dry eye. J Immunol Baltim Md 1950. 2014;193:5264-72.

156. Tensen CP, Flier J, van der Raaj-Helmer EM, Sampat-Sardjoepersad S, Van Der Schors RC, Leurs R, et al. Human IP-9: A keratinocyte-derived high affinity CXCchemokine ligand for the IP-10/Mig receptor (CXCR3). J Invest Dermatol. 1999;112:716-22.

157. Sherry B, Tekamp-Olson P, Gallegos C, Bauer D, Davatelis G, Wolpe SD, et al. Resolution of the two components of macrophage inflammatory protein 1, and 
cloning and characterization of one of those components, macrophage inflammatory protein 1 beta. J Exp Med. 1988;168:2251-9.

158. Tsai S-C, Lin S-J, Lin C-J, Chou Y-C, Lin J-H, Yeh T-H, et al. Autocrine CCL3 and CCL4 Induced by the Oncoprotein LMP1 Promote Epstein-Barr Virus-Triggered B Cell Proliferation. J Virol. 2013;87:9041-52.

159. Abdi R, Smith RN, Makhlouf L, Najafian N, Luster AD, Auchincloss $H$, et al. The role of $\mathrm{CC}$ chemokine receptor 5 (CCR5) in islet allograft rejection. Diabetes. 2002;51:2489-95.

160. Gregg RK, Nichols L, Chen Y, Lu B, Engelhard VH. Mechanisms of spatial and temporal development of autoimmune vitiligo in tyrosinase-specific TCR transgenic mice. J Immunol. 2010;184:1909-17.

161. Hancock WW, Lu B, Gao W, Csizmadia V, Faia K, King JA, et al. Requirement of the chemokine receptor CXCR3 for acute allograft rejection. J Exp Med. 2000;192:1515-20.

162. Clark RA, Huang SJ, Murphy GF, Mollet IG, Hijnen D, Muthukuru M, et al. Human squamous cell carcinomas evade the immune response by down-regulation of vascular E-selectin and recruitment of regulatory $T$ cells. $J$ Exp Med. 2008;205:2221-34.

163. Weishaupt C, Munoz KN, Buzney E, Kupper TS, Fuhlbrigge RC. T-cell distribution and adhesion receptor expression in metastatic melanoma. Clin Cancer Res. 2007;13:2549-56.

164. Enarsson K, Johnsson E, Lindholm C, Lundgren A, Pan-Hammarström Q, Strömberg $E$, et al. Differential mechanisms for $T$ lymphocyte recruitment in normal and neoplastic human gastric mucosa. Clin Immunol. 2006;118:24-34.

165. Blank C, Brown I, Kacha AK, Markiewicz MA, Gajewski TF. ICAM-1 contributes to but is not essential for tumor antigen cross-priming and CD8+ T cell-mediated tumor rejection in vivo. J Immunol. 2005;174:3416-20.

166. Dirkx AEM, Egbrink MGA oude, Kuijpers MJE, Niet ST van der, Heijnen VVT, Steege JCAB, et al. Tumor angiogenesis modulates leukocyte-vessel wall interactions in vivo by reducing endothelial adhesion molecule expression. Cancer Res. 2003;63:2322-9.

167. Yoong KF, McNab G, Hübscher SG, Adams DH. Vascular adhesion protein-1 and ICAM-1 support the adhesion of tumor-infiltrating lymphocytes to tumor endothelium in human hepatocellular carcinoma. J Immunol. 1998;160:3978-88.

168. Coppola D, Nebozhyn M, Khalil F, Dai H, Yeatman T, Loboda A, et al. Unique ectopic lymph node-like structures present in human primary colorectal carcinoma are identified by immune gene array profiling. Am J Pathol. 2011;179:37-45. 
169. Harlin H, Meng Y, Peterson AC, Zha Y, Tretiakova M, Slingluff C, et al. Chemokine expression in melanoma metastases associated with CD8+ T-cell recruitment. Cancer Res. 2009;69:3077-85.

170. Messina JL, Fenstermacher DA, Eschrich S, Qu X, Berglund AE, Lloyd MC, et al. 12Chemokine gene signature identifies lymph node-like structures in melanoma: potential for patient selection for immunotherapy? Sci Rep. 2012;2:765.

171. Buckanovich RJ, Facciabene A, Kim S, Benencia F, Sasaroli D, Balint K, et al. Endothelin $B$ receptor mediates the endothelial barrier to $\mathrm{T}$ cell homing to tumors and disables immune therapy. Nat Med. 2008;14:28-36.

172. Wang L, Fan J, Thompson LF, Zhang Y, Shin T, Curiel TJ, et al. CD73 has distinct roles in nonhematopoietic and hematopoietic cells to promote tumor growth in mice. J Clin Invest. 2011;121:2371-82.

173. Afanasiev OK, Nagase K, Simonson W, Vandeven N, Blom A, Koelle DM, et al. Vascular E-Selectin expression correlates with CD8 lymphocyte infiltration and improved outcome in Merkel cell carcinoma. J Invest Dermatol. 2013;133:2065-73.

174. Seguin J, Nicolazzi C, Mignet N, Scherman D, Chabot G. Vascular density and endothelial cell expression of integrin alpha $v$ beta 3 and E-selectin in murine tumours. Tumour Biol. 2012;33:1709-17.

175. Lohr J, Ratliff T, Huppertz A, Ge Y, Dictus C, Ahmadi R, et al. Effector T-cell infiltration positively impacts survival of glioblastoma patients and is impaired by tumor-derived TGF- $\beta$. Clin Cancer Res. 2011;17:4296-308.

176. Fisher DT, Chen Q, Skitzki JJ, Muhitch JB, Zhou L, Appenheimer MM, et al. IL-6 trans-signaling licenses mouse and human tumor microvascular gateways for trafficking of cytotoxic T cells. J Clin Invest. 2011;121:3846-59.

177. Kunz M, Toksoy A, Goebeler M, Engelhardt E, Bröcker E, Gillitzer R. Strong expression of the lymphoattractant $\mathrm{C}-\mathrm{X}-\mathrm{C}$ chemokine Mig is associated with heavy infiltration of T cells in human malignant melanoma. J Pathol. 1999;189:552-8.

178. Mullins IM, Slingluff CL, Lee JK, Garbee CF, Shu J, Anderson SG, et al. CXC chemokine receptor 3 expression by activated CD8+ T cells is associated with survival in melanoma patients with stage III disease. Cancer Res. 2004;64:7697701.

179. Goelz S, Kumar R, Potvin B, Sundaram S, Brickelmaier M, Stanley P. Differential expression of an E-selectin ligand (SLex) by two Chinese hamster ovary cell lines transfected with the same alpha (1,3)-fucosyltransferase gene (ELFT). J Biol Chem. 1994;269:1033-40.

180. Goelz SE, Hession C, Goff D, Griffiths B, Tizard R, Newman B, et al. ELFT: A gene that directs the expression of an ELAM-1 ligand. Cell. 1990;63:1349-56. 
181. Knibbs RN, Craig RA, Natsuka S, Chang A, Cameron M, Lowe JB, et al. The fucosyltransferase FucT-VII regulates E-selectin ligand synthesis in human T cells. J Cell Biol. 1996;133:911-20.

182. Malý P, Thall A, Petryniak B, Rogers CE, Smith PL, Marks RM, et al. The alpha(1,3)fucosyltransferase Fuc-TVII controls leukocyte trafficking through an essential role in L-, E-, and P-selectin ligand biosynthesis. Cell. 1996;86:643-53.

183. Stark FC, Gurnani K, Sad S, Krishnan L. Lack of functional selectin ligand interactions compromises long term tumor protection by CD8+ T cells. PloS One. 2012;7:e32211.

184. Mlecnik B, Tosolini M, Charoentong P, Kirilovsky A, Bindea G, Berger A, et al. Biomolecular network reconstruction identifies T-cell homing factors associated with survival in colorectal cancer. Gastroenterology. 2010;138:1429-40.

185. Boissonnas A, Fetler L, Zeelenberg IS, Hugues S, Amigorena S. In vivo imaging of cytotoxic $\mathrm{T}$ cell infiltration and elimination of a solid tumor. $J$ Exp Med. 2007;204:345-56.

186. Hollenbaugh JA, Dutton RW. IFN-y regulates donor CD8 T cell expansion, migration, and leads to apoptosis of cells of a solid tumor. J Immunol. 2006;177:3004-11.

187. Peng W, Liu C, Xu C, Lou Y, Chen J, Yang Y, et al. PD-1 blockade enhances T-cell migration to tumors by elevating IFN-Y inducible chemokines. Cancer Res. 2012;72:5209-18.

188. Weis SM, Cheresh DA. Tumor angiogenesis: molecular pathways and therapeutic targets. Nat Med. 2011;17:1359-70.

189. Hamzah J, Jugold M, Kiessling F, Rigby $\mathrm{P}$, Manzur M, Marti HH, et al. Vascular normalization in Rgs5-deficient tumours promotes immune destruction. Nature. 2008;453:410-4.

190. Ogawa H, Binion DG, Heidemann J, Theriot M, Fisher PJ, Johnson NA, et al. Mechanisms of MAdCAM-1 gene expression in human intestinal microvascular endothelial cells. Am J Physiol - Cell Physiol. 2005;288:C272-81.

191. Huang Y, Yuan J, Righi E, Kamoun WS, Ancukiewicz M, Nezivar J, et al. Vascular normalizing doses of antiangiogenic treatment reprogram the immunosuppressive tumor microenvironment and enhance immunotherapy. Proc Natl Acad Sci. 2012;109:17561-6.

192. Shrimali RK, Yu Z, Theoret MR, Chinnasamy D, Restifo NP, Rosenberg SA. Antiangiogenic Agents Can Increase Lymphocyte Infiltration into Tumor and Enhance the Effectiveness of Adoptive Immunotherapy of Cancer. Cancer Res. 2010;70:6171-80. 
193. Lutz ER, Wu AA, Bigelow E, Sharma R, Mo G, Soares K, et al. Immunotherapy converts nonimmunogenic pancreatic tumors into immunogenic foci of immune regulation. Cancer Immunol Res [Internet]. 2014 [cited 2015 Mar 25]; Available from: http://cancerimmunolres.aacrjournals.org/content/early/2014/06/10/23266066.CIR-14-0027

194. Winograd R, Byrne KT, Evans RA, Odorizzi PM, Meyer ARL, Bajor DL, et al. Induction of T-cell immunity overcomes complete resistance to PD-1 and CTLA-4 blockade and improves survival in pancreatic carcinoma. Cancer Immunol Res. 2015;3:399-411.

195. Kirk CJ, Hartigan-O'Connor D, Mule JJ. The dynamics of the T-cell antitumor response: chemokine-secreting dendritic cells can prime tumor-reactive $\mathrm{T}$ cells extranodally. Cancer Res. 2001;61:8794-802.

196. Kirk CJ, Hartigan-O'Connor D, Nickoloff BJ, Chamberlain JS, Giedlin M, Aukerman $\mathrm{L}$, et al. T cell-dependent antitumor immunity mediated by secondary lymphoid tissue chemokine augmentation of dendritic cell-based immunotherapy. Cancer Res. 2001;61:2062-70.

197. Schrama D, Voigt H, Eggert AO, Xiang R, Zhou H, Schumacher TNM, et al. Immunological tumor destruction in a murine melanoma model by targeted LTalpha independent of secondary lymphoid tissue. Cancer Immunol Immunother. 2008;57:85-95.

198. Hernot S, Klibanov AL. Microbubbles in ultrasound-triggered drug and gene delivery. Adv Drug Deliv Rev. 2008;60:1153-66.

199. Konkalmatt PR, Deng D, Thomas S, Wu MT, Logsdon CD, French BA, et al. Plectin1 Targeted AAV Vector for the Molecular Imaging of Pancreatic Cancer. Front Oncol. 2013;3:84.

200. Irvine DJ, Stachowiak AN, Hori Y. Lymphoid tissue engineering: Invoking lymphoid tissue neogenesis in immunotherapy and models of immunity. Semin Immunol. 2008;20:137-46.

201. Twyman-Saint Victor C, Rech AJ, Maity A, Rengan R, Pauken KE, Stelekati E, et al. Radiation and dual checkpoint blockade activate non-redundant immune mechanisms in cancer. Nature. 2015;520:373-7.

202. Newberg MH, Smith DH, Haertel SB, Vining DR, Lacy E, Engelhard VH. Importance of MHC class I $\alpha 2$ and $\alpha 3$ domains in the recognition of self and non-self $\mathrm{MHC}$ molecules. J Immunol. 1996;156:2473-80.

203. Nichols LA, Chen Y, Colella TA, Bennet CL, Clausen BE, Engelhard VH. Deletional self-tolerance to a melancyte/melanoma antigen derived from tyrosinase is mediated by a radio-resistant cell in peripheral and mesenteric lymph nodes. $J$ Immunol. 2007; 179:993-1003. 
204. Hargadon KM, Brinkman CC, Sheasley-O'Neill SL, Nichols LA, Bullock TNJ, Engelhard VH. Incomplete differentiation of tumor-specific CD8+ T cells in tumordraining lymph nodes. J Immunol. 2006;177:6081-90.

205. Mullins DW, Bullock TN, Colella TA, Robila VV, Engelhard VH. Immune responses to the HLA-A*0201-restricted epitopes of tyrosinase and glycoprotein 100 enable control of melanoma outgrowth in HLA-A*0201- transgenic mice. J Immunol. 2001;167:4853-60.

206. Pages F, Berger A, Camus M, Sanchez-Cabo F, Costes A, Molidor R, et al. Effector memory T cells, early metastasis, and survival in colorectal cancer. N Engl J Med. 2005;353:2654-66.

207. Pages F, Galon J, Dieu-Nosjean M-C, Tartour E, Sautès-Fridman C, Fridman W-H. Immune infiltration in human tumors: a prognostic factor that should not be ignored. Oncogene. 2010;29:1093-102.

208. Butcher EC, Picker LJ. Lymphocyte homing and homeostasis. Science. 1996;272:60-6.

209. Streeter PR, Berg EL, Rouse BT, Bargatze RF, Butcher EC. A tissue-specific endothelial cell molecule involved in lymphocyte homing. Nature. 1988;331:41-6.

210. Sigmundsdottir H, Butcher EC. Environmental cues, dendritic cells and the programming of tissue-selective lymphocyte trafficking. Nat Immunol. 2008;9:9817.

211. Johansson-Lindbom B, Agace WW. Generation of gut-homing T cells and their localization to the small intestinal mucosa. Immunol Rev. 2007;215:226-42.

212. Svensson M, Marsal J, Ericsson A, Carramolino L, Broden T, Marquez G, et al. CCL25 mediates the localization of recently activated CD8alphabeta(+) lymphocytes to the small-intestinal mucosa. J Clin Invest. 2002;110:1113-21.

213. Henninger DD, Panes J, Eppihimer M, Russell J, Gerritsen M, Anderson DC, et al. Cytokine-induced VCAM-1 and ICAM-1 expression in different organs of the mouse. J Immunol. 1997;158:1825-32.

214. Lu B, Humbles A, Bota D, Gerard C, Moser B, Soler D, et al. Structure and function of the murine chemokine receptor CXCR3. Eur J Immunol. 1999;29:3804-12.

215. Groom JR, Luster AD. CXCR3 ligands: redundant, collaborative and antagonistic functions. Immunol Cell Biol. 2011;89:207-15.

216. Dustin ML, Springer TA. Lymphocyte function-associated antigen-1 (LFA-1) interaction with intercellular adhesion molecule-1 (ICAM-1) is one of at least three mechanisms for lymphocyte adhesion to cultured endothelial cells. J Cell Biol. 1988;107:321-31. 
217. Yamada M, Yanaba K, Hasegawa M, Matsushita Y, Horikawa M, Komura K, et al. Regulation of local and metastatic host-mediated anti-tumour mechanisms by Iselectin and intercellular adhesion molecule-1. Clin Exp Immunol. 2006;143:21627.

218. Nishimura F, Dusak JE, Eguchi J, Zhu X, Gambotto A, Storkus WJ, et al. Adoptive transfer of type 1 CTL mediates effective anti-central nervous system tumor response: critical roles of IFN-inducible protein-10. Cancer Res. 2006;66:4478-87.

219. Bose A, Taylor JL, Alber S, Watkins SC, Garcia JA, Rini BI, et al. Sunitinib facilitates the activation and recruitment of therapeutic anti-tumor immunity in concert with specific vaccination. Int J Cancer. 2011;129:2158-70.

220. Mikucki ME, Fisher DT, Matsuzaki J, Skitzki JJ, Gaulin NB, Muhitch JB, et al. Nonredundant requirement for $\mathrm{CXCR} 3$ signaling during tumoricidal T-cell trafficking across tumour vascular checkpoints. Nat Commun. 2015;6:7458.

221. Clancy-Thompson E, Perekslis TJ, Croteau W, Alexander MP, Chabanet TB, Turk MJ, et al. Melanoma Induces, and Adenosine Suppresses, CXCR3-Cognate Chemokine Production and T-cell Infiltration of Lungs Bearing Metastatic-like Disease. Cancer Immunol Res. 2015;3:956-67.

222. Sasaki K, Zhu X, Vasquez C, Nishimura F, Dusak JE, Huang J, et al. Preferential expression of very late antigen-4 on type 1 CTL cells plays a critical role in trafficking into central nervous system tumors. Cancer Res. 2007;67:6451-8.

223. D. N. Granger, Senchenkova E. Leukocyte-Endothelial Cell Adhesion. Inflamm Microcirc. Chapter 7: Morgan \& Claypool Life Sciences; 2010.

224. Liao F, Rabin RL, Yannelli JR, Koniaris LG, Vanguri P, Farber JM. Human Mig chemokine: biochemical and functional characterization. $J$ Exp Med. 1995;182:1301-14.

225. Thompson ED. Characterization of naive T cell infiltration into tumors and their in situ activation and effector differentiation [PhD Dissertation]. University of Virginia; 2010.

226. Haraldsen G, Kvale D, Lien B, Farstad IN, Brandtzaeg P. Cytokine-Regulated Expression of E-Selectin, Intracellular Adhesion Molecule-1 (ICAM-1), and Vascular Cell Adhesion Molecule-1 (VCAM-1) in Human Intestinal Microvascular Endothelial Cells. J Immunol. 1996;156:2558-65.

227. Siegelman MH, Stanescu D, Estess $P$. The CD44-initiated pathway of T-cell extravasation uses VLA-4 but not LFA-1 for firm adhesion. J Clin Invest. 2000;105:683-91.

228. Nandi A, Estess $P$, Siegelman M. Bimolecular Complex between Rolling and Firm Adhesion Receptors Required for Cell Arrest: CD44 Association with VLA-4 in T cell Extravasation. Immunity. 2004;20:455-65. 
229. Cohen JN, Guidi CJ, Tewalt EF, Qiao H, Rouhani SJ, Ruddell A, et al. Lymph noderesident lymphatic endothelial cells mediate peripheral tolerance via Aireindependent direct antigen presentation. J Exp Med. 2010;207:681-8.

230. CL Ramos, Kunkel E, Lawrence M, Jung U, Vestweber D, Bosse R, et al. Differential effect of E-selectin antibodies on neutrophil rolling and recruitment to inflammatory sites. Blood. 1997;89:3009-18.

231. Butcher EC, Williams M, Youngman K, Rott L, Briskin M. Lymphocyte trafficking and regional immunity. Adv Immunol. 1999;72:209-53.

232. Hillen F, Arjan W. Griffioen. Tumour vascularization: sprouting angiogenesis and beyond. Cancer Metastasis Rev. 2007;26:489-502.

233. Peske JD, Woods AB, Engelhard VH. Control of CD8 T-cell infiltration into tumors by vasculature and microenvironment. Fisher X-YW and PB, editor. Adv Cancer Res. 2015;128:263-307.

234. DeGrendele HC, Estess $\mathrm{P}$, Siegelman MH. Requirement for CD44 in activated T cell extravasation into an inflammatory site. Science. 1997;278:672-5.

235. Beyersdorf N, Kerkau T, Hünig T. CD28 co-stimulation in T-cell homeostasis: a recent perspective. Immunotargets Ther. 2015;4:111-22.

236. Wolchok JD, Saenger Y. The Mechanism of Anti-CTLA-4 Activity and the Negative Regulation of T-Cell Activation. The Oncologist. 2008;13:2-9.

237. Hodi FS, O'Day SJ, McDermott DF, Weber RW, Sosman JA, Haanen JB, et al. Improved survival with ipilimumab in patients with metastatic melanoma. $\mathrm{N}$ Engl $\mathrm{J}$ Med. 2010;363:711-23.

238. Postow MA, Chesney J, Pavlick AC, Robert C, Grossmann K, McDermott D, et al. Nivolumab and ipilimumab versus ipilimumab in untreated melanoma. $\mathrm{N}$ Engl $\mathrm{J}$ Med. 2015;372:2006-17.

239. Larkin J, Chiarion-Sileni V, Gonzalez R, Grob JJ, Cowey C, Lao C, et al. Combined Nivolumab and Ipilimumab versus Ipilimumab in Untreated Melanoma. N Engl J Med. 2015;373:23-34.

240. Gajewski TF. The Next Hurdle in Cancer Immunotherapy: Overcoming the Non-TCell-Inflamed Tumor Microenvironment. Semin Oncol. 2015;42:663-71.

241. Pitt JM, Vétizou M, Daillère R, Roberti MP, Yamazaki T, Routy B, et al. Resistance Mechanisms to Immune-Checkpoint Blockade in Cancer: Tumor-Intrinsic and Extrinsic Factors. Immunity. 2016;44:1255-69.

242. Gubin MM, Zhang X, Schuster H, Caron E, Ward JP, Noguchi T, et al. Checkpoint blockade cancer immunotherapy targets tumour-specific mutant antigens. Nature. 2014;515:577-81. 
243. Gao J, Shi LZ, Zhao H, Chen J, Xiong L, He Q, et al. Loss of IFN-y Pathway Genes in Tumor Cells as a Mechanism of Resistance to Anti-CTLA-4 Therapy. Cell. 2016;167:397-404.e9.

244. Overwijk WW, Theoret MR, Finkelstein SE, Surman DR, de Jong LA, Vyth-Dreese FA, et al. Tumor regression and autoimmunity after reversal of a functionally tolerant state of self-reactive CD8+ T cells. J Exp Med. 2003;198:569-80.

245. Overwijk WW, Tsung A, Irvine KR, Parkhurst MR, Goletz, Tj, et al. gp100/pmel 17 is a murine tumor rejection antigen: induction of "self"-reactive, tumoricidal $T$ cells using high-affinity, altered peptide ligand. J Exp Med. 1998;188:277-86.

246. Hailemichael Y, Dai Z, Jaffarzad N, Ye Y, Medina MA, Huang X-F, et al. Persistent antigen at vaccination sites induces tumor-specific CD8+ $\mathrm{T}$ cell sequestration, dysfunction and deletion. Nat Med. 2013;19:465-72.

247. Zamarin D, Holmgaard RB, Subudhi SK, Park JS, Mansour M, Palese P, et al. Localized Oncolytic Virotherapy Overcomes Systemic Tumor Resistance to Immune Checkpoint Blockade Immunotherapy. Sci Transl Med. 2014;6:226ra32226 ra32.

248. Fu J, Kanne DB, Leong M, Glickman LH, McWhirter SM, Lemmens E, et al. STING agonist formulated cancer vaccines can cure established tumors resistant to PD-1 blockade. Sci Transl Med. 2015;7:283ra52.

249. Bencherif SA, Sands RW, Ali OA, Li WA, Lewin SA, Braschler TM, et al. Injectable cryogel-based whole-cell cancer vaccines. Nat Commun. 2015;6:ncomms8556.

250. Liu H, Moynihan KD, Zheng Y, Szeto GL, Li AV, Huang B, et al. Structure-based programming of lymph-node targeting in molecular vaccines. Nature. 2014;507:519-22.

251. Kim J, Li WA, Choi Y, Lewin SA, Verbeke CS, Dranoff G, et al. Injectable, spontaneously assembling, inorganic scaffolds modulate immune cells in vivo and increase vaccine efficacy. Nat Biotechnol. 2015;33:64-72.

252. Tan AC, Goubier A, Kohrt HE. A quantitative analysis of therapeutic cancer vaccines in phase 2 or phase 3 trial. J Immunother Cancer [Internet]. 2015 [cited 2017 Oct 16];3. Available from: https://www.ncbi.nlm.nih.gov/pmc/articles/PMC4647658/

253. Marshall A, Celentano A, Cirillo N, McCullough M, Porter S. Tissue-specific regulation of CXCL9/10/11 chemokines in keratinocytes: Implications for oral inflammatory disease. PLoS ONE [Internet]. 2017 [cited 2017 Oct 16];12. Available from: https://www.ncbi.nlm.nih.gov/pmc/articles/PMC5333845/

254. Mahalingam S, Chaudhri G, Tan CL, John A, Foster PS, Karupiah G. Transcription of the Interferon y (IFN-y)-inducible Chemokine Mig in IFN-y-deficient Mice. J Biol Chem. $2001 ; 276: 7568-74$. 
255. Cuff CA, Schwartz J, Bergman CM, Russell KS, Bender JR, Ruddle NH. Lymphotoxin a3 Induces chemokines and adhesion molecules: insight into the role of LTa in inflammation and lymphoid organ development. J Immunol. 1998;161:6853-60.

256. Koo GC, Hasan A, O'Reilly RJ. Use of humanized severe combined immunodeficient mice for human vaccine development. Expert Rev Vaccines. 2009;8:113-20.

257. Vivier E, Santo JD, Moretta A. Natural Killer Cells. Springer; 2016.

258. Meyer M, Hensbergen PJ, Raaij-Helmer EMH van der, Brandacher G, Margreiter R, Heufler $\mathrm{C}$, et al. Cross reactivity of three $\mathrm{T}$ cell attracting murine chemokines stimulating the $\mathrm{CXC}$ chemokine receptor $\mathrm{CXCR} 3$ and their induction in cultured cells and during allograft rejection. Eur J Immunol. 2001;31:2521-7.

259. Ohta K, Shigeishi H, Taki M, Nishi H, Higashikawa K, Takechi M, et al. Regulation of CXCL9/10/11 in Oral Keratinocytes and Fibroblasts. J Dent Res. 2008;87:1160-5.

260. Gasperini S, Marchi M, Calzetti F, Laudanna C, Vicentini L, Olsen H, et al. Gene Expression and Production of the Monokine Induced by IFN-y (MIG), IFN-Inducible $\mathrm{T}$ Cell a Chemoattractant (I-TAC), and IFN-Y-Inducible Protein-10 (IP-10) Chemokines by Human Neutrophils. J Immunol. 1999;162:4928-37.

261. Hiroi $\mathrm{M}$, Ohmori $\mathrm{Y}$. Constitutive nuclear factor $\mathrm{KB}$ activity is required to elicit interferon-y-induced expression of chemokine CXC ligand 9 (CXCL9) and CXCL10 in human tumour cell lines. Biochem J. 2003;376:393-402.

262. Weber J. Review: Anti-CTLA-4 Antibody Ipilimumab: Case Studies of Clinical Response and Immune-Related Adverse Events. The Oncologist. 2007;12:864-72.

263. Lanitis E, Irving M, Coukos G. Targeting the tumor vasculature to enhance $T$ cell activity. Curr Opin Immunol. 2015;33:55-63.

264. Noy R, Pollard JW. Tumor-Associated Macrophages: From Mechanisms to Therapy. Immunity. 2014;41:49-61.

265. Bugyik E, Renyi-Vamos F, Szabo V, Dezso K, Ecker N, Rokusz A, et al. Mechanisms of vascularization in murine models of primary and metastatic tumor growth. Chin $\mathrm{J}$ Cancer [Internet]. 2016 [cited 2017 Nov 10];35. Available from: https://www.ncbi.nlm.nih.gov/pmc/articles/PMC4752760/ 